Florida International University

FIU Digital Commons

$11-6-2018$

\title{
Understanding and Improving Older Male Participation and Older Adult Adherence in Evidence-Based Health Promotion Programs
}

Chelsie L. Anderson

Florida International University, cande067@fiu.edu

Follow this and additional works at: https://digitalcommons.fiu.edu/etd

Part of the Public Health Education and Promotion Commons

\section{Recommended Citation}

Anderson, Chelsie L., "Understanding and Improving Older Male Participation and Older Adult Adherence in Evidence-Based Health Promotion Programs" (2018). FIU Electronic Theses and Dissertations. 3875. https://digitalcommons.fiu.edu/etd/3875

This work is brought to you for free and open access by the University Graduate School at FIU Digital Commons. It has been accepted for inclusion in FIU Electronic Theses and Dissertations by an authorized administrator of FIU Digital Commons. For more information, please contact dcc@fiu.edu. 


\title{
FLORIDA INTERNATIONAL UNIVERSITY
}

\author{
Miami, Florida
}

\section{UNDERSTANDING AND IMPROVING OLDER MALE PARTICIPATION AND OLDER}

\section{ADULT ADHERENCE IN EVIDENCE-BASED HEALTH PROMOTION PROGRAMS}

\author{
A dissertation submitted in partial fulfillment of \\ the requirements for the degree of \\ DOCTOR OF PHILOSOPHY \\ in \\ PUBLIC HEALTH \\ by \\ Chelsie Anderson
}

2018 
To: $\quad$ Dean Tomás R. Guilarte

Robert Stempel College of Public Health \& Social Work

This dissertation, written by Chelsie Anderson, and entitled Understanding and Improving Older Male Participation and Older Adult Adherence in Evidence-Based Health Promotion Programs, having been approved in respect to style and intellectual content, is referred to you for judgment. We have read this dissertation and recommend that it be approved.

Leslie Frazier

Elena Bastida

Richard C. Palmer

H. Virginia McCoy, Major Professor

Date of Defense: November 6, 2018

The dissertation of Chelsie Anderson is approved.

Dean Tomás R. Guilarte Robert Stempel College of Public Health \& Social Work

Andrés G. Gil

Vice President for Research and Economic Development and Dean of the University Graduate School

Florida International University, 2018 
(C) Copyright 2018 by Chelsie Anderson

All rights reserved. 


\section{DEDICATION}

This dissertation is dedicated to my loving family and fiancé who have been patient and supportive throughout the years that it has taken to complete this Ph.D. program and dissertation. 


\section{ACKNOWLEDGMENTS}

I would like to express gratitude to my committee chair Dr. H. Virginia McCoy whose persistent guidance and genuine interest in my well-being and success have helped me to complete this dissertation. I would also like to express sincere appreciation to Dr. Richard Palmer for introducing me to the field of healthy aging research and continuing to provide encouragement. I would also to thank my committee members Dr. Elena Bastida and Dr. Leslie Frazier for their expert advice and time. Gratitude is also owed to the Health Foundation of South Florida and members of the Healthy Aging Regional Collaborative. Finally, I would like to thank the EnhanceFitness participants and instructors who generously shared their time and personal experiences with me. 
ABSTRACT OF THE DISSERTATION

UNDERSTANDING AND IMPROVING OLDER MALE PARTICIPATION AND

OLDER ADULT ADHERENCE IN EVIDENCE-BASED HEALTH PROMOTION

PROGRAMS

by

Chelsie Anderson

Florida International University, 2018

Miami, Florida

Professor H. Virginia McCoy, Major Professor

The aging population and burden of chronic conditions have led researchers and practitioners to develop, implement, and evaluate evidence-based programs (EBPs) for older adults. The Healthy Aging Regional Collaborative (HARC) was established to make EBPs including Diabetes Self-Management Program, Chronic Disease SelfManagement Program, Matter of Balance, and EnhanceFitness (EF) accessible in south Florida.

According to the REAIM model, reach, effectiveness, adoption, implementation, and maintenance determine the impact of EBPs. Evaluation of HARC demonstrated widespread adoption of EBPs by community organizations that reached diverse participants and effectiveness among participants attending the recommended number of sessions, but only $19 \%$ of EBP participants were male, and only $25 \%$ of EF participants met attendance criteria for adherence. This mixed-methods dissertation explored program instructor and coordinator perspectives on barriers and strategies related to male participation in EBPs, examined predictors of short-term and long-term adherence to EF, 
and applied a theoretical framework to explore participant and instructor perspectives on factors influencing adherence to EF.

Fourteen program coordinators participated in a focus group to identify barriers and strategies to improve male participation, and 49 instructors participated in a survey to triangulate findings. Themes among barriers to male participation included women outnumbering men in programs, incompatibility of programs with male gender roles, and preference for other activities. Themes among strategies included endorsement by male community leaders, advertisements featuring males, and content adaptation.

Among 5,619 EF participants, logistic regression confirmed age, race/ethnicity, gender, and health status as significant predictors of adherence. The likelihood of shortterm and long-term adherence increased with age and health. Black participants were less likely than whites to adhere short-term $(\mathrm{OR}=0.82, \mathrm{p}=.05)$ but more likely to adhere longterm $(\mathrm{OR}=1.77, \mathrm{p}=.000)$. Hispanics were more likely than whites to adhere short-term $(\mathrm{OR}=1.25, \mathrm{p}=.008)$ and long-term $(\mathrm{OR}=1.30, \mathrm{p}=.001)$. Men were more likely to meet the criteria for short-term $(\mathrm{OR}=1.47, \mathrm{p}=.001)$ and long-term adherence $(\mathrm{OR}=1.19, \mathrm{p}=.04)$. Interviews with 12 adherent EF participants and 10 instructors revealed cues to action, goals, beliefs, intentions, program factors, social factors, and benefits that supported adherence. Findings inform efforts to improve participation and adherence in EBPs and maximize their impact on health among older adults. 


\section{TABLE OF CONTENTS}

CHAPTER

PAGE

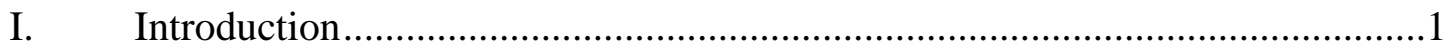

Demographics and Health of the Older Adult Population ...................................

Cost of Care for Older Adults.............................................................................

Evidence-Based Health Promotion for Older Adults...........................................

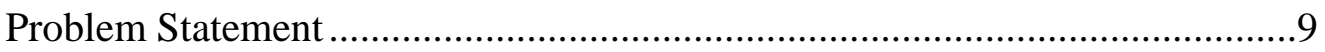

Purpose of the Current Study ...........................................................................11

Theoretical Framework ………………........................................................

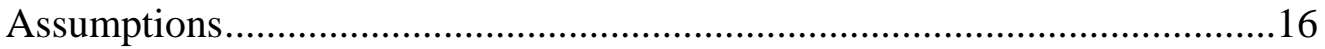

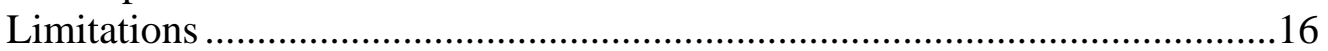

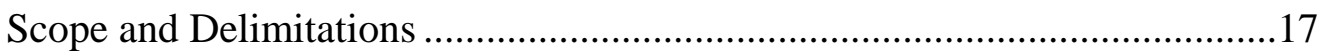

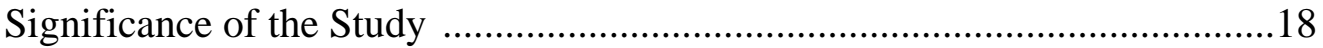

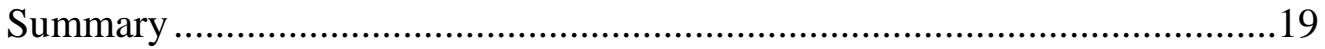

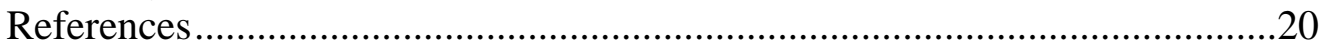

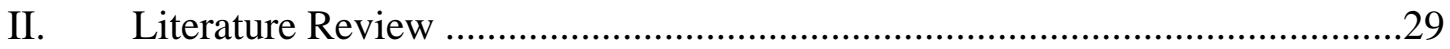

Literature Search Strategy................................................................................

Health Status of Older Adults ..........................................................................31

The Links Between Physical Activity and Health .............................................33

Physical Activity Among Older Adults ..............................................................34

Healthy Aging Regional Collaborative of South Florida Evidence-Based

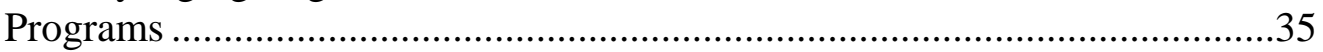

Male Participation in Evidence-Based Health Promotion Programs .................42

Adherence to Exercise Programs .......................................................................44

Significance of Adherence............................................................................4

Extended Theory of Planned Behavior ...............................................................4

Review of Factors Associated with Exercise Adherence .................................51

Qualitative Exploration of Factors .................................................................64

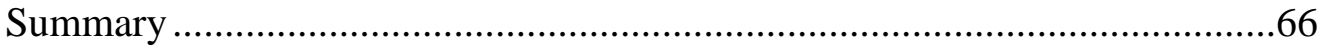

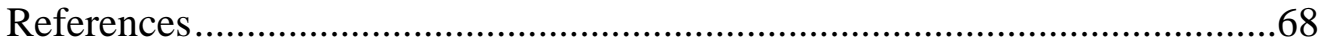

III. Manuscript Title: Recruiting and Engaging Older Men in Evidence-Based Health Promotion Programs: Perspectives on Barriers and Strategies .............83

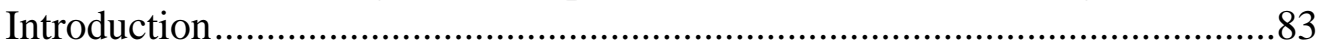

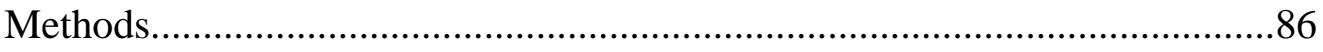

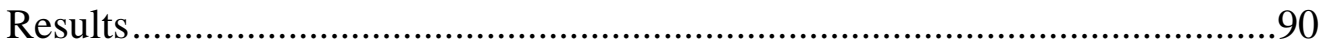

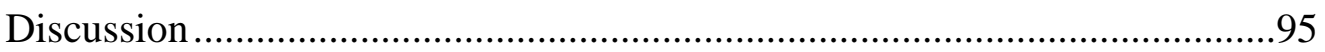

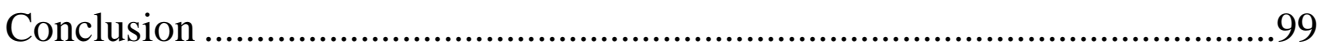

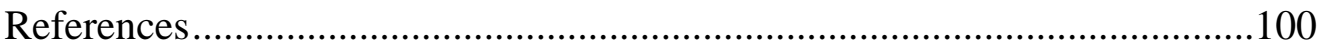

IV. Manuscript Title: Adhering to EnhanceFitness: Do Demographic Factors and Health Matter for Short-Term and Long-Term Adherence?....................105

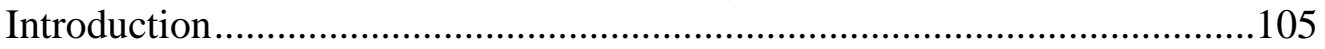




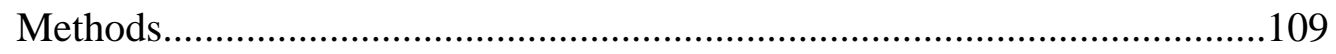

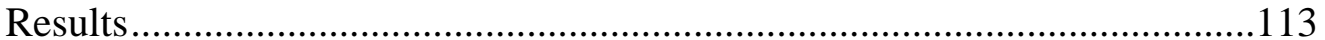

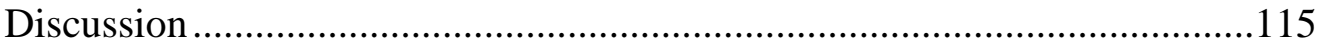

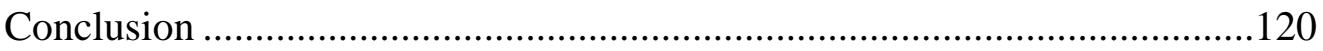

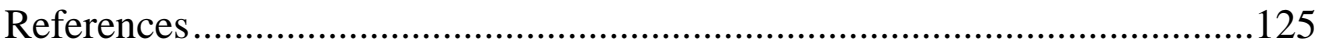

V. Manuscript Title: Participant and instructor perspectives on adherence to EnhanceFitness: a descriptive qualitative study to inform program

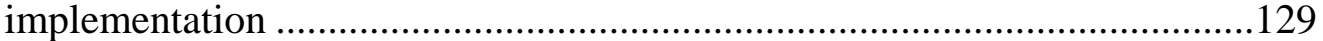

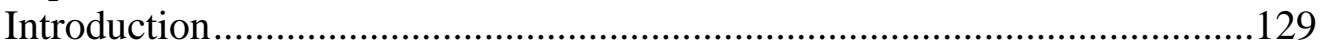

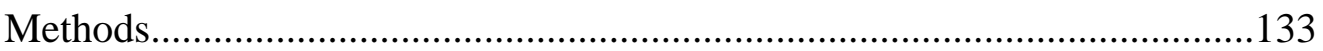

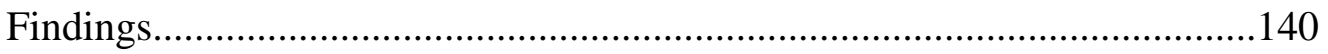

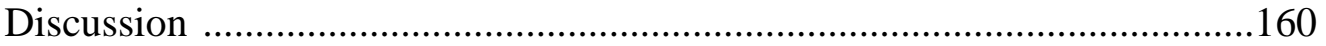

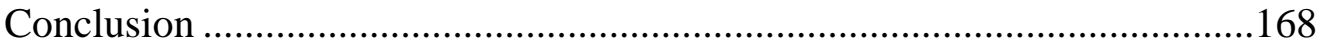

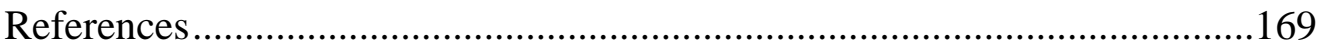

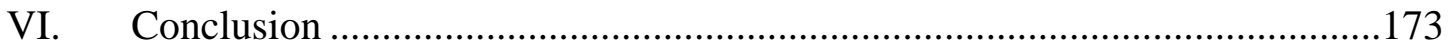

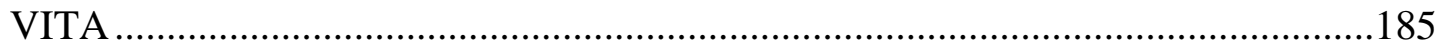




\section{LIST OF TABLES}

TABLE

PAGE

3.1 Agreement with Statements Explaining Why Older Males Do Not Participate in HARC Programs $(n=49)$

3.2 Agreement with Statements Regarding Men's Beliefs and Participation (n=47)

3.3 Likelihood of Strategies Successfully Increasing Male Participation in HARC

Programs $(n=46)$

4.1 Sample Characteristics and Comparison of Participants Who Met the Criteria for Short-Term Adherence of Attending $\geq 32$ Sessions in 16 Weeks with Those Who Attended $\leq 32$ Sessions in 16 Weeks

4.2 Comparison of Participants Who Met the Criteria for Long-Term Adherence by Attending an Average of at Least Once Per Week for One Year with Those Who Attended Less Than an Average of Once Per Week for One Year

4.3 Logistic Regression Model of Factors Predicting Short-Term Adherence $(\mathrm{N}=4,409)$.

4.4 Logistic Regression Model of Factors Predicting Long-Term Adherence $(\mathrm{N}=4,409)$.

5.1 Categories and Themes That Influence Adherence to EnhanceFitness .141

5.2 Themes Among Barriers to Adherence

5.3 Themes Among Strategies to Improve Adherence .158 


\section{Chapter I}

\section{Introduction}

The population of the United States, like the global population, is aging rapidly. In 2016, the population ages 65 and older included 49.2 million people (U.S. Census Bureau, 2017a). These 49.2 million older adults represented over $15 \%$ of the total population (U.S. Census Bureau, 2017a). By nearly 2060, the older adult population is projected to increase to 98.2 million and to represent nearly $25 \%$ of the population (U.S. Census Bureau, 2017b). The 85+ population is projected to increase from 6.4 million in 2016 to 14.6 million in 2040 (United States Department of Health and Human Services: Administration for Community Living [USDHHS: ACL], 2018). This dramatic change in the age structure creates new challenges and opportunities for public health in the 21st century.

\section{Demographics and Health of the Older Adult Population}

In addition to the growing number of older adults in the United States, the characteristics of the older adult population also have important implications for policy and program decisions in the United States. The older population is becoming more racially and ethnically diverse. Racial and ethnic minority populations represented 23\% of the older adult population in 2016 and are projected to increase to $28 \%$ of the older adult population by 2030 (USDHHS: ACL, 2018). The racial and ethnic minority population ages 65 and over is projected to increase by 89\% between 2016 and 2030 compared to a projected increase of 39\% for non-Hispanic whites (USDHHS: ACL, 2018). 
Women outnumber men in the older population with 27.5 million older women and 21.8 million older men in 2016 (USDHHS:ACL, 2018). The gender gap in life expectancy has been narrowing, but women continue to have a higher life expectancy and lower mortality rates in older adulthood (Werner, 2011). At age 65, women have an average of 20.6 years of life remaining and men have an average of 18 years of life remaining (USDHHS:ACL, 2018).

\section{Chronic Disease}

The older adult population is characterized by a high prevalence of chronic conditions. Eighty percent of older adults have at least one chronic condition, and having multiple chronic diseases is becoming increasingly common among older Americans (Hung, Ross, Boockvar, \& Siu, 2011). The prevalence of multiple chronic conditions increases with age and is significantly higher among women than men (Ward \& Schiller, 2010). The most common chronic conditions among older adults include arthritis, heart disease, cancer, diabetes, and hypertension (USDHHS, 2015). Chronic conditions including heart disease, cancer, and chronic lower respiratory disease are the leading causes of death for older adults (Centers for Disease Control, 2015).

Based on data collected between 2011 and 2014, 28.5\% of people age 65 and over had diabetes (National Center for Health Statistics [NCHS], 2016). Data from 20092012 indicate that hypertension affected $63.4 \%$ of men ages $65-74$ and $64.3 \%$ of women ages 65-74 (NCHS, 2016). Among people 75 years of age and older, over $72.3 \%$ of men and $79.9 \%$ of women had hypertension. Among people $65-74$, over $36 \%$ of men and $40 \%$ of women were obese NCHS, 2016). In 2014, 26 million older adults also had at least one activity limitation (NCHS, 2016). The 2015 Florida Behavioral Risk Factor Surveillance 
System Survey estimates that among older Floridians, 51.7\% have arthritis, 23\% have diabetes, and $21.5 \%$ had reported coronary heart disease, heart attack, or stroke (Florida Department of Health, 2016).

Falls

Falls are the leading cause of injury and emergency department visits among older adults and affect more than one out of four older adults annually (Bergen, Stevens, \& Burns, 2016). In 2014, 29 million falls caused seven million injuries among older adults in the United States (Bergen et al., 2016). In addition to causing injuries and death, falls can also negatively impact older adults by increasing fear of falling and decreasing independence. Risk factors for falls include fear of falling, low self-reported health status, frailty, poor balance, and dependence on a walking aid. Chronic conditions also place older adults at greater risk for falls through both direct and indirect effects including reduced physical activity, functional limitations, chronic pain, and poor balance (Lawlor, Patel, \& Abrahim, 2003).

Due to its large population of older adults, Florida bears a disproportionate burden of falls morbidity and mortality in the United States. In Florida, 2,845 older adults were fatally injured in falls during 2016 (Florida Department of Health, 2016). Among Floridians ages 65 and older, 9.7\% had a fall-related injury in the past 12 months (Florida Department of Health, 2016).

\section{Physical Inactivity}

Physical inactivity is among the most important modifiable health risk behaviors for chronic disease and disability (CDC, 2012). Evidence indicates that physical activity and exercise can help to prevent at least some of the conditions and loss of function that 
have historically been associated with normal aging and help to older adults to live independently and maintain a high quality of life (USDHHS, 2018; Vogel et al., 2009).

Physical activity has a favorable impact on risk factors for cardiovascular disease such as hypertension and obesity (Myers, 2003). Physical activity also reduces the risk of stroke and improves cardiovascular health by increasing aerobic capacity and improving endurance (Vogel et al., 2009). Physical activity helps the body to use insulin to control glucose levels which is important for older adults managing diabetes (Myers, 2003). Arthritis is the most common cause of disability in adults and may impede the management of other chronic conditions for which physical activity is a useful selfmanagement tool (CDC, 2009). Research supports that regular exercise reduces pain and disability while improving function among people with arthritis (Kelley, Kelley, Hootman, \& Jones, 2011; Fransen \& McConnell, 2009). Lower extremity weakness and instability place older adults at a high risk for falls and related injuries. Physical activity has been shown to increase strength, balance, and flexibility which can all reduce the risk of falling (Rose \& Hernandez, 2010). Physical activity also slows declines in bone mineral density which reduces the risk of fall-related fractures (Muir, Ye, Bhandari, Adachi, \& Thabane, 2013).

In addition to the benefits for physical health, physical activity has been associated with mental health benefits including general psychological well-being, reduced anxiety, reduced depression, and improved cognition (Netz, Wu, Becker, \& Tenenbaum, 2005; Arent, Landers, \& Etnier, 2000; Lindwall, Rennemark, Halling, Berglund \& Hassman, 2007; Fox, Stathi, McKenna \& Davis, 2007; Behrer, Erickson, \& Liu, 2013). Evidence indicates that physical activity is protective against the development 
of dementia and can improve health among individuals living with dementia (Sofi et al., 2011; Ahlslog et al., 2011). Evidence also supports the association between increased physical activity and decreases in health care utilization and health care costs (Martin, Powell, Peel, Zhu, \& Allman, 2006; Martinson, Crain, Pronk, O’Connor, \& Maciosek, 2003; Andreyeva \& Sturm, 2006).

The research-supported benefits of physical activity have led physical activity to become a top public health priority. For the first time ever, national guidelines for physical activity were published in 2008 (USDHHS). To obtain important health benefits, the U.S. Department of Health and Human Services recommends that adults ages 65 and older obtain at least 150 minutes of moderate-intensity physical activity, 75 minutes of vigorous-intensity physical activity, or an equivalent combination of moderate and vigorous physical activity each week (USDHHS, 2008). Healthy People 2020 also emphasizes the importance of physical activity in improving the health of Americans. Physical activity objectives for Healthy People 2020 include decreasing the proportion of adults who engage in no physical activity and increasing the proportion of adults who meet the national guidelines for both aerobic and strength activities (USDHHS, 2010).

Experts on physical activity and health were appointed to the 2018 Physical Activity Guidelines Advisory Committee and prepared the 2018 Physical Activity Guidelines Advisory Committee Scientific Report (USDHHS: Office of Health Promotion and Disease Prevention [USDHSS:OPHPD], 2018). Based on knowledge acquired in the 10 years following the 2008 Scientific Report, the 2018 Scientific Report describes evidence of more health benefits of physical activity and indicates that there is more flexibility in the ways that these benefits and increased physical activity can be achieved 
(2018 Physical Activity Guidelines Advisory Committee, 2018). The Department of Human Services is reviewing the committee's recommendations and public comments on the report and plans to release the second edition of the Physical Activity Guidelines for Americans (USDHHS:OPHPD, 2018). The 2018 Committee agreed with the target physical activity range suggested in the 2008 Scientific Report but explained that small increases in regular moderate-intensity physical activity can produce health benefits even if the target range is not met (2018 Physical Activity Guidelines Advisory Committee, 2018).

Analysis of the 2011 Behavioral Risk Factor Surveillance System (BRFSS) survey data revealed that only $15.9 \%$ of adults over 65 met both the aerobic and strength activity guidelines (CDC, 2013a). Among older adults, 31.4\% reported no leisure-time physical activity in the past month (CDC, 2013b). The estimate of insufficient activity among older adults was even higher when based on objectively measured physical activity (Tucker, Welk, \& Beyler, 2011). In Florida, 47.5\% of adults ages 65 and older were classified as inactive or insufficiently active (Florida Department of Health, 2013). Further, $85.6 \%$ of older adults in Florida did not meet the national guidelines for physical activity (Florida Department of Health 2011).

\section{Cost of Care for Older Adults}

Chronic conditions, falls, and physical inactivity threaten the independence and quality of life among older adults and place a heavy burden on the healthcare system and the economy (Salive, 2013; Chatterjee, 2014). Health care expenditures in the United States are the highest among developed countries and are projected to increase $25 \%$ by 2030 due in part to the growing number of older adults with chronic disease. Treatment 
of chronic conditions for older adults accounts for $66 \%$ of the total healthcare budget in the United States (CDC, 2013b). Chronic disease care accounts for 95\% of health care spending for older Americans (CDC, 2013b).

Analysis of Medicare claims determined that payments for a beneficiary with one chronic condition cost \$7,172 annually (Schneider, O'Donnell, \& Dean, 2009). Annual Medicare payment increases to $\$ 14,931$ for beneficiaries with two or more chronic conditions and to $\$ 32,498$ for beneficiaries with three or more conditions (Schneider, O'Donnell, \& Dean, 2009). The total costs for diabetes in all age groups in the United States were \$245 billion in 2012 (American Diabetes Association, 2013). Total costs for heart disease and stroke in 2010 were over $\$ 315$ billion (CDC, 2012). The average cost of hospitalization for a fall-related injury is over $\$ 30,000$ and total medical costs for falls in 2015 exceeded \$50 billion (Burns, Stevens, \& Lee, 2016; Florence, Bergen, Atherly, Burns, Stevens, \& Drake, 2018). The costs of falls are projected to increase to nearly $\$ 70$ billion by 2020 (CDC, 2014).

Older adults who are frail and who have a limited capacity for self-care due to chronic illness, injury, or disability require long-term care services such as assistance with activities of daily living and health maintenance tasks (USDHHS, 2013). Estimates place annual spending on long-term care services and supports between $\$ 210$ billion and \$306 billion (O'Shaughnessy, 2013; Colello, Girvan, Mulvey, \& Talaga, 2012).

Financing long-term care is a challenge for older adults, the families of older adults, and the government (Reinhard, Kassner, House, \& Mollica, 2011). 


\section{$\underline{\text { Evidence-Based Health Promotion for Older Adults }}$}

Many of the risks for chronic disease and falls and resulting disability, morbidity, and mortality are modifiable. Evidence-based programs (EBPs) are interventions that have been demonstrated through rigorously conducted research to teach participants selfmanagement skills and encourage adoption of lifestyle behaviors that have positive outcomes for health preservation and disease prevention. EBPs also have the potential to reduce the need for expensive medical care. The Administration on Aging, the National Council on Aging, the Centers for Disease Control, and foundations have supported initiatives that bring the aging services network, public health, health care, long-term care, and research together to promote the translation of evidence-based programs into community settings to increase the accessibility and quality of health programming for older adults.

Florida has the second highest percent of older adults in the United States with individuals over age 65 representing 19\% of the total population in Florida according to the Current Population Survey (U.S. Census Bureau, 2016). In 2008, the Healthy Aging Regional Collaborative of South Florida (HARC) was established by the Health Foundation of South Florida, a nonprofit grant making organization, to make evidencebased health promotion programs widely available to the large population of older adults in community settings throughout Broward, Miami-Dade, and Monroe counties. The HARC funded community-based organizations to offer Healthy IDEAS to address depression, A Matter of Balance to address falls, the Stanford Chronic Disease SelfManagement Program and the Diabetes Self-Management program to address chronic health conditions, and EnhanceFitness to address physical inactivity. 


\section{Problem Statement}

The effectiveness of evidence-based health promotion programs has been demonstrated, but recruiting, engaging, and retaining participants is an ongoing implementation challenge (Paone, 2014). Low participation by older males is a commonly reported issue in EBP implementation (Ory et al., 2015; Smith et al., 2015; Batra et al., 2012; Melchior et al., 2014). Low participation by males prevents EBPs from reaching the entire priority population of older adults and is especially problematic given that older males have higher rates of chronic disease and higher healthcare costs than older women (Yamamoto, 2013). Research has shown that men are reluctant to use health services in general, but research is needed to understand why so few men participate in evidence-based health promotion and disease prevention programs offered in community settings (Courtenay, 2000).

Adherence is important for participants of evidence-based programs, because participants must receive the minimum dose upon which the evidence for the effectiveness of the program is based in order to have the best chance of experiencing the desired outcomes of the program. Translational efforts generally have fewer resources for retention efforts than the controlled trials that provided evidence for the program (Cross \& West, 2011; Frank, Coviak, Healy, Belza, \& Casado, 2008). Adherence has been conceptualized as the extent to which a behavior corresponds to recommendations or the level of participation in a behavioral regimen once an individual has agreed to undertake it (Mock et al.,2005; Roddy et al., 2005; Dishman, 1998). Definitions of adherence in exercise studies typically include the proportion of participants completing exercise programs as prescribed, the proportion of available sessions attended, or the number of 
sessions completed per week (Picorelli, Pereira, Pereira, Felicio, \& Sherrington, 2014). Dropout is synonymous with attrition and is used to refer to participants who withdraw from an exercise program. Estimates suggest that 50\% of participants drop out within 6 months of beginning an exercise program (Dishman, 1998; Jancey et al., 2007). High dropout rates are concerning because long-term adherence to exercise programs is required in order to sustain benefits (Morey, Pieper, Crowley, Sullivan, \& Puglisi, 2002; Belza, Topolski, Kinne, Patrick, \& Ramsey, 2002).

Researchers have examined the associations between a wide range of factors and adherence. Demographic factors such as age, gender, and race/ethnicity have been positively associated with adherence in some studies and negatively associated with adherence in other studies (Martin \& Sinden, 2001; King \& King, 2010; Anderson et al., 2006; Batra et al., 2016; Jancey et al., 2007). Better health status is generally associated with higher adherence, but poor health has also been reported as a motivator for engaging in exercise in order to manage health conditions (Belza et al, 2004; Picorelli et al, 2014; Van Stralen, De Vries, Mudde, Bolman, \& Lechner, 2009).

Although studies have examined various predictors of adherence, there is a lack of literature examining the factors that older adults identify as contributing to their own long-term adherence (Picorelli et al, 2014; Farrance, Tsofliou, \& Clark; 2016; Findorff, Wyman, \& Gross, 2009). To ensure that evidence-based exercise programs have a public health impact among older adults, it is important to consult with older adult participants to develop knowledge about what they want and need to sustain adherence. Based on the factors that are important to older adults, researchers and program implementers can develop strategies to support older adults in achieving long-term exercise adherence. 


\section{Purpose of the Current Study}

Evaluation of the HARC EBPs demonstrated effectiveness for participants who attended the recommended number of sessions, however, males were underrepresented in the programs making up only 19\% of the total HARC participant population while making up $44 \%$ of the population in the three counties served by the HARC (U.S. Census Bureau, 2015). EnhanceFitness, the evidence-based group exercise program implemented by HARC, was developed by Senior Services in Seattle a to improve the functional fitness of older adults. A six-month randomized clinical trial demonstrated that EF participants experienced improvements in physical functioning, social functioning, and depression (Wallace et al., 1998). The program includes a structured 1-hour group exercise class taught three times a week by a certified EnhanceFitness instructor. In a study of EF offered at congregate meal sites, participants who attended fewer than $66 \%$ of the classes did not show a significant difference in performance measures from baseline to four-month follow up whereas participants who attended two or more of the three classes offered per week showed significant improvements in measurements of functional fitness (Belza, Snyder, Thompson, \& LoGerfo, 2010).

Based on data from the first four years of the HARC, only 25\% of EF participants were adherent to the program in terms of attending at least 32 sessions during the first four months of participation and 41\% dropped out within this initial 4-month period (Palmer, Batra, Anderson, Page, Vieira, \& Seff, 2016). Advancing understanding of the

factors that influence adherence to EF is an important step in promoting sustained adherence to the program. 
A mixed methods study was undertaken to explore factors that influence participation in evidence-based health promotion programs by older males and adherence to the evidence-based group exercise program Enhance Fitness (EF) by older adult participants in order to improve program reach and implementation. The first aim of this study was to explore EBP coordinator and instructor perspectives on barriers to male participation and strategies to engage men in EBPs. The second aim of the study was to examine predictors of short-term and long-term participant adherence to EF using quantitative analysis. The final aim of this investigation was to examine the factors that adherent older adult participants and experienced instructors identify as influencing sustained adherence to the program and strategies to increase adherence using qualitative analysis.

The following research questions are addressed in three manuscripts (chapters 3-5):

Research Question 1: What barriers to recruiting and engaging men in health promotion programs do coordinators and instructors identify and what strategies do they suggest to improve male participation?

Research Question 2: Are age, gender, race/ethnicity, and the baseline measurement of health status associated with adherence to EnhanceFitness?

Hypothesis 1: Younger age, female gender, non-Hispanic white race/ethnicity, and good health at baseline will be positively associated with participant adherence to EnhanceFitness.

Research Question 3: What factors do adherent participants and EF instructors perceive as important to achieving sustained adherence to EnhanceFitness and what strategies do they suggest to improve adherence? 
To answer the first research question, a focus group with program coordinators to identify barriers to male participation and strategies to engage older males in EBPS. Then, a survey of instructors was conducted to triangulate the findings from the coordinator focus group. To answer the second research question, adherence rates were examined and logistic regression was performed using five years of data from the HARC to examine the association of age, gender, race/ethnicity, and the baseline measurement of health status associated with short-term and long-term adherence to EnhanceFitness. To answer the third research question, a qualitative approach was applied to collect data through semi-structured interviews with older adult EF participants and EF instructors to develop knowledge about the factors that participants and instructors identify as influencing participant adherence to EF.

Mixed methods research design mixes quantitative and qualitative methods in order to provide a broader perspective of the research problem (Creswell \& Clark, 2011). Used in combination, quantitative and qualitative methods help to capture both the trends and details needed to understand complex research problems such as participation and adherence in EBPs (Tashakkori \& Teddlie, 1998). The sequential explanatory mixed methods design was used to explain quantitative findings about poor adherence rates in greater depth and detail through the exploration of participant and instructor perspectives of adherence (Creswell, Plano, Clark, Gutmann, \& Hanson, 2003).

Program participants, instructors, and coordinators are important resources in understanding participation and adherence in EBPs, but the literature in this area is lacking. Qualitative research has the potential to reveal new variables and relationships that may enhance understanding of the complex processes involved in sustaining exercise 
behavior. Priority was given to the qualitative methods because the primary purpose of the study was to understand the factors that influence participation and adherence in order to inform the development of strategies for program improvement. The quantitative findings provide an overview of the research problem in terms of demographic and health status factors that influence adherence to EF while the qualitative findings help to provide a more complete understanding of the quantitative findings and sustained exercise adherence by exploring participant and instructor perspectives.

\section{Theoretical Framework}

The scope of influences on exercise behavior has led to a call for the integration of theories and concepts to promote exercise behavior (King, Stokols, Talen, Brassington, \& Killingsworth, 2002). To guide the study of adherence, a theoretical framework was developed to integrate the theory of planned behavior (TPB) with concepts identified in the literature as relevant to sustained participation in exercise (Ajzen, 1991). The TPB is useful in explaining and predicting a variety of health behaviors. The key component of the TPB is behavioral intent which is influenced by attitudes about the behavior, norms related to the behavior, and perceived behavioral control.

The TPB explains that behavior is guided by beliefs about the effects of behavior, beliefs about the normative expectations of other people, and beliefs about facilitators and barriers to the behavior. These beliefs are based on a range of personal background factors including age, gender, race/ethnicity, health status, and past experience, so personal background factors are included in the extended theory (Ajzen \& Fishbein, 2005; Blanchard et al., 2003). 
The extended TPB framework incorporates the cues to action concept from the Health Belief Model to explain the link between intention and behavior (Glanz, Rimer, \& Lewis, 2002). Cues to action can be anything that triggers an individual to act upon a health belief. Without reinforcement, it is unlikely that the constructs of TPB will sustain a challenging behavior such as exercise, so this theory incorporates the benefits resulting from $\mathrm{EF}$ as an influential factor.

Social factors such as social support or having an exercise partner or exercise role model can shape beliefs and in turn behavior (Rogers et al., 2011; McGuire, Waltman, \& Zimmerman, 2011). Social factors have been added to the extended TPB framework to develop a clearer understanding of the context in which exercise beliefs and behavior occur. Based on additional variance in physical activity behavior found to be accounted for by descriptive norms, the proposed framework also modifies the TPB subjective norms construct to a norms construct that includes subjective norms as well as descriptive norms of important others and referent groups (Rivis \& Sheeran, 2003).

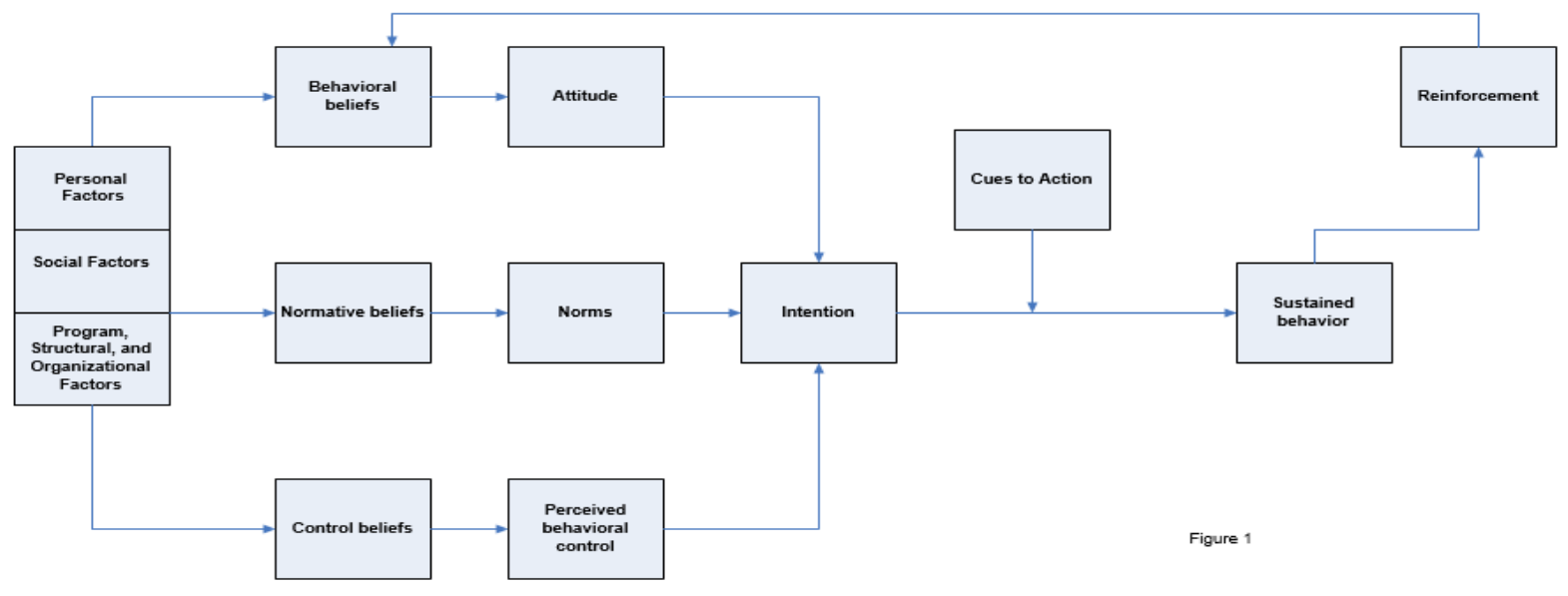

The extended TPB framework illustrated in Figure 1 serves to focus attention on factors theorized to influence sustained exercise behavior which is required to adhere to 
the evidence-based EnhanceFitness guidelines of attending at least two sessions per week. The framework was also used to guide data analysis.

\section{$\underline{\text { Assumptions }}$}

A mixed methods paradigm was selected for this study, so the assumption is that qualitative and quantitative methods can be complementary. The study design is based on the pragmatic assumption that a researcher should employ whichever methods generate the best information needed to address the research question so qualitative and quantitative methods are seen as compatible. Study participants were informed that the individual survey and interview data collected would be kept confidential and that their responses were voluntary, so it is assumed that participants answered survey and interview questions honestly.

\section{$\underline{\text { Limitations }}$}

The study findings may not generalize to older adults outside of South Florida, because data were only collected from coordinators, instructors, and a small sample of participants in South Florida. Secondary data collected in a real-world setting were used for the quantitative segment of the study, data were missing for some fields. Selection bias may also limit the findings of the study because the older adults who agreed to participate in the program and in the interviews may differ from those who refused the invitation to participate. Due to time and access limitations, it was not possible to interview participants who dropped out of EnhanceFitness. The organization offering EF

provided access to active classes but did not provide contact information for dropouts. 


\section{$\underline{\text { Scope and Delimitations }}$}

This study examines multilevel factors that influence male participation in EBPs and older adult adherence to a community-based exercise program. Physical activity is the broad term for body movement that requires more energy expenditure than resting (Caspersen, Powell, \& Christenson, 1985). Exercise is a type of physical activity that is planned and structured and has an objective to improve or maintain physical fitness (Caspersen, Powell, \& Christenson, 1985). Examining the factors that influence participation in other types of physical activity is beyond the scope of the current study. The variables age, race/ethnicity, gender, and health status were chosen for the quantitative portion of the study because they are important personal characteristics that are likely to have an impact on life experiences relevant to exercise behavior and were available in the HARC database. There are an infinite number of questions that could be asked about influences on exercise, so the questions asked during the participant interviews were guided by an extended Theory of Planned Behavior to collect information on a complex range of factors that shape exercise behavior (Ajzen \& Fishbein, 2005).

Due to the large population of diverse EF participants in south Florida, a large sample and extensive time and resources would have been required to achieve data saturation. Meaningful findings can be obtained from a small sample if the information power is sufficient. This study was able to achieve the aim of providing insights into the factors influencing adherence from the perspective of EF instructors and participants that can inform program improvement strategies by selecting interview participants with experiences highly relevant to the study aims, using an established theory, and employing 
focused dialogue (Malterud, Siersma, \& Guassora, 2016). Participant perspectives were triangulated by instructor perspectives to provide a well-rounded picture of participant adherence to EF.

\section{Significance of the Study}

Due in part to an increased focus on prevention efforts, healthy aging, and scientifically backed interventions to ensure efficient use of resources, evidence-based programs are now being implemented in community settings across the United States to combat high rates of physical inactivity, chronic disease, and falls among older adults. DSMP, CDSMP, MOB, and EF have been shown to be effective in community settings, but improvements in the health of the older adult population is dependent upon the participation of the target population. The potential for physical activity to reduce the risk of chronic disease and disability has made it a public health priority, and the aging population increases the public health significance of promoting adherence to exercise programs among older adults. Sustaining participation in exercise programs at recommended levels is essential to maintaining and improving health. This study improves understanding of the barriers to male participation in EBPs from the view of coordinators and instructors and factors that contribute to sustained adherence from the view of older adult participants and instructors. The knowledge gained can be used by program developers, instructors, and organizations offering EBPs to understand the experience and needs of participants and generate potential solutions to improve male participation and older adult adherence to ensure successful replication of EBP outcomes in community settings. 


\section{Summary}

Older adults are living longer than previous generations and the number of older adults living with disease or disability is increasing rapidly. EBPs are an increasingly popular strategy for promoting health and managing disease among older adults, but low participation in EBPs by older males limits their impact. EnhanceFitness (EF) is an evidence-based program that has been implemented by the Healthy Aging Regional Collaborative of South Florida to increase physical activity among older adults, but, as is the case with adherence to national physical activity guidelines, the percent of program participants adhering to the attendance recommendations for EF in south Florida are very low. This study aimed to explore barriers to male participation, identify predictors of adherence, and to develop an understanding of the factors that EF participants and instructors perceive as contributing to sustained adherence. The findings of this study expand the knowledge base on male participation in EBPs and older adult adherence to an evidence-based exercise program delivered in community settings. Findings are significant to the field of public health because they provide a basis for developing strategies to improve program reach and implementation and in turn the impact of EBPs on healthy aging. 


\section{References}

2018 Physical Activity Guidelines Advisory Committee (2018). Physical Activity

Guidelines Advisory Committee Scientific Report. Washington, DC: U.S.

Department of Health and Human Services, 2018. Retrieved from

https://health.gov/paguidelines/second-edition/report/pdf/PAG_Advisory_

Committee_Report.pdf

Ajzen, I (1991). The theory of planned behavior. Organizational Behavior and Human Decision Processes, 50(2):179-211.

Ajzen, I., \& Fishbein, M. (2005). The influence of attitudes on behavior. In D.

Albarracín, B. T. Johnson, \& M. P. Zanna (Eds.), The handbook of attitudes (pp. 173-221). Mahwah, NJ: Erlbaum.

Ahlslog, J.E., Geda, Y.E., Graff-Radford, N.R., \& Peterson, R.C. (2011). Physical exercise as a preventive or disease-modifying treatment of dementia and brain aging. Mayo Clinic Proceedings, 86(9), 876-884.

American Diabetes Association (2013). Statistics About Diabetes. Retrieved from http://www.diabetes.org/diabetes-basics/statistics/

Anderson, E.S., Wojcik, J.R., Winett, R.A., \& Williams, D.M. (2006). Social-cognitive determinants of physical activity: The influence of social support, self-efficacy, outcome expectations, and self-regulation among participants in a church-based health promotion study. Health Psychology, 25(4), 510-520.

Andreyeva, T., \& Sturm, R. (2006). Physical activity and changes in health care costs in late middle age. Journal of Physical Activity and Health, 3, S6-S19.

Arent, S., Landers, D., \& Etnier, J. (2000). The effects of exercise on mood in older adults: A meta-analytic review. Journal of Aging and Physical Activity, 8(4):407430.

Batra, A., Melchior, M., Seff, L., Newman, F., \& Palmer, R.C. (2012). Evaluation of a Community-Based Falls Prevention Program in South Florida, 2008-2009. Preventing Chronic Disease, 9, E13.

Batra, A., Coxe, S., Page, T.F., Melchior, M., Palmer, R.C. (2016). Evaluating the factors associated with the completion of a community-based group exercise program among older women. Journal of Aging and Physical Activity, 24(4), 649-658.

Belza, B., Walwick, J., Schwartz, S., LoGerfo, J., Shiu-Thornton, S., Taylor, M. (2004). Older adult perspectives on physical activity and exercise: Voices from multiple cultures. Preventing Chronic Disease, 1(4), A09. 
Belza, B., Topolski, T., Kinne, S., Patrick, D.L., \& Ramsey, S.D. (2002). Does adherence make a difference? Results from a community-based aquatic exercise program. Nursing Research, 51(5), 285-291

Belza, B., Synyder, S., Thompson, M., \& LoGerfo, J. (2010). From research to practice: EnhanceFitness, an innovated community-based senior exercise program. Topics in Geriatric Rehabilitation, 26(4), 299-309.

Bergen, G., Stevens, M.R., \& Burns, E.R.B. (2016). Falls and fall injuries among adults aged $\geq 65$ years - United States, 2014. MMWR, Morbidity and Mortality Weekly Report, 65, 993-998.

Behrer, L., Erickson, K.I., \& Liu-Ambrose, T. (2013). A review of the effects of physical activity and exercise on cognitive and brain function in older adults. Journal of Aging Research. doi:10.1155/2013/657508

Blanchard, C.M., Rhodes, R.E., Nehl, E., Fisher, J., Sparling, Pl, \& Courneya, K.S. (2003). Ethnicity and the theory of planned behavior in the exercise domain. American Journal of Public Health, 27(6):579-591.

Burns, E.R., Stevens, J.A., \& Lee, R. (2016). The direct costs of fatal and non-fatal falls among older adults - United States. Journal of Safety Research, 58, 99-103

Caspersen, C.J., Powell, K.E., \& Christenson, G.M. (1985). Public Health Reports, 100(2), 126-131.

Colello, K.J., Girvan, G.A., Mulvey, J., \& Talaga, S.R. Congressional Research Service. (2013). Long-term services and supports: Overview and financing. Report No. R42345.

Centers for Disease Control and Prevention (2014). Costs of Falls Among Older Adults. Retrieved from http://www.cdc.gov/homeandrecreationalsafety/falls/fallcost.html

Centers for Disease Control and Prevention (2013a). Adult participation in aerobic and muscle-strengthening physical activities - United States 2011. MMWR. Morbidity and Mortality Weekly Report. Retrieved from http://www.cdc.gov/mmwr/ preview $/ \mathrm{mmwrhtml} / \mathrm{mm} 6217 \mathrm{a} 2 . \mathrm{htm}$ ?scid=mm6217a2_w

Centers for Disease Control and Prevention. (2013b). The state of aging and health in America 2013. Atlanta, GA. Retrieved from http://www.cdc.gov/features/ agingandhealth/state_of_aging_and_health_in_america_2013.pdf

Centers for Disease Control and Prevention (2012). Chronic Diseases and Health Promotion. Retrieved from http://www.cdc.gov/chronicdisease/overview/index.htm. 
Centers for Disease Control and Prevention (2009). Prevalence and most common causes of disability among adults--United States, 2005. MMWR Morbidity and Mortality Weekly Report, 58(16), 421-426.

Chatterjee, A. (2014). Checkup time: Chronic disease and wellness in Americameasuring the economic burden in a changing nation. Santa Monica, CA: Milken Institute.

Courtenay, W.H. (2000). Behavior factors associated with disease, injury, and death among men. Evidence and implications for prevention. The Journal of Men's Studies, 9, 81-142

Creswell, J. W., Plano Clark, V. L., Guttman, M., Hanson, W. (2003). Advanced mixed methods research designs. In: A. Tashakkori \& C. Teddlie (Eds.), Handbook on mixed methods in the behavioral and social sciences, pp. 209-240. Thousand Oaks, CA: SAGE.

Creswell, J.W. \& Clark, V.L. (2011). Designing and conducting mixed methods research. (2nd ed.). Thousand Oaks, CA: SAGE.

Cross, W. F. \& West, J. C. (2011). Examining implementer fidelity: Conceptualizing and measuring adherence and competence. Journal of Children's Services, 6, 18-33.

Dishman, R.K. (1998). Overview. In Exercise Adherence, Dishman RK (ed.). Human Kinetics: Champaign, IL; pp. 1-9.

Farrance, C., Tsofliou, F., \& Clark, C. (2016). Adherence to community based group exercise interventions for older people: A mixed-methods systematic review. Preventive Medicine, 87, 155-166.

Findorff, M.J., Wyman, J.F., \& Gross, C.R. (2009). Predictors of long-term exercise adherence in a community-based sample of older women. Journal of Women's Health, 18(11), 1769-1776.

Florence, C.S., Bergen, G., Atherly, A., Burns, E., Stevens, J., \& Drake, C. (2018). Medical Costs of Fatal and Nonfatal Falls in Older Adults. Journal of the American Geriatrics Society, 66, 693-698

Florida Department of Health (2016). Florida Behavior Risk Factor Surveillance System (BRFSS) 2015 Data Book. Retrieved from http://www.floridahealth.gov/ statistics-and-data/survey-data/behavioral-risk-factor-surveillancesystem/reports/_documents/2015-brfss.pdf 
Florida Department of Health (2011). Florida Behavioral Risk Factors: Results from the 2000-2009 Behavioral Risk Factor Surveillance System. Tallahassee: Florida Department of Health, Bureau of Epidemiology. Retrieved from http://www.floridahealth.gov/statistics-and-data/survey-data/behavioral-riskfactor-surveillance-system/reports/_documents/flbrf.pdf

Florida Department of Health (2013). Florida Behavioral Risk Factor Surveillance System (BRFSS) State and County Data Summary 2013. Tallahassee: Florida Department of Health, Bureau of Epidemiology. Retrieved from http://www. floridahealth.gov/statistics-and-data/survey-data/behavioral-risk-factor-surveillan cesystem/reports/documents/2013county/_documents/2013_summary.pdf.

Fox K.R., Stathi, A., McKenna, J., \& Davis, M. (2007). Physical activity and mental well-being in older people participating in the Better Ageing Project. European Journal of Applied Physiology, 100, 591-602.

Frank, J. C., Coviak, C. P., Healy, T. C., Belza, B., \& Casado, B. L. (2008). Addressing Fidelity in Evidence-Based Health Promotion Programs for Older Adults. Journal of Applied Gerontology 27(1), 4-33.

Fransen, M., \& McConnell, S. (2009). Land-based exercise for osteoarthritis of the knee: a meta-analysis of randomized controlled trials. Journal of Rheumatology, 36(6), 1109-1117.

Glanz, K., Rimer, B. K., \& Lewis, F. M. (2002). Theory, research, and practice in health behavior and health education. In K. Glanz, B. K., Rimer, \& F. M. Lewis (Eds.), Health Behavior and Health Education: Theory, Research, and Practice (3rd ed.) (pp. 22-39). San Francisco, CA: John Wiley \& Sons.

Hung, W.W., Ross, J.S., Boockvar, K.S., \& Siu, A.L. (2011). Recent trends in chronic disease, impairment and disability among older adults in the United States. BMC Geriatrics, 11, 47.

Jancey, J., Lee, A., Howat, P., Clarke, A., Wang, K., \& Shilton, T. (2007). Reducing attrition in physical activity programs for older adults. Journal of Aging and Physical Activity, 15, 152-165.

Kelley, G.A., Kelley, K.S, Hootman, J.M., \& Jones, D.L. (2011). Effects of communitydeliverable exercise on pain and physical function in adults with arthritis and other rheumatic diseases: a meta-analysis. Arthritis Care Research, 63(1), 79-93.

King, A.C., \& King, D.K. (2010). Physical Activity for an Aging Population. Public Health Reviews, 32, 401-426. 
King, A.C., Stokols, D., Talen, E., Brassington, G.S., \& Killingsworth, R. (2002). Theoretical approaches to the promotion of physical activity. American Journal of Preventive Medicine, 23(2S):15-25.

Lawlor, D.A., Patel, R., \& Ebrahim, S. (2003). Association between falls in elderly women and chronic diseases and drug use: cross sectional study. British Medical Journal, 327 (7417), 712-717.

Lindwall, M., Rennemark, M., Halling, A., Bergelund, J., \& Hassman, P. (2007). Depression and exercise in elderly men and women: Findings from the Swedish National Study on Aging and Care. Journal of Aging and Physical Activity, 15(1):41-55.

Malterud, K., Siersma, V.D., \& Guassora, A.D. (2016). Sample Size in Qualitative Interview Studies: Guided by Information Power. Qualitative Health Research, 26(13), 1753-1760.

Martin, M.Y., Powell, M.P., Peel, C., Zhu, S., \& Allman, R. (2006). Leisure-time physical activity and health-care utilization in older adults. Journal of Aging and Physical Activity, 14(4), 392-410.

Martin, K.A., \& Sinden, A.R. (2001). Who will stay and who will go? A review of older adults' adherence to randomized controlled trials of exercise. Journal of Aging and Physical Activity, 9, 91-114.

Martinson, B.C., Crain, A.L., Pronk, N.P., O'Connor, P.J., \& Maciosek, M.V. (2003). Changes in physical activity and short-term changes in health care charges: a prospective cohort study of older adults. Preventive Medicine, 37, 319-326.

McGuire, R., Waltman, N., \& Zimmerman, L. (2011), Intervention components promoting adherence to strength training exercise in breast cancer survivors with bone loss. West Journal of Nursing Research, 33, 671-689.

Melchior, M.A., Seff, L.R., Albatineh, A.N., McCoy, H.V., Page, T.F., \& Palmer, R.C. (2014). Intermediate outcomes of chronic disease self-management program offered by members of the Healthy Aging Regional Collaborative in south Florida. Research on Aging, 36, (4), 431-449.

Mock, V., Frangakis, C., Davidson, N. E., Ropka, M. E., Pickett, M., Poniatowski, B., et al. (2005). Exercise manages fatigue during breast cancer treatment: A randomized controlled trial. Psycho-oncology, 14(6), 464-477.

Morey, M.C., Pieper, C.F., Crowley, G.M., Sullivan, R.J., \& Puglisi, C.M. (2002). Exercise adherence and 10-year mortality in chronically ill older adults (2002). Journal of the American Geriatric Society, 50(12), 1929-1933 
Muir, J.M., Ye, C., Bhandari, M., Adachi, J.D., \& Thabane, L. (2013). The effect of Regular physical activity on bone mineral density in post-menopausal women aged 75 and over: a retrospective analysis from the Canadian multicenter osteoporosis study. BMC Musculoskeletal Disorders, 14, 253.

Myers, J. (2003). Exercise and cardiovascular health. Circulation, 107, e2-e5. National Center for Health Statistics (2016). Health, United States, 2015: With Special Feature on Racial and Ethnic Disparities. Hyatsville, MD. Retrieved from https://www.cdc.gov/nchs/data/hus/hus15.pdf\#054

Netz, Y., Wu, M.J., Becker, B., \& Tenenbaum, G. (2005). Physical activity and psychological well-being in advanced age: A meta-analysis of intervention studies. Psychology and Aging, 20(20):272-284.

Ory, M.G., Smith, M.L., Parker, E.M., Jiang, L., Chen, S., Wilson, A.D., Stevens, J.A., Ehrenreich, H., \& Lee, R. (2015). Fall prevention in community settings: results from implementing Tai Chi: Moving for Better Balance in three states. Frontiers in Public Health, 2, 216-221.

O'Shaughnessy, C. (2013). The basics: National spending for long-term services and supports (LTSS), 2011. Washington, DC: The George Washington University National Health Policy Forum, 2013. Retrieved from http://www.nhpf.org/library/the-basics/Basics_LTSS_02-01-13.pdf

Palmer, R.C., Batra, A., Anderson, C., Page, T., Vieira, E., \& Seff, L. (2016). Implementation of an Evidence-Based Exercise Program for Older Adults in South Florida. Journal of Aging Research, 2016, Article ID 9630241. http://dx.doi.org/10.1155/2016/9630241

Paone, D. (2014). Factors supporting implementation among CDSMP organizations. Frontiers in Public Health, 2, 237.

Picorelli, A.M.A., Pereira, L.S.M. Pereira, D.S., Felicio, D., \& Sherrington, C. (2014). Adherence to exercise programs for older people is influenced by program characteristics and personal factors: a systematic review. Journal of Physiotherapy, 60, 151-156.

Rivis, A., \& Sheeran, P. (2003). Descriptive norms as an additional predictor in the theory of planned behaviour: A meta-analysis. Current Psychology: Developmental, Learning, Personality, Social, 22, 218-233.

Reinhard, S.C., Kassner, E., Houser, A., \& Mollica, R.L. (2011). State scorecard on long-term services and supports for older adults, people with physical disabilities, and family caregivers. Retrieved from https://www.aarp.org/ content/dam/aarp/ research/public_policy_institute/ltc/2014/raising-expectations-2014-AARP.pdf 
Roddy, E., Zhang, W., Doherty, M., Arden, N. K., Barlow, J., Birrell, F., et al. (2005). Evidence-based recommendations for the role of exercise in the management of osteoarthritis of the hip or knee--the MOVE consensus. Rheumatology (Oxford, England), 44(1), 67-73.

Rogers, L.Q., Markwell, S., Hopkins-Price, P., Vicari, S., Courneya, K.S., Hoelzer, K., Verhulst, S., 2011) Reduced barriers mediated physical activity maintenance among breast cancer survivors. Journal of Sport and Exercise Psychology, 33, 235-254.

Rose, D.J., \& Hernandez, D. (2010). The role of exercise in fall prevention in older adults. Clinics in Geriatric Medicine, 26(4), 607-631.

Salive, M.E. (2013). Multimorbidity in older adults. Epidemiologic Reviews, 35(1), 7583.

Schneider, K. M., O’Donnell, B. E., \& Dean, D. (2009). Prevalence of multiple chronic conditions in the United States' Medicare population. Health and Quality of Life Outcomes, 7, 82.

Smith, M.L., Wilson, M.G., DeJoy, D.M., Padilla, H., Zuercher, P.C., Vandenbeg, R., Lorig, K., \& Ory, M.G. (2015). Chronic disease self-management program in the workplace: opportunities for health improvement. Frontiers in Public Health, 2, 166-171.

Sofi, F., Valecchi, D., Bacci, D., Abbate, R., Gensini, G.F., Casini, A., Macchi, C. (2011). Physical activity and risk of cognitive decline: a meta-analysis of prospective studies. Journal of Internal Medicine, 269(1), 107-117.

Tashakkori, A., \& Teddlie, C. (1998). Mixed methodology: Combining qualitative and quantitative approaches (Vol. 46). (L. Bickman, \& D. Rog, Eds.) Thousand Oaks, CA: SAGE.

Tucker, J. M., Welk, G. J., \& Beyler, N. K. (2011). Physical activity in US adults: Compliance with the physical activity guidelines for Americans. American Journal of Preventive Medicine, 40(4), 454-461.

U.S. Census Bureau (2015). Annual Estimates of the Resident Population for Selected Age Groups by Sex for the United States, States, Counties, and Puerto Rico Commonwealth and Municipios: April 1, 2010 to July 1, 2014. Retrieved from https://factfinder.census.gov

U.S. Census Bureau (2017a). The Nation's Older Population Is Still Growing, Census Bureau Reports. Retrieved from https://www.census.gov/newsroom/pressreleases/2017/cb17-100.html 
U.S. Census Bureau (2017b). Older Americans Month: May 2017. Retrieved from https://www.census.gov/content/dam/Census/newsroom/facts-for-features/ 2017/cb17-ff08.pdf

U.S. Census Bureau (2016). Annual Estimates of the Resident Population for Selected Age Groups by Sex for the United States: April 1, 2010 to July 1, 205. Retrieved From https://factfinder.census.gov/faces/tableservices/jsf/pages/productview. xhtml?src=bkmk

U.S. Department of Health and Human Services (2013). What is long-term care? Retrieved from http://longtermcare.gov/the-basics/what-is-long-term-care/

U.S. Department of Health and Human Services: Administration for Community Living (2015). A Profile of Older Americans: 2015. Retrieved from https:/aoa.acl.gov/aging_statistics/Profile/ 2015/docs/2015-Profile.pdf

U.S. Department of Health and Human Services: Administration for Community Living (2017). A Profile of Older Americans: 2017. Retrieved from https://www.acl.gov/ sites/ default/files/Aging\%20 and\%20Disability\%20in\%20America /2017 OlderAmericansProfile.pdf

U.S. Department of Health and Human Services (2010). Office of Disease Prevention and Health Promotion. Healthy People 2020. Washington, DC. Retrieved from http://www.healthypeople.gov/2020/topicsobjectives2020/objectiveslist.aspx

U.S. Department of Health and Human Services (2008). 2008 Physical Activity Guidelines for Americans. Retrieved from https://health.gov/paguidelines/pdf/ paguide.pdf

U.S. Department of Health and Human Services: Administration of Community Living (2018). Office of Disease Prevention and Health Promotion. Upcoming Guidelines. Retrieved from https://health.gov/paguidelines/second-edition/

Van Stralen, M.M., De Vries, H., Mudde, A.N., Bolman, C., Lechner, L. (2009). Determinants of initiation and maintenance of physical activity among older adults: a literature review. Health Psychology Review, 3(2), 147-207.

Vogel, T, Brechat, PH, Lepretre, PM, Kaltenbach,G, Berther, M., \& Lonsdorfer, J. (2009). Health benefits of physical activity in older patients: A review. International Journal of Clinical Practice, 63(2), 303-220.

Wallace, J.I., Buchner, D.M., Grothaus, L. Leveille, S., Tyll, L., LaCroix, A.Z., \& Wagner, E.H. (1998). Implementation and effectiveness of a community-based health promotion program for older adults. Journal of Gerontology: Medical Sciences, 53a(4), M301-M306. 
Ward, B.W., \& Schiller, J.S. (2013). Prevalence of multiple chronic conditions among US adults: From the National Health Interview Survey, 2010. Preventing Chronic Disease, 10, E65. doi:10.5888/pcd10.120203

Werner, C. (2011). The Older Population 2010: 2010 Census Briefs. Retrieved from http://www.census.gov/prod/cen2010/briefs/c2010br-09.pdf.

Yamamoto, D. H. (2013). Health Care Costs - from Birth to Death (Report 2013-1). Retrieved from https://www.healthcostinstitute.org/images/easyblog_articles/ 134/Age-Curve-Study_0.pdf 


\section{CHAPTER II}

\section{Literature Review}

Public health and medical developments contributed to a 20-year increase in the human lifespan between 1950 and 2000 (Goulding, Rogers, \& Smith, 2003). These developments combined with the post-World War II baby boom have led to an unprecedented increase in the aging population that has implications for public health and the health care system. Older adults represented $15 \%$ of the United States population in 2015 and are projected to represent 21\% of the population by 2040 (U.S. Census Bureau, 2015). Older adults represent almost $19 \%$ of the population in Florida which is the highest percent of older adults in the United States (US Census Bureau, 2014). In 2013, older adults accounted for $15 \%$ of the population in Broward County, 14.9\% in MiamiDade County, and 19.7\% in Monroe County (US Census Bureau, 2014).

In addition to the size of the older adult population, the health issues faced by this population make older adults a priority for public health interventions. Chronic diseases affect $80 \%$ of older adults and are the leading causes of death for older adults (Hung et al., 2011; Kramarow et al., 2007). Arthritis, heart disease, cancer, diabetes, and hypertension are among the most common conditions that affect older adults (USDHHS, 2015). Physical limitations and the risk for falls also increase with age which can reduce both health-related quality of life and life expectancy. Physical inactivity is a modifiable risk factor for chronic disease, functional limitations, falls, and disability (Warburton, Nicol, \& Bredin, 2006; CDC, 2012; Durstine, Gordon, Wang, \& Luo, 2013).

The United States Department of Health and Human Services recommends 150 minutes of moderate-intensity physical activity or 75 minutes of vigorous-intensity 
physical activity each week for adults ages 65 and older (USDHHS: ODPHP, 2008). In addition, USDHHS recommends that older adults do muscle strengthening activities that work all major muscle groups at least 2 days per week (USDHHS, 2008). Less than 16\% of older adults meet both the strength and aerobic activity guidelines

Interventions can be implemented to support older adults in developing the skills to manage their conditions, reducing the risk of falling, and becoming more active (CDC, 2013b). Government and private organizations have supported efforts to develop and disseminate evidence-based programs (EBPs) that have been demonstrated through rigorous studies to promote health behaviors and health outcomes. To ensure that the positive outcomes of the program shown in the research are replicated when the programs are implemented in community settings, it is important to understand the factors that influence participation and adherence in the programs.

This chapter presents the literature that provided the basis for this study. The chapter begins with an overview of the health status of older adults, the links between physical activity and health, and physical activity among older adults. In the subsequent section, EBPs offered by HARC are described. Next, the literature on male participation in EBPs is reviewed. The chapter presents research on adherence to exercise programs and the significance of adherence for achieving program outcomes. The chapter also examines theories that have been applied to understand exercise behavior and describes the extended Theory of Planned Behavior which guided this study. Finally, the chapter explores existing literature on the factors that influence adherence to physical activity guidelines and exercise programs and highlights the gap that the current study addresses. 


\section{Literature Search Strategy}

Electronic databases available to Florida International University (FIU) students were searched using a keyword article search. The search strategy involved using search terms AND, OR, and the wildcard character. Medical Subject Headings (MeSH) terms were searched in PubMed. Google Scholar was also used to identify journal articles and books. Interlibrary Loan was used to obtain any relevant articles found that were not available through the FIU databases. Websites of agencies such as The U.S. Department of Health and Human Services, Centers for Disease Control and Prevention, and Florida Department of Health were also accessed. Reference lists of selected articles were also used to identify relevant references.

Only English language resources were included. Studies published before 2000 were not included except for those that were relevant to the discussion of theories and definitions and early studies of EBPs. Key words used for the search included older adults, older men, men 's health, aging, physical activity, inactivity, exercise, group exercise, community-based exercise program, evidence-based program, health promotion and disease prevention, chronic disease, functional status, disability, gender, attendance, male participation, engagement, adherence, and EnhanceFitness.

\section{Health Status of Older Adults}

Over $80 \%$ of older adults have at least one chronic condition and $62 \%$ are living with multiple chronic conditions (National Council on Aging, 2018). The prevalence of chronic disease and the risk of multiple chronic conditions increase with age. Less than half of Americans ages 50-64 have a chronic condition while 92\% of Americans ages 75 and older suffer from at least one chronic condition (Machlin, Cohen \& Beauregard, 
2008). Lower income older adults also experience a disproportionate burden of chronic conditions including heart disease, diabetes, mental illness, and kidney disease (United States Department of Health and Human Services: Administration for Community Living [USDHHS:ACL] 2015). The percentage of Medicare beneficiaries with multiple chronic conditions varies little between race and ethnicity groups (CMS, 2012).

The most common chronic conditions among Medicare beneficiaries are hypertension, high cholesterol, heart disease, arthritis, and diabetes (CMS, 2012). Chronic diseases are the leading causes of death among older adults and have other negative impacts including functional decline, an extended period of disease-associated disability, and diminished quality of life (CDC, 2011; Maaten, Kephart, Kirkland, \& Andreou, 2008). Overall, 44\% of people 65 and older rated their health as excellent or very good but racial disparities exist for self-assessed health. Only $27 \%$ of older AfricanAmericans and 31\% of Hispanics rated their health as excellent or very good compared to 48\% of older non-Hispanic Whites (USDHHS:ACL, 2015).

Older adults represent the fastest growing segment of Florida's population (Florida Department of Health, 2014). The 2015 Florida Behavioral Risk Factor Surveillance System Survey estimates that among older Floridians, 51.7\% have arthritis, 23\% have diabetes, and $21.5 \%$ had reported coronary heart disease, heart attack, or stroke (Florida Department of Health, 2016). It is estimated that over 2.4 million people in Florida have diabetes (American Diabetes Association, 2015). A number of behavioral factors place older Floridians at risk for chronic disease. Nearly 26\% of older Floridians are obese and $40 \%$ are overweight, $8.4 \%$ smoke, $29 \%$ are sedentary, and only $15 \%$ eat at least the recommended 5 servings of fruit and vegetables per day (CDC, 2013b). 
Medicare beneficiaries with multiple chronic conditions use the most health care services and are more likely to visit the emergency room, more likely to be hospitalized, and more likely to be readmitted to the hospital (CMS, 2012). Medicare spending increases with the number of chronic conditions among all sociodemographic groups (CMS, 2012). Two-thirds of all health care costs in the United States are for chronic diseases. Among older adults, 95\% of healthcare costs are for the treatment chronic conditions (CDC, 2013a). Medicare spending was over $\$ 300$ billion in 2010. Due to a growing population of older adults, rising rates of chronic disease, and inflation, Medicare spending is expected to increase to $\$ 903$ billion by 2020 (CDC, 2013a).

While the risk for chronic disease increases with age, practicing healthy lifestyle behaviors can significantly reduce the risk of developing chronic disease. Avoiding tobacco, eating a healthy diet, and engaging in regular physical activity can decrease the risk of diabetes, heart disease, cancer and other chronic conditions (CDC, 2013b).

\section{The Links Between Physical Activity and Health}

Exercise helps to attenuate the changes associated with aging and reduce the risk of chronic diseases and associated disabilities, so increasing physical activity and exercise in older adults is a key target for public health. Physical activity is any movement produced by the skeletal muscles that uses energy (Westerkerp, 2013). Physical activity includes activities of daily living such as walking and leisure activities. Exercise is a type of physical activity that is planned and structured such as an aerobics class or weight training (American College of Sports Medicine, 2010).

As people age, metabolism slows, blood pressure rises, and muscle mass diminishes (Allen \& Morelli, 2011). Declines in cognitive function can also occur. 
Changes in the muscles, joints, and bones associated with aging make older adults more prone to fractures, weakness, loss of balance, reduced mobility, and falls (Daley \& Spinks, 2012). The loss of physical function may lead older adults to be unable to perform activities of daily living such as feeding themselves and maintaining personal hygiene. This loss of ability in turn can interfere with the enjoyment of life and often leads to the need for supportive care in an institutional setting.

Exercise can decrease risk factors for chronic disease such as hypertension, obesity, glucose intolerance, and insulin resistance. Evidence is well documented for the decreased risk of cardiovascular disease, cancer, and metabolic disorders associated with regular exercise (Friedenreich, Neilson, \& Lynch, 2010; Katmarzyk et al., 2003).

Exercise can also support the treatment and management of existing diseases such as depression, hypertension, heart failure, osteoarthritis, and diabetes (American College of Sports Medicine, 1998).

Falls also have a strong association with morbidity and mortality among older adults (Dionyssiotis, 2012). Balance, flexibility, and strength training exercises help older adults to improve their balance, and mobility which reduces the risk for falls (Boskovic et al., 2013). Exercise can also minimize physiological changes of aging related to falls and related complications such as decreased bone mass, decreased muscle mass, joint flexibility, and impaired balance (Daley \& Spinks, 2012).

\section{Physical Activity Among Older Adults}

Less than one third of the older adult population in the United States engages in regular physical activity and only half of the older population engages in any physical activity. Among older Floridians, 57\% meet aerobic recommendations but only 25\% 
meet the recommendations for strength exercises (CDC, 2015). In addition, 55.9\% of older Floridians are inactive or insufficiently active (Florida Department of Health, 2016).

Common barriers to physical activity for older adults include poor health, fear of pain, fear of falls, and lack of transportation (Rasinaho et. al, 2006; Cohen-Mansfield et. al, 2003; Garber \& Blissmer, 2002). Compared to older adults without mobility limitations, older adults with severe mobility limitations more often report fear, negative experiences, and unsuitable environment as barriers to exercise (Rasinaho et al., 2006).

Sociodemographic factors associated with lower levels of physical activity include older age, race other than white, and lower levels of education (Trost et al., 2002; Anderson et al., 2006; King \& King, 2010). Older women are less likely than older men to exercise with $34 \%$ of women over 75 engaging in physical activity and $46 \%$ of men over 75(CDC, 2014). Poor self-rated health status is also associated with lower levels of physical activity (Bauman et al., 2012).

\section{Healthy Aging Regional Collaborative of South Florida Evidence-Based Programs}

Knowledge of the importance of adopting health behaviors in later life has led to the development and evaluation of a variety of evidence-based programs for older adults. The Health Foundation of South Florida established the Healthy Aging Regional Collaborative (HARC) to increase access to evidence-based programs among older adults in South Florida. Programs offered to older adults included the Chronic Disease SelfManagement Program, Diabetes Self-Management Program, Matter of Balance for falls prevention, and EnhanceFitness to address physical inactivity. 


\section{Stanford Self-Management Programs}

Self-management involves the actions that individuals do in their daily lives to feel better and take a central role in managing their health and illness. The CDC's National Center for Chronic Disease Prevention and Health Promotion includes efforts that support self-management of chronic conditions as one of its top priorities (Brady, Anderson, \& Kobau, 2014). Self-management support interventions help participants develop the knowledge, skills, and confidence to do what is needed to live well with their chronic conditions.

The Stanford Chronic Disease Self-Management Program is a peer-led program that was developed in the 1990s and was shown to be effective at improving weekly minutes of exercise, cognitive symptom management, communication with providers, self-reported health, fatigue, and activity limitation in a 6-month randomized controlled trial at community-based sites (Lorig et al., 1999). The program is delivered by two certified peer leaders to a group of 10 to 15 participants for $2 \frac{1}{2}$ hours weekly for 6 weeks. Strategies taught in the group workshop include action planning, problemsolving, and decision-making, and symptom management techniques include sleep, medication management, healthy eating, exercise, relaxation, and communication with healthcare providers.

An evaluation of the outcomes of CDSMP in real world settings showed that at one-year post-program, participants showed significant improvements in health behaviors, self-efficacy, and health status as well as fewer emergency department visits (Lorig, Ritter, \& Hobbs, 2001). The mid-term evaluation of CDSMP workshops offered by HARC demonstrated significant improvement in self-efficacy to manage disease and 
emotions, perceived activity limitations, and physical activity (Melchior, Seff, Albatineh, McCoy, Page, Palmer; 2013).

The Stanford Diabetes Self-Management Program is delivered in the same format as CDSMP and teaches techniques to deal with symptoms of diabetes, pain, hyper/hypoglycemia, and fatigue. The program also educates participants about action planning, for self-management, healthy eating, exercise for strength and endurance, mediation use, and working with health care providers. A randomized trial of peer-led DSMP in community-based settings showed that participants experienced significant improvement in communication with physicians, healthy eating, reading food levels, selfefficacy, and patient activation compared to controls (Lorig, Ritter, Villa, \& Armas, 2009).

During the first five years of HARC, 3,404 older adults participated in CDSMP and 2,790 older adults participated in the culturally appropriate version of CDSMP developed for Hispanic populations called Tomando Control de su Salud. Another 1,436 older adults participated in the Diabetes Self-Management Program and 1,555 older adults participated in the Spanish version of DSMP. Based on pre-program and postprogram measures from five years of HARC program implementation, the increase in confidence reported by CDSMP and DSMP participants was significant for ability to limit pain and discomfort from interfering in activities, managing emotional ups and downs with exercise, and use self-management techniques to manage discomfort and pain. The average cost of program implementation per participant in South Florida was \$204 (Page \& Palmer, 2013). The literature indicates that healthcare costs are reduced by $\$ 1,381$ during the first year following participation in CDSMP which suggests that 
CDSMP is likely to provide a strong return on investment for older south Floridians (Page \& Palmer, 2013).

\section{A Matter of Balance}

A Matter of Balance is a group program that teaches cognitive-behavioral techniques to reduce participants' fear of falling. A randomized clinical trial of the original version of MOB, which was professionally-led, showed that MOB was effective at improving confidence in performing daily activities without falling and perceived ability to manage falls risk (Tennestedt et al., 1998). The program teaches exercises to reduce falls risk by improving balance and strength, goal setting for increasing activity to improve falls self-efficacy and management, cognitive restructuring and behavioral activation activities to encourage belief in the controllability of falls and falls risks, and the promotion of changes in modifiable falls risk factors (Tennested et al., 1998)MOB was translated into a lay-leader model and tested in community settings using a repeated measures design (Healy, Peng, Haynes, McMahon, Botler \& Gross, 2008). MOB is delivered as two hour sessions for 8 weeks. Outcomes of the lay leader model were found to be comparable to the professionally led model (Healy et al., 2008).

During the five-year HARC evaluation period, a total of 3,445 older adults participated in MOB and another 3,641 older adults participated in the Spanish version of the program, Asunto de su Equilibrio. The Year 5 HARC report indicates that confidence in ability to reduce the risk of falls, ability to protect themselves during a fall, get up from a fall, become steadier on their feed, and increase physical strength improved significantly for MOB participants in south Florida. 


\section{EnhanceFitness}

EnhanceFitness (EF) is an adaptable, low-cost, evidence-based physical activity program for older adults. The program was developed in partnership with the Washington Health Promotion Research Center, Senior Services Seattle (now Sound Generations), and Group Health Organization Seattle (Belza et al., 2010). EnhanceFitness has long been listed on the approved list for federal funding for Physical Activity programs and is now included on the evidence-based intervention list for Chronic Disease SelfManagement Support and will be included on the pre-approved list for Falls Prevention (National Council on Aging, 2017). EF classes meet for one hour three times each week. The class consists of 5-8 minutes of warming up, 20 minutes of aerobics, 3-5 minutes of cooling down, 20 minutes of strength training, and 8-10 minutes of stretching (Senior Services, 2012). There are two variations of EF. EF may be conducted as a seated class for frail older adults (Level 1) or as a standing class which was the original class design (Level 2). Classes are often a mixture of the two levels which allows the program to accommodate participants of varied capabilities within one class (Senior Services, 2012). The implementation and dissemination of EF is overseen by Sound Generations.

A randomized controlled trial of EF was conducted at a senior center in Washington with participants who were 65 years of age or older who had received physician's approval to participate. Older adults who were blind, frail, or cognitively impaired were excluded (Wallace et al., 1998). Measures included self-rated health status, measures of exercise, the CES Depression scale, self-reported restricted activity days, days spent in bed due to illness or injury, and the eight health assessment scales from the Medical Outcomes Study Short-Form 36 (Wallace at al., 1998). Subscales 
include physical functioning, limitations due to physical health, limitations due to emotional health, social functioning, bodily pain, mental health, energy/fatigue, and general health perceptions. EF participants improved on seven of the eight SF-36 subscales and CES-D scale while scores of the control group declined (Wallace et al., 1998). Differences between participants and controls were assessed at baseline, 2 months, and 6 months. Many of the differences were observed at 2 months but continued at 6 months (Wallace et al., 1998). The finding that participants improved and nonparticipants declined, demonstrates that EF can help older adults to prevent declines and improve physical and social functioning.

Other studies have supported the effectiveness of EF across settings with diverse participants. Belza et al. (2006) studied the effectiveness of EF implemented in community settings in nine states using measures of functional fitness and health status at 4 and 8 months to assess program effectiveness. Participants improved on 30-second arm curls, 30 second chair stands, and the eight-foot-up-and-go circuit (Belza et al., 2006). EF participants also reported improvements in their emotional health and social functioning (Belza et al., 2006). EF was offered in congregate meal sites for 12 weeks to evaluate the effectiveness of the program among low income older adults (Moore-Harrison et al., 2009). Analyses of the functional fitness tests and responses to the SF-36 revealed improvements in chair stands, eight foot up and go, bodily pains, social functioning, and mental health (Moore-Harrison et al., 2009). EF was successfully replicated in Hawaii with white and Asian Pacific Islander older adults. Participant outcomes included significant improvements in chair stands, arm curls, and the up-and-go test (Tomioka, Sugihara, \& Braun, 2010). From 2008 through 2013, a total of 8,600 individuals 
participated in EF classes offered by HARC member agencies. Among participants who attended at least 32 sessions within the first 16 weeks, significant improvements were observed for fitness test measurements of upper body strength, lower body strength, and functional mobility.

Ackerman et al. (2003) conducted a controlled study comparing the healthcare costs of older adult Medicare managed care beneficiaries participating in EnhanceFitness to those not participating in the program. Analyses did not reveal any significant differences in total healthcare costs during the first 12 months of participation, however, a $20 \%$ reduction in healthcare costs was found for beneficiaries who participated in the program at least once per week on average (Ackerman et al, 2003). The benefits of physical activity accrue over time, so Ackerman et al., (2008) conducted another retrospective cohort study with members of a health maintenance organization was conducted to examine healthcare utilization and costs of EF participants over two years (Ackerman et all, 2008). EF participants had a lower hospitalization rate than nonparticipants during the first months but higher primary care costs. During the second year, EF participants continued to have higher primary care costs but the adjusted total healthcare costs were $\$ 1,186$ lower for EF participants than for nonparticipants (Ackerman et al., 2008).

The study also found that attendance level affected the cost and utilization differences (Ackerman et al., 2008). Average attendance per week was calculated and those attending at least 52 classes during the first year were classified as higher EF users. Low EF users had higher predicted primary care costs than nonparticipants and similar inpatient care costs, whereas higher EF users had no difference in predicted primary care 
visits from nonparticipants and significantly lower healthcare costs and fewer hospitalizations than nonparticipants (Ackermann et al., 2008). Higher EF users also had fewer hospitalizations and lower healthcare costs than nonparticipants in the second year (Ackermann et al., 2008). EF participants attending at least once weekly had healthcare costs that were $\$ 1,929$ lower than nonparticipants during the first year and \$1,784 lower than nonparticipants during the second year (Ackerman et al., 2008).

Sugihara et al. (2011) conducted a cost-benefit analysis of the EF pilot program on Kauai. The expected healthcare costs were calculated using national statistics on annual healthcare costs. Based on the program cost and the $20 \%$ reduction in healthcare costs reported by Ackerman et al. (2003) for participants who attend weekly, Sugihara et al. (2011) estimated that the savings for 96 participants who attended at least weekly would save $\$ 344,256$ per year.

Page and colleagues (2014) collected information on EF program costs from agencies participating in the Health Foundation of South Florida's Healthy Aging Regional collaborative, and calculated an average monthly implementation cost of $\$ 1,713$ during the first year of implementation and $\$ 873$ during the second year of implementation. Based on the annual healthcare cost savings of $\$ 1,784-\$ 1,929$ per participant reported in the literature, the monthly program cost estimates suggest that EF can also produce a positive return on investment in Florida if older adults participate attend consistently over time (Page et al., 2014).

\section{Male Participation in Evidence-Based Health Promotion Programs}

Males are traditionally underrepresented in evidence-based programs delivered to older adults (Smith, Belza, Alpeter, Ahn, Dickerson \& Ory, 2012; Smith, Ory, Belza \& 
Alpeter; 2012; Smith et al., 2014). Towne and colleagues (2015) examined the dissemination of CDSMP, MOB and EF to determine the extent to which vulnerable populations including older adults, racial/ethnic minorities, residents of medically underserved areas, and individuals with low incomes were reached. These vulnerable populations carry a disproportionate burden of chronic disease, so ensuring their inclusion in programs is an important step to addressing health disparities. The three programs attracted diverse participants but males only represented 22\% of CDSMP participants, 16.6\% MOB participants, and 14.6\% of EF participants (Towne et al., 2015). The five-year evaluation of the Healthy Aging Regional Collaborative reach data showed that males only represented 19\% of participants across all programs.

Research on participation in EBPs by older adults in general has identified a range of factors that can influence willingness to participate include attitudes, cultural beliefs, and gender roles (Han, Kang, Kim, Ry, \& Kim, 2007; Bunn, Dickinson, Barnett-Page, Mcinnes, \& Horton, 2008). Barriers to participation that have been identified include time constraints, lack of information about the programs, transportation, and lack of affiliation with other program participants (Wright \& Hyner, 2009; Wright \& Hyner, 2011; Biedenweg et al., 2014). Effective strategies for recruiting African American men into a cancer screening trial included addressing transportation barriers, hosting churchbased session, overcoming fear and mistrust of research, and providing follow-up call for programs (Ford, Havstad, \& Tilley, 2003).

Analysis of health care utilization data by Blue Cross Blue Shield of North Carolina revealed underuse of preventive services by adult males in a managed care setting (Meador \& Linnan, 2006). The health plan implemented applied the PRECEDE 
planning model to identify key reasons for underuse and strategies to improve utilization of the services by men (Green \& Kreuter, 1991). The model outlines a systematic process for health promotion program planning and evaluation which involves conducting social, epidemiological, behavioral and environmental, educational and organizational, and administrative and policy diagnoses to identify multidimensional factors that influence health status. It is important to note that the majority of BCBSNC's managed care members are working-age adults and their children. Based on the planning process, physician recommendations, increasing perceived susceptibility, and increasing health knowledge/awareness were identified as priority interventions for addressing the underuse of preventive services by men (Meador \& Linnan, 2006).

The factors and strategies related to older adults' participation and younger men's participation in health-related activities may be relevant to the participation of older men in EBPs, but there is a lack of research examining barriers and strategies unique to older men that can influence their participation in EBPs. Studies examining the factors that shape older males' participation in CDSMP, DSMP, MOB and EF are also missing from the literature. Compared to women, men have a reduced life expectancy, higher premature death rates, and higher chronic disease rates (Courtenay, 2000; CDC, 2011). Targeted research focused specifically on the barriers to male participation in EBPs and effective recruiting techniques for older males could improve understanding of the reasons for low male participation rates and help to address gender-based inequities.

\section{Adherence to Exercise Programs}

While EnhanceFitness and other group exercise programs have been shown to increase physical activity and improve health outcomes among older adults, exercise 
programs face the challenges of low adherence rates. Adherence is defined inconsistently in the literature. It has been defined in terms of retention, dropout, duration, completion, and attendance. Retention refers to participants who are maintained in a program until its conclusion or for the recommended amount of time (Picorelli et al., 2014). Conversely, measures of dropouts reflect individuals who discontinue participation in a program before its conclusion (Dishman, 1982). Duration measures are used to examine how long a participant is linked to the program. In some studies, completion is synonymous with retention, but other times, completion is determined by calculating percentage or number of sessions attended and classifying participants as completers based on program criteria (Hawley-Hague, Home, Skelton, \& Todd, 2016; Batra et al., 2016). The percent, number, or average number of sessions attended has also been used to calculate adherence rates or to categorize participants as low or high adherers based on set cutoff points (Ackerman et al., 2003; Picorelli et al., 2014; Hawley-Hague, Horne, Skelton, \& Todd, 2016).

Literature has documented a dropout rate of approximately 50\% within the first six months of participation (Dishman, 1982; Resnick \& Spellbring, 2000). Other interventions to increase physical activity among older adults report dropout rates ranging from $22 \%$ to $76 \%$ within the first year of participation (Prohaska, Peters, \& Warren, 2000; Schmidt et al., 2000). A study of 200 older adults who enrolled in twice weekly strength training classes found that $60 \%$ of the participants continued to participate at one year with an adherence rate of 58\% among all participants (Layne, 2009). In a study of older women allocated to either a strength or aerobic exercise group that met 3 times a week for 10 weeks, the retention rate was nearly $67 \%$ for strength training and over $71 \%$ for aerobic exercise, but the adherence rates were $56 \%$ and $50 \%$ in the strength and 
aerobic groups respectively (Picorelli et al., 2014). These findings suggest that while a high percentage of participants were retained in the program, they did not attend frequently enough to obtain the expected benefits of the program.

Similarly, Brittle et al. (2009) conducted a randomized controlled trial of a group exercise program for older adult care home residents and reported a retention rate of $82 \%$ in exercise programs for older adults, but the participants attended less than $43 \%$ of the session offered on average. In a retrospective study of EF with a follow-up period of 20 months, Ackerman et al. (2003) reported that only 50\% of EF participants attended weekly over the course of one year. Sugihara et al. (2011), however, reported that $73 \%$ of EF participants attended weekly during one year of program implementation.

In the current study, adherence is defined in terms of attendance frequency and duration in order to examine whether participants are attending at the levels necessary to achieve health outcomes and cost savings demonstrated in previous studies on EnhanceFitness. In one study of EF offered at congregate meal sites, participants who attended fewer than $66 \%$ of the classes did not show a significant difference in performance measures from baseline to 4-month follow up, whereas participants who attended 2 or more of the 3 classes offered per week showed significant improvements in measurements of functional fitness (Belza. et. al, 2010). In a study of the implementation and effectiveness of EF classes offered during the first four years of the HARC, only $26 \%$ of participants attended at least 32 sessions during the first four months (Palmer, Batra, Anderson, Page \& Seff, 2016). In the current study, the quantitative analysis of shortterm adherence to EF was conducted using attendance of at least $66 \%$ of sessions offered during the first 4 months of participation as the cutoff point for classification as adherent. 
In another study on the effect of EnhanceFitness participation on healthcare costs, Ackermann and colleagues (2003) found that attending an average of once per week for the first year of participation was necessary in order to observe a reduction in healthcare utilization and costs. In the current study, the quantitative analysis of long-term adherence to EF was conducted using an average attendance of at least once per week during the first year of participation as the cutoff point for classification as adherent.

\section{Significance of Adherence}

Sustaining exercise participation at recommended levels is essential to improving and maintaining health, so adherence has been described as the most important factor affecting program outcomes (Woodward \& Berry, 2005; Marks \& Allegrante, 2005). To ensure that exercise programs are effective, participants must adhere to at least a minimum level of participation (Frank et al., 2008). Poor adherence rates that minimize program outcomes also affect the return on investment for exercise programs (Ackermann et al, 2003; Ackermann et al., 2008). Some health plans offer their beneficiaries free or affordable access to community-based exercise programs such as Silver Sneakers or EnhanceFitness. Participation in these exercise programs can decrease healthcare costs, but the savings are generally attributed to fewer hospital admissions, fewer Emergency Department visits, and reduced in-patient healthcare costs which have been documented only after participants attend program for greater than one year or more than once per week (Nguyen et al., 2008; Ackerman et al., 2003).

\section{Extended Theory of Planned Behavior}

Theories that have commonly been applied to understand exercise behavior include the health belief model, social cognitive theory, the theory of planned behavior, 
self-determination theory, and the transtheoretical model. Social cognitive theories that help to identify the factors motivating behavior have been suggested to be important to understanding the initiation and maintenance of exercise behavior (Biddle \& Nigg, 2000). Sonstroem (1988) reviewed exercise adherence and proposed that Ajzen and Fishbein's theory of reasoned action is best suited to understanding exercise adherence as it considers personal, environmental, and activity-specific influences. The theory of reasoned action has now been expanded to include the construct of perceived behavioral control under the name of the theory of planned behavior (Ajzen, 1991). Based on Sonstroem's recommendation and a review of the literature, the theoretical framework for this study was developed from the theory of planned behavior (TPB). The framework integrates the TPB in its entirety with factors identified in the literature as relevant to exercise behavior including structural and organizational factors, social factors, personal factors, and benefits.

The TPB states that intention is the best predictor of behavior and that intention is predicted by attitude towards the behavior, subjective norms regarding the behavior, and perceived behavioral control or perception of one's ability to perform the behavior successfully (Ajzen, 1991; Ajzen \& Manstead, 2007). The strength of the relationship between intention and behavior varies across situations and is subject to the influence of other factors (Ajzen \& Manstead, 2007). Depending on the context, different aspects of attitudes, norms, and perceived behavioral control are triggered.

There is a debate concerning the ability of TPB to predict adherence to healthrelated behaviors. A study of home-based exercise for cardiac rehabilitation reported that perceived behavioral control and attitude predicted intention to exercise from baseline to 
3 months and from 3 months to 6 months and that intention predicted exercise for both time intervals (Blanchard, 2008). The efficacy of TPB in predicting adherence to treatment adherence in chronic illness was tested in a meta-analysis which found that TPB predicted 33\% of the variance in intention, but it only predicted $9 \%$ of the variance adherence behavior (Rich, Brandes, Mullan, \& Hagger, 2015). Adhering to a complex chronic illness treatment regimen involves multiple health behaviors such as exercise, diet, and medication use, so it is expected that TPB is more effective at predicting adherence to a group exercise program than a treatment regimen.

Intention to exercise was found to predict actual exercise at baseline and maintenance of exercise at 12 weeks in a quasi-experimental trial of an exercise intervention among sarcopenic older adults, but attitude was a stronger influence on exercise among men and subjective norm was a stronger predictor of exercise among women (Ahmad et al., 2014). Another application of TPB to exercise among older adults found that while measures of attitudes, perceived behavioral control, and subjective norms predicted exercise behavior at one month but not at 3 and 9 months (Brenes, Strube, \& Storandt, 2006). A meta-analysis of the TPB applied to exercise behavior found that the theory's variables explained $30 \%$ of the variance in intentions to exercise (Downs \& Hausenblas, 2005).

Exercise intention declines with age, but research shows that older adults are more likely to translate their intentions to exercise into exercise behavior (Hagger et al., 2002; Downs \& Hausenblas, 2005). Data from several other studies reveal that TPB constructs explain 45-72\% of the variance in PA intention among older adults whereas the TPB constructs have been shown to account for 39 - $44 \%$ of the variance in exercise 
among the general population (Motalebi, Iranagh, Abdollahi, \& Lim, 2014). These findings suggest that TPB is well-suited to guide the study of adherence to a group exercise program among older adults.

While TPB has been shown to predict exercise behavior among older adults, a large portion of the variance in behavior remains unexplained by the TPB, so the TPB is open to the addition of predictors if they are theoretically justified and if they explain a unique portion of variance in behavior. Literature on exercise uptake and adherence suggests that a number of constructs from other theories are important to explaining the variance in sustained exercise behavior. Social ecological theory explains that individuals are embedded within settings and that personal factors and contextual factors combine to influence outcomes (Bronfenbrenner, 1979). Social, cultural, structural, and organizational factors can have an indirect influence on behavior that is mediated by individual level factors such as beliefs. The TPB is limited in its ability to consider macrosocial factors, so they were added to the extended TPB framework. Based on additional variance in physical activity behavior found to be accounted for by descriptive norms, the proposed framework also modifies the TPB subjective norms construct to a norms construct that includes subjective norms as well as descriptive norms of important others and referent groups (Rivis \& Sheeran, 2003).

Without reinforcement, Dishman (1986) proposes that it is unlikely that the constructs of TPB will sustain a challenging behavior such as exercise, so the extended TPB incorporates the reinforcement construct from social-cognitive theory (Bandura, 1999). Positive outcomes resulting from exercising are expected to be required in order to reinforce exercise behavior and sustain it. The TPB presents behavior as the result of a 
linear process which does not account for changes over time. In the study by Brenes et al. (2006), the variance in exercise behavior of older adults explained by TPB decreased from 1 month to 3 months and from 3 months to 9 months. Their findings suggest that other variables not included in the TPB influence the exercise of older adults as time passes and highlights the need to consider the variables that influence the behavior of older adults at different stages of exercise. Herbert and Teague (1989) also recommend investigating the processes underlying exercise adherence at different stages of change in order to develop effective strategies to promote exercise adherence (Herbert \& Teague, 1989).

The extended theory of planned behavior was applied to explore the experiences of participants in relation to initiation of participation and long-term adherence to the EnhanceFitness program to examine the factors underlying adherence to the program over the course of participation. Overall, the theoretical framework represents an attempt to enhance the TPB by considering the structural, organizational, cultural, social, and individual factors that support sustained behavior. This framework was used to develop the interview guides and to guide coding.

\section{Review of Factors Associated with Exercise Adherence}

The importance of exercise adherence in achieving and maintaining positive health outcomes has led to a large body of research aimed at identifying factors associated with adherence to physical activity recommendations and exercise programs among older adults. Factors examined include a wide range of modifiable and nonmodifiable barriers and facilitators to exercise. Knowledge of non-modifiable factors related to exercise adherence can be applied to tailor programs and target strategies for 
recruiting and retention while knowledge of modifiable factors can inform the development of strategies to increase facilitators and reduce or overcome barriers.

\section{Personal Factors.}

Demographics. Literature documenting the association between age and decreased physical activity suggests that age could be an important influence on adherence to exercise programs (Anderson et al., 2006; Aslan et al., 2010; Sjogren \& Stjernberg, 2010; King \& King, 2010). An evaluation of the Arthritis Foundation Exercise Program reported that $71 \%$ of participants completed an average of $75 \%$ of classes offered twice per week for eight weeks and were classified as high adherers (Schoster et al., 2005). Compared to high adherers, the 29\% of participants who were classified as low adherers were younger but were similar in terms of other demographics (Schoster et al., 2005). Bouchard et al. 2012 reported that age is associated reduced readiness for lifestyle modification. Older adults were reported to have lower intentions to initiate and maintain physical activity than younger age groups (Bouchard et al., 2012; King \& King, 2010). Jancey (2007) did not find a significant association between age and attrition.

In a cohort study of predictors of attendance to a group exercise program in older adults at long-term care facilities, socio-economic characteristics were significantly associated with participant attendance at exercise groups in the residential homes but not in nursing homes (Finnegan, Bruce, Lamb \& Griffiths, 2015). One study of adherence to community exercise classes found that individual factors such as housing, education were associated with adherence by older adults (Hawley-Hague, 2013). 
Researchers have reported high rates of physical inactivity among women (Anderson et al., 2006; Aslan et al., 2008; King \& King, 2010; Sjogren \& Stjernber, 2010). A prospective cohort study of 10 organized exercise programs designed for older adults found that female gender was a significant positive predictor of intention to continue participating, but gender was not a significant predictors of actual continued participation (Stiggelbout et al., 2006).

Physical inactivity has also been found to be more prevalent among minorities than among whites (Anderson et al., 2006; King \& King, 2010). A cross-sectional study of determinants of ongoing participation in EF reported that white ethnicity was associated with an increased probability of dropout (Gillette et al., 2015). Batra et al. (2016) reported that black, non-Haitian women were less likely to complete EF classes offered in community settings in South Florida. A review of older adults' adherence to exercise in randomized controlled trials found that demographics are inconsistent predictors of adherence (Martin \& Sinden, 2001). Different variables were associated with adherence at different time points and to different aspects of adherence such as frequency, intensity, and duration (Martin \& Sinden, 2001). These findings suggest that it is important to examine the influence of demographic variables for the specific programs, populations, and desired types of adherence in order to determine the factors that would be the best targets for tailoring strategies.

Health. Health is a prominent factor associated with physical activity and adherence to exercise programs. A review of qualitative and quantitative studies on barriers and motivators to physical activity among older adults found that health concerns were the most common determinant of physical activity (Baert, Gorus, Mets, Geerts, \& 
Bautmans, 2011). Another review identified health status as an important influence on physical activity initiation and maintenance (Van Stralen et al., 2009). A systematic review of prospective studies examining adherence to exercise programs also revealed that having fewer health conditions, better self-rated health, and reporting use of fewer medications were associated with higher adherence (Picorelli et al., 2014). In a six-month randomized controlled trial of EnhanceFitness, illness was the main reason reported for dropout (Wallace, 1998). An 18-month RCT of older adults participating in communitybased or home-based exercise programs also found that adverse health events were a strong predictor of attrition (Schmidt, 2000). In a cross-sectional study of determinants of ongoing participation in EnhanceFitness, health barriers were also significant predictors of dropout (Gillette et al., 2015).

A one-year longitudinal study of the dissemination of a strength training program for older adults did not find an association between health status and adherence rates or dropout (Layne, 2007). A prospective cohort study of 10 types of exercise programs found that health influenced exercise participation and maintenance indirectly through the likelihood of lapses which were directly associated with maintenance of exercise participation (Stiggelbout, Hopman-Rock, Crone, Lechner, \& van Mechelen, 2006). Stineman (2011) found that poor mental health had a stronger association with nonadherence than poor physical health among participants of a falls reduction exercise program.

Bethancourt (2014) explained that different aspects of health could be motivators or barriers to physical activity. Physical limitations and aging related pain were barriers to physical activity but some participants with health conditions saw physical activity as a 
way to manage their health conditions and ability to perform daily living activities. Belza et al. (2004) also found that health acted as both a motivator to physical activity and explained that poor health can lead to sedentary behavior or can serve as a cue to engage in behaviors to achieve better health. The potential for health conditions to interfere with exercise adherence and the potential for the desire to manage health conditions to encourage exercise adherence make health status an important factor to consider in studies of exercise adherence.

\section{Exercise History and Identity}

Past exercise behavior is supported as a consistent predictor current physical activity participation (Trost, Owen, Bauman, Sallis \& Brown, 2002). A review of 20 randomized controlled trials determined that a history of being active and high selfefficacy for exercise were associated with better adherence (Martin \& Sinden, 2001). McCauley et al., (2003) also found evidence that past exercise behavior likely contributes to exercise self-efficacy and in turn better adherence. Ethnically diverse older adults who participated in focus groups discussed being active as young people and maintaining an active lifestyle later in life (Belza et al., 2004). This theme suggests that the propensity to be physically active begins developing early in life. Exercise identity among older adults was found to be a strong predictor of physical activity behavior, self-regulatory efficacy, physical activity intentions, and satisfaction with life when they are participating in physical activity (Strachan, Brawley, Spink, \& Glazebrook, 2010). Exercise identity in older adulthood may be important in avoiding acting in accordance with stereotypes that older adults are frail and less mobile (Ory et al., 2003). 


\section{Social and Cultural Factors.}

Social Support. Social support has been consistently found to be a significant predictor of exercise (Smith, Bantin, Eime, O’Sullivan, \& van Uffelen, 2017;

Bethancourt, Rosenburg, Beatty, \&Arterburn, 2014). Friends and family have been found to influence physical activity, but older adults usually receive less encouragement from others to exercise than people in other age groups (Stahl et al., 2001). In a qualitative study, older adults reported a lack of guidance and physical activity recommendations from healthcare providers, so support and information on safe exercise for older adults from healthcare professionals could be an important motivator for participation in physical activity (Bethancourt et al., 2014).

An article on best practices for community-based exercise programs explains that programs provide a source of social support which can facilitate long-term adherence (Cress et al, 2005). A multiple case study of adherence to community based group exercise programs found that social features of the program contributed to a sense of belonging and helped participants to adhere to the programs (Killingback, Tsofliou, \& Clark, 2017). These findings are in line with a qualitative study of barriers and facilitators to use of physical activity programs which identified group activities, social interaction, role models in class, camaraderie, and a sense of community as important motivators for attending group-based programs (Bethancourt, Rosenburg, Beatty, \& Arterburn, 2014). Interaction in the classes helped some older adults to overcome intrapersonal barriers to exercise such as lack of motivation to exercise alone (Bethancourt et al., 2014). Some older adults, however, reported that feeling embarrassed about their appearance or anxious about keeping up were barriers to participation (Bethancourt et al, 2014). 


\section{Instructors.}

Research indicates that the exercise instructor is an important influence on older adults’ uptake and adherence to classes. The quality of instruction and leadership provided influence engagement in classes (Ecclestone \& Jones, 2004). Participant perceptions of instructors are also reported as important influences on adherence (Chiang, Seman, Belza, \& Hsin-Chun Tsai, 2008; Estabrooks, Munroe, Fox \& Gyurcsik, 2004). The multiple case study by Killingback et al. (2017) reported that instructor personality and professionalism were important in helping older adults to adhere to exercise programs for a year or more.

Seguin et al. (2010) found that instructor experience with leading a program significantly increased adherence among older women. Hawley, Skelton, Campbell, and Todd (2012) administered a questionnaire to instructors in the United Kingdom with older adult exercise qualifications and found that instructors who had been delivering the classes for more time had more positive attitudes toward older adult participation in exercise than instructors with less experience. Instructors who express positive beliefs about older adults' abilities to participate in exercise and achieve positive outcomes by attending can influence older adults' attitudes and in turn their intention to participate in and maintain exercise (Lucidi et al., 2006; Yardley, Donovan-Hall, Francis, \& Todd, 2007). Given the potential for instructors and their attitudes to influence older adults' attitudes and adherence, it is important for research on exercise adherence to include instructor perspectives.

Culture. Exercise adherence may also be influenced by cultural factors. Cultural differences likely exist in norms and motives for participation. Belza et al. (2004) 
conducted ethnic-specific focus groups to examine barriers and facilitators to exercise among older adults. Focus group participants recommended providing culture-specific exercise in order to improve participation. American Indians and Alaska Natives expressed feeling out of place at fitness facilities around people who do not look like them and a desire to be around people of a similar identify and cited cultural connection as an important motivator for exercise. Cantonese-speaking Chinese and Korean older adults expressed views of exercise as essential for maintaining health and longevity. African American adults expressed that determination and the social aspect of programs were important influences on exercise participation. Filipinos reported the importance of socializing, blood circulation, and appetite stimulation. Spanish-speaking Latinos emphasized faith and socializing in their discussions of physical activity while Vietnamese older adults highlighted the importance of a consistent daily routine of exercise and maintaining good health in spite of age.

While this study points out ethnic-specific factors that are important to physical activity participation, many themes are common across groups including health status, availability of ethnic-specific exercise facilities, transportation, costs, and exercise history (Belza et al, 2004). Evidence on cultural influences on group exercise adherence among older adults is limited, so additional research is needed in this area.

\section{Structural and Organizational Factors.}

\section{Program Factors.}

Findings from a review of randomized controlled trials of exercise involving older adults suggest that adherence is greater in strength and flexibility exercise programs compared to aerobic exercise programs (Martin \& Sinden, 2001). Group-based and 
resistance exercise also predicted higher attendance rates than individual or aerobic exercise (Hong, Hughes, Prohaska, 2008). In a randomized controlled trial of home-based and center-based exercise interventions among 40-65 year-old women, retention and attendance were better for center-based programs at 6,12, and 18 months (Cox, Burke, Gorely, Beilin \& Puddey, 2003).

A study of multiple programs reported that program design factors including location, cost, use of music, and adaptable content supported adherence (Killingback et al., 2017). Expense, accessibility, and convenience of classes are consistently reported to be associated with participation (Bethancourt et al., 2014; Bauman et al., 2012; Baert, 2011; Costello, Kafchinski, Vrazel, \& Sullivan, 2011). It is also important to consider the frequency, intensity, and duration of programs and the fit of the programs with participant expectations and abilities (Bethancourt et al., 2014; Warren-Findlow, Prohaska, \& Freedman, 2003). Exit interviews conducted with dropouts and completers of the Perth Active Living Seniors study revealed that the time of the class was inconvenient for some older adults, while other cited competing priorities or health problems (Jancey et al., 2007).

Participants of EnhanceFitness cited lack of variation in classes and interest in other classes as barriers to participation (Bethancourt et al., 2014) Among people who had access to but never used physical activity programs, inadequate information about the programs was a key barrier to participation (Bethancourt et al, 2014). Although the design of evidence-based exercise programs is set by program developers, it is important to understand which adaptable program features can be modified to improve adherence. 


\section{Beliefs, Attitudes, Norms, Perceived Behavioral Control.}

A study evaluating the predictive ability of constructs from the theory of planned behavior for predicting exercise adherence among cardiac rehabilitation patients found that attitude, subjective norm, and perceived behavioral control explained $30 \%$ of the variance in intention to exercise (Blanchard, Rhodes, Nehl, Fisher, Sparling, \& Courneya, 2003). In a separate study of the theory of planned behavior in the exercise domain was conducted with African American and Caucasian undergraduate students, ethnicity and gender moderated the relationship between attitudes and exercise intention and ethnicspecific behavioral beliefs, normative beliefs, and control beliefs were identified (Blanchard et al., 2003).

Beliefs about exercise have consistently been shown to influence exercise behavior among older adults (Yardley et al., 2007). Beliefs about the threats and benefits of strength and balance training were examined among 60 to 95 year olds. The belief that training has multiple benefits, is associated with a positive identity, and the belief that family, friends, and doctors would approve were all related to the intention to participate in strength and balance training. A multiple case study of community-based group exercise programs also found that perceptions of physical and psychosocial benefits of participation explained older adults' adherence (Killingback, Tslofiou, \& Clark, 2017). Findings from focus groups conducted with physically active and inactive older adults regarding their beliefs about physical activity showed that inactive older adults have lower fitness expectations for older adults and perceived themselves to be active because their perceptions are based in a social context (Costello et al., 2011). Inactive older adults also reported more perceived barriers to physical activity (Costello et al., 2011). 
Due to the decline in physical abilities experienced by many older adults, perceived behavioral control is an important predictor of exercise intention (Gretebeck et al., 2007). Wu et al., (2015) found that perceived behavioral control had a stronger effect on general exercise intention than on intention to participate in group exercise specifically. Related to the theory of planned behavior construct of perceived behavioral control, self-efficacy is a concept from social cognitive theory that has been applied to improve exercise behavior (Schwartzer, Luszczynksa, Ziegelmann, Scholz, \& Lippke, 2005). Bandura explained, however, that behavior change is evolving and that and individual must master tasks requiring varying types of self-efficacy (Bandura, 1999). High self-efficacy for exercise may motivate uptake of a physical activity program but not result in long-term adherence to the program.

Studies that have examined types of self-efficacy for exercise support the need for multiple types of self-efficacy in order to achieve sustained adherence (Rodgers, Murray, Courneya, Bell, \& Harber, 2009; Rodgers \& Sullivan, 2001). Focus groups conducted with long term adheres to community based cardiac rehabilitation physical activity program highlighted the importance of task, barrier, and recovery self-efficacy for longterm adherence (Martin \& Woods, 2012). A study of stage-specific self-efficacy beliefs in cardiac rehabilitation found that task self-efficacy was associated with intention to begin cardiac rehabilitation exercise but maintenance self-efficacy or barrier self-efficacy was needed to continue exercising in the face of challenges. Recovery self-efficacy was found to be required to support the individual in continuing to perform exercise after an interruption in maintenance or a change (Scholz, Sniehotta, \& Schwarzer, 2005) The association of different types of self-efficacy with adherence to physical activity is also 
supported in the general older adult population (Rodgers et al., 2009; Stigglebout, Hopman-Rock, Crone, Lechner, \& van Mechelen, 2006).

Intention.

Stiggelbout et al. (2005) found that high intention at baseline was a significant predictor of continued participation in organized exercise programs. A cross-sectional study of EF participants found a significantly higher proportion of respondents who reported wanting to exercise and planning to exercise among current participants than among dropouts (Gillette et al, 2015). Newson and Kemps (2007) found that the older adults' intentions to engage in regular exercise were positively associated with fitness as motivation to exercise and negatively associated with lack of knowledge of physical capabilities and lack of access to exercise facilities. The researchers also found that the motivators and barriers which were associated with intention to exercise differed by age, gender, and exercise level (Newson \& Kemps, 2007). These findings highlight the importance of considering the influence of contextual factors on intention to engage in regular exercise.

Sometimes a discrepancy occurs between an intention to undertake a health behavior and the action itself. This discrepancy is often referred to as an intentionbehavior gap. Sniehotta, Scholz, and Schwarzer (2005) examined participation in exercise among cardiac rehabilitation patients and found that action planning, maintenance self-efficacy, and control all mediated the relationship between intentions and physical activity adoption and maintenance. These findings suggest that in addition to assessing intention to engage in exercise, it is important to explore how factors influence the pathway from intention to behavior. 


\section{Reinforcement.}

The reinforcing nature of exercise behavior has been examined among children and adults (Roemmich et al., 2008; Flack, Johnson \& Roemmich, 2016). Among adults, those who met the physical activity guidelines for aerobic and strength activities had greater relative reinforcing values of aerobic exercise training and resistance training than adults who did not meet the guidelines (Flack, Johnson, \& Roemmich, 2016). Behaviors with high reinforcing values elicit motivational effects that lead individuals to do more work to perform the behavior, so the reinforcement value of exercise is likely to influence exercise adherence among older adults as well. A study of older women’s feelings about exercise and adherence to an aerobic exercise group that met three times per week found that women who were exercising more frequently at the 6 and 18 month follow-ups valued the benefits of exercise more than women who were exercising less often (Caserta \& Gillett, 1998). A study of community-dwelling Korean older adults evaluated motivational and social cognitive strategies related to physical activity and found that the most common motivational strategy reported was focusing on outcomes of exercise including positive emotions or health benefits of exercise (Park, Elavsky, \& Koo, 2014).

A review of correlates of participation in physical activity by adults reported that positive feedback and enjoying improved quality of life are important motivators for continued exercise (Trost et al., 2002). Sears and Stanton (2001) found that people are more likely to drop out if exercise does not meet their expectations for fitness and weight loss, so it is important to understand what types of benefits participants expect to receive from participation in group exercise and whether or not the desired outcomes are obtained. Brassington et al. (2002) also found that physiological and psychological 
outcome expectancies and realizations were important mediators of exercise adherence among older adults. The multiple case study by Killingback et al. (2017) found that physical improvements in the areas of weight, balance, strength, cardiovascular fitness, coordination, and walking ability helped to maintain attendance to community-based group exercise programs. Participants also reported that mood improvements, enjoyment, feeling good about themselves, and empowering and energizing effects of the program were important factors for attendance (Killingback et al., 2017). These studies highlight the importance of understanding the role of program outcomes in reinforcing sustained exercise adherence.

\section{Qualitative Exploration of Factors}

Some factors that influence adherence may not be apparent to researchers or may not be fully understood from measures collected in quantitative studies. Qualitative research emphasizes investigating issues in context and exploring and understanding meaning from the experiences and opinions of participants (Creswell, 2013; Denzin \& Lincoln, 2005). The scope of exercise adherence research can be extended with qualitative research which can help to capture the rich details about context, factors, and

processes involved in exercise adherence and to understand the needs and preferences for exercise programs among older adults.

In a qualitative study of physical activity program use by Medicare members, key barriers included physical limitations, lack of professional guidance, and lack of information on the programs (Bethancourt et al., 2014). Important facilitators included motivation to maintain health and access to affordable and stimulating physical activities (Bethancourt, 2014). Analysis of semi-structured interviews with instructors who deliver 
exercise classes to older adults revealed several barriers to older adults' exercise uptake and adherence including identity, control, cost, location, and social support (HawleyHague, 2016). Instructors suggested encouraging commitment, building social cohesion, and emphasizing outcomes in order to improve uptake and adherence (Hawley-Hague, 2016). The theme of older adults' attitudes related to all of the barriers and solutions reported (Hawley-Hague, 2016). Telephone interviews with former participants of groupbased falls prevention exercise revealed that the program ending and poor health or injury were the primary reasons that older adults stopped participating, and disliking groups or the social aspect the most commonly coded barriers to participation (Robins et al., 2016).

A study of uptake and adherence to exercise among people with chronic conditions employed semi-structured interviews with 130 people and found that exercise identity, support, and perceived benefits of attending were especially influential (Pentecost \& Taket, 2011). Social and cultural norms, importance of exercise and confidence to exercise emerged as important influences on exercise identity. The qualitative analysis also revealed monitoring, information, practical support, and emotional support as four distinct types of support and details about their roles in influencing uptake and adherence (Pentecost \& Taket, 2011). A qualitative study was conducted with ethnically diverse older adult to understand their perspectives on physical activity and exercise (Belza et al., 2004). In order to improve participation in programs, ethnic-specific focus groups suggested culture-specific exercise, partnering with social service programs, educating families about the importance of physical activity, and involving older adults in program development (Belza et al., 2004). 
Limited qualitative research has been conducted to understand the views of older adults participating in EnhanceFitness. In one known qualitative study, focus groups were conducted with Chinese, Japanese, and African American older adults to understand the factors that drew them to the program and their experiences adhering to the program (Chiang et al., 2008). Themes identified included the physical environment, program design, social factors, and individual factors (Chiang et al., 2008).

Participants reported satisfaction with the location of classes and facilities where the classes were held, and many commented about carpooling or riding the bus. Participants perceived the class content as meeting the health needs of seniors and reported liking that the program provided a complete body workout and was easy to follow. Social factors influencing adherence included enjoyment of socializing, forming a network of peers, shared language and religion, and support from family, healthcare providers, and instructors. Individual factors reported by participants included personality traits such as competitiveness, perseverance, positive attitude, and confidence. Participants emphasized the desire to maintain their independence and improve their chronic diseases, strength, flexibility, balance, and well-being. Participants also mentioned participation in other physical activities done in the past or alongside EF and the cognitive benefits of EF including clear thinking, improved memory, depression prevention, and happiness (Chiang et al., 2008).

\section{Summary}

The population is aging rapidly, and $80 \%$ of older adults are living with one or more chronic conditions (U.S. Census Bureau, 2015; National Council on Aging, 2018). Evidence-based programs can reduce the impact of chronic disease, reduce the risk of 
falls, promote mental well-being, and improve quality of life (CDC, 2011; Durstine et al., 2013; Daley \& Spinks, 2012). While EBPs are known to improve health outcome and reduce healthcare costs, low participation by males and poor adherence by older adults threaten the potential impact and return on investment for EBPs (Smith et al., 2014; Wallace at al., 1998; Belza et al., 2006; Moore-Harrison et al., 2009; Ackerman et al., 2003; Sugihara et al., 2011; Schmidt et al., 2000; Picorelli et al., 2014). Understanding the barriers to male participation and the factors that influence whether older adults meet the minimum level of program participation required to improve health is key to ensuring that EBPs help older adults and produce a positive public health impact (Woodward \& Berry, 2005; Marks \& Allegrante, 2005).

It is established that older men are underrepresented in EBPs, but a question remains as to whether the underrepresentation of males is due to the EBPs not being of interest to males or if the recruiting strategies are not effective for reaching men (Towne et al., 2015). While researchers have identified a range of factors influencing exercise adherence, a systematic review of adherence to exercise programs for older adults identified a lack of research on long-term adherence in community-based exercise programs and views of participants (Farrance, Tsofliou, and Clark, 2016). Picorelli et al. (2014) identified influences on older women's adherence to exercise and recommended qualitative studies that ask older people directly about the factors that influence them.

Therefore, the first aim of the present study was to address the gap in the literature by exploring barriers to male participation and strategies to improve male participation. The second aim of the study was to examine attendance patterns and factors associated adherence among older adults participating in EnhanceFitness classes offered for five 
years by the Healthy Aging Regional Collaborative of South Florida. The final aim of the study was to deepen understanding of the factors and processes influencing adherence by exploring the perspectives of EnhanceFitness participants and instructors. Knowledge of the barriers to male participation, identification of factors influencing long-term adherence, and incorporation of the views of participants and instructors informs the development of innovative strategies to support sustained adherence to evidence-based programs and in turn, improve health and well-being among older adults.

\section{References}

Ackermann, R. T., Cheadle, A., Sandhu, N., Madsen, L., Wagner, E. H., \& LoGerfo, J. P. (2003). Community exercise program use and changes in healthcare costs for older adults. American Journal of Preventive Medicine, 25(3), 232-237.

Ackermann, R.T., Williams, B., Nguyen, H.Q. Berke, E.M., Maciejewski, M.L. \& LoGerfo, J.P. (2008). Healthcare cost differences with participation in a community-based group physical activity benefit for Medicare Managed Care health plan members. Journal of the American Geriatrics Society, 56(8), 14591465. doi: 10.1111/j.1532-5415.2008.01804.x

Ahmad, M.H., Shahar, S., Mohd, N.I., Teng, F., Manaf, Z.A., Sakian, N.I.M., \& Omar, B. (2014). Applying theory of planned behavior to predict exercise maintenance in sarcopenic elderly. Clinical Interventions in Aging, 9, 1551-1561.

American College of Sports Medicine (1998). ACSM position stand. Exercise and physical activity for older adults. Medicine \& Science in Sports \& Exercise, 30, 992-1008.

Ajzen, I (1991). The theory of planned behavior. Organizational Behavior and Human Decision Processes, 50(2):179-211.

Ajzen, I., \& Manstead, A. S. R. (2007). Changing health-related behaviors: An approach based on the theory of planned behavior. In K. van den Bos, M. Hewstone, J. de Wit, H. Schut \& M. Stroebe (Eds.), The scope of social psychology: Theory and applications (pp. 43-63). New York: Psychology Press

Allen, J., \& Morelli, V. (2011). Aging and exercise. Clinical Geriatric Medicine, 27(4), 661-671. doi: 10.1016/j.cger.2011.07.010 
American College of Sports Medicine (2010). ACSM's guidelines for exercise testing and prescription. 8th ed. Baltimore: Lippincott Williams \& Wilkins.

American Diabetes Association (2013). Statistics About Diabetes. Retrieved from http://www.diabetes.org/diabetes-basics/statistics/

Anderson, E.S., Wojcik, J.R., Winett, R.A., \& Williams, D.M. (2006). Health Psychology, 25(4), 510-520.

Aslan, D., Ozcebe, H., Temel, F., Takmaz, S., Topatan, S., Sahin, A., ... Tanriverdi, B. (2008). What influences physical activity among elders? A Turkish experience From Ankara, Turkey. Archives of Gerontology and Geriatrics, 46(1), 79-88.

Baert, V., Gorus,, E., Mets, T., Geerts, C., \& Bautmans, I. (2011). Motivators and barriers for physical activity in the oldest old: A systematic review. Aging Research Reviews, 10, 464-474.

Bandura, A. (1999). A social cognitive theory of personality. In L. Pervin \& O. John (Ed.), Handbook of personality (2nd ed., pp. 154-196). New York: Guilford Publications. (Reprinted in D. Cervone \& Y. Shoda [Eds.], The coherence of personality. New York: Guilford Press.)

Batra, A., Coxe, S., Page, T.F., Melchior, M., Palmer, R.C. (2016). Evaluating the factors associated with the completion of a community-based group exercise program among older women. Journal of Aging and Physical Activity, 24(4), 649-658.

Bauman, A.E., Reis, R.S., Sallis, J.F., Wells, J.C., Loos, R.J., \& Martin, B.W. (2012). Correlates of physical activity: why are some people physically active and others not? The Lancet, 380(9838), 258-271. doi: 10.1016/S0140-6736(12)60735-1

Belza, B., Walwick, J., Schwartz, S., LoGerfo, J., Shiu-Thornton, S., Taylor, M. (2004). Older adult perspectives on physical activity and exercise: Voices from multiple cultures. Preventing Chronic Disease, 1(4), A09.

Belza, B., Synyder, S., Thompson, M., \& LoGerfo, J. (2010). From research to practice: EnhanceFitness, an innovated community-based senior exercise program. Topics in Geriatric Rehabilitation, 26(4), 299-309.

Belza, B., Shumway-Cook A., Phelan, E. A., Williams, B., Snyder, S. J., \& LoGerfo, J. P. (2006). The effect of a community-based exercise program on function and health in older adults: The EnhanceFitness program. Journal of Applied Gerontology, 25, 291-306. doi:10.1177/gbh0733464806290934 
Bethancourt, H.J., Rosenburg, D.E., Beatty T., \&Arterburn, D.E. (2014). Barriers to and facilitators of physical activity program use among older adults. Clinical Medicine \& Research, 12(1-2), 10-20.

Biddle, S.J., \& Nigg, C.R. (2000). Theories of exercise behavior. International Journal of Sport Psychology, 31, 290-304.

Biedenweg, K., Meischke, H., Bohl, A., Hammerback, K., Williams, B., Poe, P., \& Phelan, E.A. (2014). Understanding older adults' motivators and barriers to participating in organized programs supporting exercise behaviors. Journal of Primary Prevention, 35, 1-11. doi: 10.1007/s10935-013-0331-2

Blanchard, C.M. (2008). Understanding exercise behaviour during homebased cardiac rehabilitation: a theory of planned behaviour perspective. Canadian Journal of Physiology \& Pharmacology, 86, 8-15.

Blanchard, C.M., Rhodes, R.E., Nehl, E., Fisher, J., Sparling, Pl, \& Courneya, K.S. (2003). Ethnicity and the theory of planned behavior in the exercise domain. American Journal of Public Health, 27(6):579-591.

Bouchard, D., Langlois, M., Domingue, M., Brown, C., LeBrun, V., \& Baillargeon, J. (2012). Age differences in expectations and readiness regarding lifestyle modifications in individuals at high risk of diabetes. Archives of Physical Medicine and Rehabilitation, 93(6), 1059-64. doi: 10.1016/j.apmr.2011.12.028

Brady, T.J., Anderson, L., \& Kobau, R. (2014). Chronic disease self-management Support: public health perspectives. Frontiers in Public Health, 2, 234. doi:10.3389/fpubh.2014.00234

Brittle, N., Patel, Smitaa, Wright, C., Baral, S., Versfelf, P., \& Sackley, C. (2009). An exploratory cluster randomized controlled trial of group exercise on mobility and depression in care home residents. Clinical Rehabilitation, 23(2), 146-154. doi: 10.1177/0269215508098891

Brassington, G., A. Atienza, et al. (2002). Intervention-related cognitive versus social mediators of exercise adherence in the elderly. American Journal of Preventive Medicine, 23(2S): 80-86.

Brenes, G.A., Strube, M.J., \& Storandt, M. (2006). An Application of the Theory of Planned Behavior to exercise among older adults. Journal of Applied Social Psychology, 28(24). doi: 10.1111/j.1559-1816.1998.tb01371.x

Bronfenbrenner, U. (1979). The ecology of human development. Cambridge, Mass.: Harvard University Press. 
Bunn, F., Dickinson, A., Barnett-Page, E., Mcinnes, E., \& Horton, K. (2008). A systematic review of older people's perceptions of facilitators and barriers to participation in falls-prevention interventions. Aging \& Society, 28, 449-472. doi: 10.1017/S0144686X07006861

Caserta, M.S., \& Gillett, P.A. (1998). Older women's feelings about exercise and their adherence to an aerobic regimen over time. The Gerontologist, 38(5), 602-609.

Centers for Disease Control and Prevention (2014). Adults need more physical activity. Retrieved from https://www.cdc.gov/physicalactivity/inactivity-amongadults-50plus/index.html

Centers for Disease Control and Prevention (2011). Older Persons' Health. Retrieved from https://www.cdc.gov/nchs/ fastats/older-american-health.htm

Centers for Disease Control and Prevention (2012). Chronic Diseases and Health Promotion. Retrieved from http://www.cdc.gov/chronicdisease/overview/ index.htm.

Centers for Disease Control and Prevention (2013a). Health and Economic Costs of Chronic Diseases. Retrieved from https://www.cdc.gov/chronicdisease/ about/costs/index.htm

Centers for Disease Control and Prevention. (2013b). The state of aging and health in America 2013. Atlanta, GA. Retrieved from http://www.cdc.gov/features/ agingandhealth/state_of_aging_and_health_in_america_2013.pdf

Chiang, K., Seman, L., Belza, B., \& Hsin-Chun Tsai, J. (2008). “It is our exercise family Of ethnic older adults in a group-based exercise program. Preventing Chronic Disease, 5(1). http://www.cdc.gov/pcd/issues/2008/jan/06_0170.htm.

Centers for Medicare \& Medicaid Services (2002). Chronic Conditions Among Medicare Beneficiaries. Chartbook, 2012 Edition. Baltimore, MD.

Cohen-Mansfield, J., Marx, M.S, \& Guralnik, J.M. (2003). Motivators and barriers to exercise in an older community-dwelling population. Journal of Aging and Physical Activity, 11, 242-253.

Costello E, Kafchinski M, Vrazel J, \& Sullivan P. (2011). Motivators, barriers, and beliefs regarding physical activity in an older adult population. Journal of Geriatric Physical Therapy, 34(3): 138-147.

Courtenay, W.H. (2000). Behavior factors associated with disease, injury, and death among men. Evidence and implications for prevention. The Journal of Men's Studies, 9, 81-142 
Cox, K.L., Burke, V., Gorely,, T.J., Beilin, L.J., \& Puddey, I.B. (2003). Controlled comparison of retention and adherence in home- vs center-initiated exercise interventions in women ages 40-65 years: The S.W.E.A.T. Study (Sedentary Women Exercise Adherence Trial). Preventive Medicine, 36(1), 17-29.

Cress, M., Buchner, D., Prohaska, T. (2005). Best practices for physical activity Programs and behavior counseling in older adult populations. Journal of Aging and Physical Activity, 13(1), 61-74.

Creswell, J.W. (2013). Qualitative inquiry and research design: Choosing among five approaches (3rd ed.). Thousand Oaks, CA: Sage.

Daley, M.J., \& Spinks, W.L. (2000). Exercise, mobility, and aging. Sports Medicine, 29(1), 1-12.

Denzin, N. K., \& Lincoln, Y. S. (2005). Introduction: The discipline and practice of qualitative research. In N. K. Denzin \& Y. S. Lincoln (Eds.), The Sage handbook of qualitative research (3rd ed., pp. 1-28). Thousand Oaks, CA: Sage.

Dionyssiotis, Y. (2012) Analyzing the problem of falls among older people. International Journal of General Medicine, 5, 805-813. doi: 10.2147/IJGM.S32651

Dishman, R.K. (1982). Compliance/adherence in health-related exercise. Health Psychology, 1(3), 237-267.

Dishman, R.K. (1986). Exercise compliance: A new view for public health. The Physician and Sports Medicine, 14(5), 127-145. doi: 10.1080/00913847.1986.11709075.

Downs, D.S., \& Hausenblas, H. A. (2005). Elicitation studies and the theory of planned behavior: A systematic review of exercise beliefs. Psychology of Sport \& Exercise, 6, 1-31.

Durstine, J.L., Gordon, B. Wang, Z., \& Luo, X. (2013). Chronic disease and the link to physical activity. Journal of Sport and Health Science, 2(1), 3-11. https://doi.org/10.1016/j.jshs.2012.07.009

Ecclestone, N.A., \& Jones, C.J., (2004). International Curriculum Guidelines for Preparing Physical Activity Instructors of Older Adults, in Collaboration with the Aging and Life Course, World Health Organization. Journal of Aging and Physical Activity, 12(4), 467-479. https://doi.org/10.1123/japa.12.4.467

Estabrooks, P.A., Munroe, K.J., Fox, E.H., Gyurcskik, N.C. (2004). Journal of Aging and Physical Activity, 12(3), 232-245. https://doi.org/10.1123/japa.12.3.232 
Farrance, C., Tsofliou, F., \& Clark, C. (2016). Adherence to community based group exercise interventions for older people: A mixed-methods systematic review. Preventive Medicine, 87, 155-166.

Florida Department of Health (2016). Adults who are inactive or Insufficiently active. Retrieved from http://www.flhealthcharts.com/charts/ Brfss/StateDataViewer.aspx?bid=108

Florida Department of Health. (2014). Florida's Population. Retrieved from http://www.floridacharts.com/charts/AtlasIntro.aspx?ID=3

Florida Department of Health (2016). Florida Behavior Risk Factor Surveillance System (BRFSS) 2015 Data Book. Retrieved from http://www.floridahealth.gov/ statistics-and-data/survey-data/behavioral-risk-factor-surveillance- system/ reports/_documents/2015-brfss.pdf

Finnegan, S., Bruce, J., Lamb, S.E., \& Griffiths, F. (2015). Predictors of attendance to group exercise: a cohort study of older adults in long-term care facilities. BMC Geriatrics, 15, 27. doi: 10.1186/s12877-015-0043-y

Flack, K.D., Johnson, L., \& Roemmich, J.N. (2016). Aerobic and resistance exercise reinforcement and discomfort tolerance predict meeting activity guidelines. Physiology \& Behavior, 170(1), 32-36. doi: 10.1016/j.physbeh.2016.11.032

Ford, E.S., Bergman, M.M., Boeing, H., Li, C., \& Capewell, S. (2012). Healthy lifestyle behaviors and all-cause mortality among adults in the United States. Preventive Medicine, 55, 23-27. doi: 10.1016/j.ypmed.2012.04.016

Frank, J. C., Coviak, C. P., Healy, T. C., Belza, B., \& Casado, B. L. (2008). Addressing Fidelity in Evidence-Based Health Promotion Programs for Older Adults. Journal of Applied Gerontology 27(1), 4-33.

Friedenreich, C. M., Neilson, H. K., \& Lynch, B. M. (2010). State of the epidemiological evidence on physical activity and cancer prevention. European Journal of Cancer, 46(14), 2593-2604.

Garber, C.E., \& Blissmer, B.J. (2002). The challenges of exercise in older adults. In P.M. Burbank \& D. Riebe (Eds.), Promoting exercise and behavior change in older adults: Interventions with the transtheoretical model (pp. 29-56). New York: Springer

Gillette, D.B., Petruscu-Prahova, M., Herting, J.R., \& Belza, B. (2015). Journal of Geriatric Physical Therapy, 38(4), 194-201. doi:10.1519/JPT.0000000000000041 
Goulding, M.R., Rogers, M.E., \& Smith, S.M. (2003). Public Health and Aging: Trends in Aging --- United States and Worldwide. Morbidity and Mortality Weekly Report, 52(6), 101-106. Retrieved from https://www.cdc.gov/mmwr/preview/ mmwrhtml/mm5206a2.htm

Green, L.W., \& Kreuter, M.W. (1991). Health Promotion Planning: An Educational and Environmental Approach. (2nd ed.) Mountain View, CA: Mayfield Publishers.

Gretebeck, K.A, Black, D.R., Blue, C.L., Glickman, L.T. Huston, S.A., \& Gretebeck, R.J. (2007). Physical activity and function in older adults: Theory of Planned Behavior. American Journal of Health Behavior, 31(2), 203-214.

Hagger, M.S., Chatzisarantis, N.L., \& Biddle, S.J. (2002). A meta-analytic review of the theories of reasoned action and planned behavior in physical activity: Predictive validity and the contribution of additional variables. Journal of Sport \& Exercise Psychology, 24(1), 3-32.

Han, H.R., Kang, J., Kim, K.B., Ry, J.P., \& Kim, M.T. (2007). Barriers to and strategies for recruiting Korean Americans for community-partnered health promotion research. Journal of Immigrant \& Minority Health, 9, 17-146. doi: 10.1007/s10903-006-9022-x

Hawley-Hague, H., Horne, M., Skelton, D.A., \& Todd, C. (2016).Older adults’ uptake and adherence to exercise classes: Instructors' perspectives. Journal of Aging and Physical Activity, 24(1):119-28.

Hawley-Hague, H. Horne, M., Campbell, M., Demack, S., Skelton, D.A., \& Todd, C. (2013). Multiple levels of influence on older adults attendance and adherence to community exercise classes. The Gerontologist. doi:10.1093/geront/gnt075

Hawley, H., Skelton, D.A., Campbell, M., \& Todd, C. (2012). Are the attitudes of exercise instructors who work with older adults influenced by training and personal characteristics? Journal of Aging and Physical Activity, 20, 47-63.

Healy, T.C., Peng, C., Haynes, McMahon, E.M., Botler, J.L., Gross, L. (2008). The feasibility and effectiveness of translating A Matter of Balance into a volunteer lay leader model. Journal of Applied Gerontology, 27(1), 34-51. doi:10.1177/0733464807308620

Herbert, L., \& Teague, M.L. (1989). Exercise adherence and older adults: A theoretical perspective. Activities, Adaptation, \& Aging, 13(1-2), 91-105. 10.1300/J016v13n01_09 
Hong, S.Y., Hughes, S., \& Prohaska, T. (2008). Factors affecting exercise attendance and completion in sedentary older adults: a meta-analytic approach. Journal of Physical Activity and Health, 5(3), 385-397.

Hung, W.W., Ross, J.S., Boockvar, K.S., \& Siu, A.L. (2011). Recent trends in chronic disease, impairment and disability among older adults in the United States. BMC Geriatrics, 11, 47.

Jancey, J., Lee, A., Howat, P., Clarke, A., Wang, K., \& Shilton, T. (2007). Reducing attrition in physical activity programs for older adults. Journal of Aging and Physical Activity, 15, 152-165.

Katzmarzyk, P. T., Leon, A. S., Wilmore, J. H., Skinner, J. S., Rao, D., Rankinen, T., \& Bouchard, C. (2003). Targeting the metabolic syndrome with exercise: Evidence from the HERITAGE family study. Medicine and Science in Sports and Exercise, 35(10), 1703-1709.

Killingback, C., Tsofliou, F., \& Clark, C. (2017). Older people’s adherence to community-based group exercise programmes: a multiple-case study. BMC Public Health, 17, 115. doi: 10.1186/s12889-017-4049-6

King, A.C., \& King, D.K. (2010). Physical Activity for an Aging Population. Public Health Reviews, 32, 401-426.

Kramarow, E., Lubitz, J., Lentzner, H., et al. (2007). Trends in the health of older Americans, 1970-2005. Health Affairs, 26(5), 1417-1425.

Layne, J.E., Arabelovic, S., Bairos Wilson, L., Cloutier, F.. Pindrus, M.A., Mallio, C.J. Roubenoff, R., Castaneda-Sceppa, C. (2009). Community-based strength training improves physical function in older women with arthritis. American Journal of Lifestyle Medicine. doi: 10.1177/1559827609342061

Lorig, K.R., Sobel, D.S., Stewart, A.L., Brown, B.W. Jr., Bandura, A., Ritter, P., ...Holman, H.R. (1999). Evidence suggesting that a chronic disease selfmanagement program can improve health status while reducing hospitalization: a randomized trial. Medical Care, 37(1), 5-14. Retrieved from http://www.ncbi.nlm.nih.gov/pubmed/10413387

Lorig, K.R., Sobel, D.S., Ritter, P.L., Laurent, D., Hobbs, M. (2001). Effective Clinical Practice 4(6), 256-262

Lorig, K., Ritter, P.L., Villa, F.J., Armas, J. (2009). Community-based peer-led diabetes self-management. The Diabetes Educator, 35(4), 641-651. 
Lucidi, F., Grano, C. Babaranelli, C., Violani, C. (2006). Social-cognitive determinants of physical activity attendance in older adults. Journal of Aging and Physical Activity, 14(3), 344-359. 10.1123/japa.14.3.344

Schwartzer, R., Luszczynksa, A., Ziegelmann, J.P., Scholz, U, \& Lippke, S. (2005). Social-cognitive predictors of physical exercise adherence: three longitudinal studies in rehabilitation. Health Psychology, 27(1s), S54-63. doi: 10.1037/0278-6133.27.1(Suppl.).S54.

Maaten, S., Kephart, G., Kirkland, S., \& Andreou, P. (2008). Chronic disease risk factors associated with health service use in the elderly. BMC Health Services Research, 8,237-245. doi:10.1186/1472-6963-8-237

Machlin, S., Cohen, J.W., \& Beuregard, K. (2008). Health Care Expenses for Adults with Chronic Conditions, 2005. Statistical Brief \#203. Retrieved from https://meps.ahrq.gov/data_files/publications/st203/stat203.pdf

Marks, R., \& Allegrante, J.P. (2005). Chronic osteoarthritis and adherence to exercise: A review of the literature. Journal of Aging and Physical Activity,13(4), 434-460. doi:10.1123/japa.13.4.434

Martin, K.A., \& Sinden, A.R. (2001). Who will stay and who will go? A review of older adults' adherence to randomized controlled trials of exercise. Journal of Aging and Physical Activity, 9, 91-114.

Martin, A.M., \& Woods, C.B. (2012). What sustains long-term adherence to structured physical activity after a cardiac event? Journal of Aging and Physical Activity,20(2), 135-147. doi:10.1123/japa.20.2.135

McAuley, E., Jerome, G.J., Elavsky, S., Marquez, D.X., \& Ramsey, S.N. (2003). Predicting long-term maintenance of physical activity in older adults. Preventive Medicine, 37, 110-118.

Meador, M.G, \& Linnan, L.A. (2006). Using the PRECEDE Model to Plan Men's Health Programs in a Managed Care Setting. Health Promotion Practice, 7(2), 186-196. doi: $10.1177 / 1524839904270502$

Melchior, M.A., Seff, L.R., Albatineh, A.N., McCoy, H.V., Page, T.F., \& Palmer, R.C. (2013). Intermediate outcomes of Chronic Disease Self-Management Program offered by members of the Healthy Aging Regional Collaborative of South Florida. Research on Aging, 36(4), 431-449. doi: 10.1177/0164027513500054

Moore-Harrison, T.L., Johnson, M.A., Quinn, M.E. Cress, M.E. (2009). An evidencebased exercise program implemented in congregate meal sites. Journal of Physical Activity and Health, 6, 247-251. 
Motalebi, S.A., Iranagh, J.A., Abdollahi, A., \& Lim, K. (2014). Applying of theory of planned behavior to promote physical activity and exercise behavior among older adults. Journal of Physical Education and Sport, 14(4), 562-568.

National Council on Aging (2017). Title III-D highest tier evidence-based health promotion/disease prevention programs. Retrieved from https://www.ncoa. org/wp-content/uploads/Title-IIID-Highest-Tier-Evidence_Feb.-2017-1.pdf

National Council on Aging (2018). 2017 Impact Report. Retrieved from https://www.ncoa.org/wp-content/uploads/2017-NCOA-Impact-Report-web.pdf

Newson, R.S., \& Kemps, E.B. (2007). Factors that promote and prevent exercise engagement in older adults. Journal of Aging and Health, 19(3), 470-481.

Nguyen, H.Q., Maciejewski, M.L., Gao, S., Lin, E., Williams, B., \& LoGerfo, J.P. (2008). Health care use and costs associated with use a health club membership benefit in older adults with diabetes. Diabetes Care, 31(8), 1562-1567.

Ory, M., et al. 2003. "Challenging Aging Stereotypes: Strategies for Creating a More Active Society.” American Journal of Preventive Medicine, 25(3Siii), 164-71.

Palmer, R.C., Batra, A., Anderson, C., Page, T., Vieira, E., \& Seff, L. (2016). Implementation of an Evidence-Based Exercise Program for Older Adults in South Florida. Journal of Aging Research, 2016, Article ID 9630241. http://dx.doi.org/10.1155/2016/9630241

Page, T.F., \& Palmer, R.C. (2013). Cost analysis of chronic disease self-management programmes being delivered in South Florida. Health Education Journal, 73(2), 228-236. doi: 10.1177/0017896912471047

Page, T.F., Batra, A., Ghouse, M.M., Palmer, R.C. (2014). Implementation Cost Analysis of a Community-Based Exercise Program for Seniors in South Florida. Health Promotion Practice, 15(4), 585-591. doi: 10.1177/1524839913518221

Park, C.H., Elavsky, S., \& Koo, K.M. (2014). Factors influencing physical activity in older adults. Journal of Exercise Rehabilitation, 10(1), 45-52. doi: $10.12965 /$ jer.140089

Pentecost, C., \& Taket, A. (2011). Understanding exercise uptake and adherence for people with chronic conditions: a new model demonstrating the importance of exercise identity, benefits of attending and support. Health Education Research, 26(5), 908-922. doi: Pentecost 
Picorelli, A.M.A., Pereira, L.S.M. Pereira, D.S., Felicio, D., \& Sherrington, C. (2014). Adherence to exercise programs for older people is influenced by program characteristics and personal factors: a systematic review. Journal of Physiotherapy, 60, 151-156.

Prohaska, T.R., Peters, K. \& Warren, J.S. (2000). Sources of attrition in a church-based exercise program for older African-Americans. American Journal of Health Promotion, 14(6), 380-385. doi: 10.4278/0890-1171-14.6.380

Rasinaho, M., Hirvensalo, M., Leinonen, R., Lintunen, T., \& Rantanen, T. (2006). Motives for and barriers to physical activity among older adults with mobility limitations. Journal of Aging and Physial Activity, 15, 90-102.

Resnick, B., \& Spellbring, A. (2000). Understanding what motivates older adults to exercise. Journal of Gerontological Nursing, 26(3), 34-42

Rich, A., Brandes, K., Mullan, B., \& Hagger, M. (2015). Theory of planned behavior and adherence in chronic illness: a meta-analysis. Journal of Behavioral Medicine, 38(4), 673-688. doi: 10.1007/s10865-015-9644-3

Rivis, A., \& Sheeran, P. (2003b). Descriptive norms as an additional predictor in the theory of planned behaviour: A meta-analysis. Current Psychology: Developmental, Learning, Personality, Social, 22, 218-233.

Robins, L.M., Hill, K.D., Day, L., Finch, C., \& Haines, T. (2016). Older adult perceptions of participation in group- and home-based falls prevention exercise. Journal of Aging and Physical Activity, 24(3), 350-362. doi: 10.1123/japa.2015-0133

Rodgers, W.M., Murray, T.C., Courneya, K.S., Bell, G.J., \& Harber, V.J. (2009). The specificity of self-efficacy over the course of a progressive exercise programme. Applied Psychology: Health and Well-Being, 1, 211-232. doi: 10.1111/j.1758-0854.2009.01012.x

Rodgers, W.M, \& Sullivan, M.J.L. (2001). Task, coping, and scheduling self-efficacy in relation to frequency of physical activity. International Journal of Psychology, 31(4). doi: 10.1111/j.1559-1816.2001.tb01411.x

Roemmich, J.N., Barkley, J.E., Lobarinas, C.L., Foster, J.H., White, T.M., \& Epstein, L.H. (2008). Association of liking and reinforcing value with children's physical activity. Physiology \& Behavior, 93,1011-1018.

Schmidt, J.A., Guman, C., King, M.B., \& Wolfon, L.I. (2000). Attrition in an exercise intervention: a comparison of early and later dropouts. Journal of the American Geriatrics Society, 48(8), 952-960. 
Scholz, U., Sniehotta, F. F., \& Schwarzer, R. (2005). Predicting exercise in cardiac rehabilitation: The role of phase-specific self-efficacy. Journal of Sport and Exercise Psychology, 27, 135-151.

Schoster, B., Callahan, L.F., Meier, A., Mielenz, T., DiMartino, L. (2005). The People with Arthritis Can Exercise (PACE) program: a qualitative evaluation of participant satisfaction. Preventing Chronic Disease, 2: A11.

Sears, S.R., \& Stanton, A.L. (2001) Expectancy-value constructs and expectancy violation as predictors of exercise adherence in previously sedentary women. Health Psychology, 20:326-333

Sound Generations (2017). Enhance. What is EnhanceFitness Retrieved from http://www.projectenhance.org/enhancefitness.aspx

Seguin R., Economos C., Palombo R., Hyatt R., Kudar J., Nelson M. (2010). Strength training and older women: A cross-sectional study examining factors related to exercise adherence. Journal of Aging and Physical Activity, 18, 201-218

Sjogren, K., \& Stjernberg, L. (2010). A gender perspective on factors that influence outdoor recreational physical activity among the elderly. BMC Geriatrics, 10, 34. doi: 10.1186/1471-2318-10-34

Smith, G.L., Bantin, L., Eime, R., O’Sullivan, G., \& van Uffelen, J.G.Z. (2017). The association between social support and physical activity in older adults: a systematic review. International Journal of Behavioral Nutrition and Physical Activity, 14, 56. doi: 10.1186/s12966-017-0509-8

Smith, M., Belza, B., Altpeter, M., Ahn, S., Dickerson, J., Ory, M. (2012). Disseminating an evidence-based disease self-management program for older Americans: implications for diversifying participant reach through delivery site adoption. In: Maddock J, editor. Rijeka. Croatia: InTech (2012). p. 385-404.

Smith, M.L., Ory, M.G., Belza, B., Altpeter, M. (2012). Personal and delivery site characteristics associated with intervention dosage in an evidence-based fall risk reduction program for older adults. Translational Behavioral Medicine, 2(2), 188-98. doi:10.1007/s13142-012-0133-8

Smith, M.L., Belza, B., Braun, K.L., King, S., Palmer, R.C., Sugihara, N.S., et al. (2014). National reach and dissemination of enhancefitness. Health Behavior and Policy Review, 2, 150-160. 
Sniehotta, F.F., Scholz, U., \& Schwarzer, R. (2005). Bridging the intention-behaviour gap: Planning, self-efficacy and action control in the adoption and maintenance of physical exercise. Psychology and Health, 20, 143-160.

Sonstroem, R. J. (1988). Psychological models. In R. Dishman (Ed.), Exercise adherence: Its impact on public health (pp. 125-153). Champaign, IL: Human Kinetics Books.

Stahl, T., Rutten, A., Nutbeam, D., Bauman, A., Kannas, L., Abel, T., et al. (2001). The importance of the social environment for physically active lifestyle-Results from an international study. Science and Social Medicine, 52, 1-10.

Stiggelbout, M., Hopman-Rock, M., Crone, M., Lechner, L. \& van Mechelen, W. (2006). Predicting older adults' maintenance in exercise participation using an integrated social psychological model. Health Education Research, 21(1), 1-14. doi: 10.1093/her/cyh037

Stineman, M.G., Strumpf, N., Kurichi, J.E., Charles, J., Grisso, J.A., \& Jayadevappa, R. (2011). Attempts to reach the oldest and frailest: recruitment, adherence, and retention of urban elderly persons to a falls reduction exercise program. The Gerontologist, 51(1), S59-S72. doi: 10.1093/geront/gnr012

Strachan, S.M., Brawley, L.R., Spink, K.S., \& Glazebrook, K. (2010). Older adults’ physically-active identity: Relationships between social-cognitions, physical activity and satisfaction with life. Psychology of Sport and Exercise, 11, 114121. doi:10.1016/j.psychsport.2009.09.002

Sugihara, N., Watanabe, M., Tomioka, M., Braun, K.L., \& Pang, L. (2011). Cost-benefit estimates of an elderly exercise program on Kaua'i. Hawaii Medical Journal, 70(6), 116-120.

Tennstedt, S., Howland, J., Lachman, M., Peterson, E., Kasten, L., \& Jette, A. (1998). A randomized, controlled trial of a group intervention to reduce fear of falling and associated activity restriction in older adults. Journals of Gerontology, Series B, Psychological Sciences and Social Sciences, 53, 384-392

Tomioka M., Sugihara N., Braun K. L. (2012). Replicating the EnhanceFitness physical activity program in Hawai'i’s multicultural population, 2007- 2010. Preventing Chronic Disease, 9, 110155. doi: 10.5888/ pcd9.110155

Towne, S.D., Smith, M.L., Ahn, S., Alpeter, M., Belza, B., Patton, K., \& Ory, M.G. (2015). National dissemination of multiple evidence-based disease prevention programs: reach to vulnerable older adults. Frontiers in Public Health, 2, 156. doi: 10.3389/fpubh.2014.00156 
Trost, S.G., Owen, N., Bauman, A.E., Sallis, J.F., \& Brown, W. (2002). Correlates of adults' participation in physical activity: review and update. Medicine \& Science in Sports \& Exercise, 34(12), 1996-2001. doi: 10.1249/01.MSS.0000038974.76900.92

U.S. Census Bureau (2015). Annual Estimates of the Resident Population for Selected Age Groups by Sex for the United States, States, Counties, and Puerto Rico Commonwealth and Municipios: April 1, 2010 to July 1, 2014. Retrieved from https://factfinder.census.gov/faces/table services/jsf/pages/productview.xhtml? src $=$ bkmk

U.S. Census Bureau (2014). State \& County Quick Facts. Available at http://quickfacts.census.gov/qfd/states/12/12011.html

U.S. Department of Health and Human Services (2008). 2008 Physical Activity Guidelines for Americans. Retrieved from https://health.gov/paguidelines/pdf/ paguide.pdf

U.S. Department of Health and Human Services: Administration for Community Living (2015). A Profile of Older Americans: 2015. Retrieved from https://aoa.acl.gov/aging_statistics/Profile/ 2015/docs/2015-Profile.pdf

Van Stralen, M.M., De Vries, H., Mudde, A.N., Bolman, C., Lechner, L. (2009). Determinants of initiation and maintenance of physical activity among older adults: a literature review. Health Psychology Review, 3(2), 147-207.

Wallace, J.I., Buchner, D.M., Grothaus, L. Leveille, S., Tyll, L., LaCroix, A.Z., \& Wagner, E.H. (1998). Implementation and effectiveness of a community-based health promotion program for older adults. Journal of Gerontology: Medical Sciences, 53a(4), M301-M306.

Warburton, D.E., Nicol, C.W., \& Bredin, S.S. (2006). Health benefits of physical activity: the evidence. Canadian Medical Association Journal, 174(6), 801-809.

Warren-Findlow, J., Prohaska, T., \& Freedman, D. (2003). Challenges and opportunities in recruiting and retaining underrepresented populations into health promotion research. Gerontologist, 43, 37-46.

Westerterp, K. R. (2013). Physical activity and physical activity induced energy expenditure in humans: Measurement, determinants, and effects. Frontiers in Physiology, 4, 90.

Woodward, C.M., \& Berry, M.J. (2005). Enhancing adherence to prescribed exercise: structured behavioral interventions in clinical exercise programs. Journal of Cardiopulmonary Rehabilitation, 21(4), 201-209. 
Wright, T.J., \& Hyner, G.C. (2009). Principal barriers to health promotion program participation by older adults. American Journal of Health Studies, 24(1), 215-222. Retrieved from http://search.proquest.com/docview/304508660/114E2030EC7/1

Wright, T.J., \& Hyner, G.C. (2011). Older adult participation in health promotion programs: Perspectives of facility administrators. Educational Gerontology, 37, 1030-1039.doi: 10.1080/03601277.2010.492734

Wu, Z., Li, J., \& Theng, Y.L.(2015). Examining the influencing factors of exercise intention among older adults: a controlled study between exergame and traditional exercise. Cyberpsychology, Behavior, and Networking, 18(9), 521-527. doi: 10.1089/cyber.2015.0065.

Yardley, L., Donovan-Hall, M., Francis, C., \& Todd, C. (2007b). Attitudes and beliefs that predict older people's intention to undertake strength and balance training. Journal of Gerontology: Psychological Sciences, 2, 199-225. 


\section{Chapter III}

\section{Manuscript Title: Recruiting and Engaging Older Men in Evidence-Based Health \\ Promotion Programs: Perspectives on Barriers and Strategies}

\section{Introduction}

The number of adults aged 65 and older in the United States is projected to increase to 71 million by 2030 (Centers for Disease Control and Prevention [CDC], 2011a). Eighty percent of older adults have at least one chronic disease and 50\% have at least two chronic diseases (CDC, 2011a). Treatment of chronic conditions for older adults accounts for $66 \%$ of the healthcare budget in the United States (CDC, 2013). Impairment and disability are also common and costly among older adults (Hung, Ross, Boockvar, \& Siu, 2011). The chronic disease burden, disability, and healthcare costs among the aging population have made the health status of older adults a top priority for the Centers for Disease Control and Prevention (CDC) and the Administration on Aging (AoA).

To ensure that limited resources for improving the health of older adults are used effectively and efficiently, policymakers, funders, and members of the aging networks are increasingly calling for the use of evidence-based programs (EBPs). Research supports the effectiveness of EBPs in improving health behaviors and health outcomes among older adults of different ethnicities in different communities (Batra, Melchior, Seff, Newman, \& Palmer, 2012; Belza, Shumway-Cook, Phelan, Williams, Snyder, \& LoGerfo, 2006; Brady et al., 2013; Lorig et al., 1999; Melchior, Seff, Albatineh, McCoy, Page, \& Palmer, 2013; Tomioka, Sugihara, \& Braun, 2012). Researchers have also demonstrated that EBPs reduce healthcare utilization and healthcare costs (Brady et al., 2013; Ackermann, Williams, Nguyen, Berke, Maciejewski, \& LoGerfo, 2008). 
Federal law now requires health promotion and disease prevention programs to be evidence-based in order to be eligible for Older Americans Act Title IIID funding (Administration for Community Living, 2014). In 2014, 43 programs that underwent the Older Americans Act Title IIID submission process met the highest-level criteria for evidence-based programs and include programs such as the Stanford Self-Management programs, EnhanceFitness, and A Matter of Balance (National Council on Aging, 2014). Evidence-based programs are supported as effective, however, members of the intended population must participate in the programs in order to benefit from them.

A variety of factors may influence an older individual's willingness to participate in health promotion programs. Cultural beliefs, attitudes about health promotion, gender roles, age-related issues, and mistrust of research have been reported as reasons why older Korean Americans do not participate in health promotion programs (Han, Kang, Kim, Ry, \& Kim, 2007). Fatalism, underestimation of risk, poor self-efficacy, and stigma associated with programs for older people were identified as barriers to participation in fall prevention programs (Bunn, Dickinson, Barnett-Page, McInnes, \& Horton, 2008). Research with participants, nonparticipants, and administrators of a health promotion program designed to reduce cardiovascular disease in older adults suggests that time constraints, transportation, lack of information about the programs, and lack of comfort are barriers to participation (Wright \& Hyner, 2009; Wright \& Hyner, 2011). Focus groups conducted at a senior wellness center revealed that social support, interpersonal engagement, and programs tailored to individual needs, interests, and limitations facilitate participation in community-based health promotion programs (Miller \& Iris, 2002). A study of older adults who declined to join or joined an exercise program 
revealed that those who joined were socially inclined and desired accountability while those who declined to join reported already getting enough exercise, lack of motivation, and lack of affiliation with people in the program (Biedenwig, Meischke, Bohl, Hammerback, Williams, Poe, \& Phelan, 2014).

A significant issue related to older adult participation in EBPss is that men are often underrepresented (Batra et al., 2012; Melchior et al., 2013; Ory et al., 2015; Smith, Ory, Ahn, Kulinski, Jiang, Horel, \& Lorig, 2015; Lee, Ory, Zollinger, Smith, \& Jiang, 2014). Given that males also suffer higher rates of most illnesses than females and have higher healthcare costs than females from age 60 to approximately age 90, efforts are needed to ensure that older men participate in EBPs (Yamamoto, 2013). While it is clear from the literature that men and women differ in the frequency of many health behaviors that may contribute to gender disparities in healthcare costs, the reasons why men are less likely than women to engage in health behaviors such as participating in EBPs are poorly understood (Courtenay, 2000).

Research suggests that a one-size-fits-all approach to male health promotion will not be successful because men are a heterogeneous group with varying health information needs and preferences (Robinson \& Robertson, 2014; Coles, Watkins, Swami, Jones, Woolf, \& Stanistreet, 2010). There is a lack of research addressing the participation of older men in health promotion programs. The present study aimed to address this gap by examining program coordinator and instructor perspectives on low male participation in EBPs offered by the Healthy Aging Regional Collaborative of South Florida (HARC). Males represented $44 \%$ of the population age 60 and older in counties where HARC offered programs, but males represented only 19\% of HARC participants (U.S. Census 
Bureau, 2010) As program implementers, HARC coordinators and instructors are responsible for recruiting and engaging participants and thus were selected to participate in this study to identify barriers to recruiting and engaging older male participants and to identify strategies to increase male participation.

\section{Methods}

\section{Setting}

The Health Foundation of South Florida established the Healthy Aging Regional Collaborative (HARC) in 2008 to disseminate evidence-based health promotion programs in Broward, Miami-Dade, and Monroe counties. Programs were selected to address physical inactivity, fall prevention, and chronic conditions among older adults. The HARC programs included EnhanceFitness (EF), Chronic Disease Self-Management (CDSMP), Tomando Control de su Salud (TCS), Diabetes Self-Management (DSMP), Manejo Personal de su Diabetes (MDP), Matter of Balance (MOB), and Asunto de Equilibrio (ADE). HARC member agencies implemented one or more of the evidencebased programs listed to meet the needs of the older adults they served. This study was approved by the Institutional Review Board at Florida International University.

\section{Participants}

Program coordinators and instructors of HARC programs were included in this study to learn why older men were not participating in HARC programs. Program coordinators and instructors were chosen as study participants because they have extensive experience working with program participants and are knowledgeable about the feasibility of potential strategies to increase participation. Each HARC agency selected a program coordinator or multiple program coordinators to manage the implementation of 
one or more evidence-based programs. Twenty program coordinators representing the 14 HARC member agencies in 2013 were invited by email to participate in a focus group. The 14 program coordinators who participated in the focus group (70\% participation rate) represented 11 of the 14 member agencies.

The agencies represented in the focus group included area agencies on aging, nonprofits, healthcare organizations, recreation organizations, and social service agencies. All of the coordinators had managed the HARC programs for multiple years at the time of the study. Program coordinators were responsible for recruiting program participants, so they have knowledge about individuals who participated and individuals who were informed about the programs but decided not to participate.

Program instructors were selected by the HARC agencies and participated in trainings according to program requirements. Instructors had professional experience in a range of fields and facilitated the programs on a part-time or volunteer basis. Instructors interacted closely with the participants in each program, so they have a sense of the barriers to participation based on observations and feedback from participants. The 269 instructors who taught one or more HARC workshops between 2008 and 2013 were invited by email to participate in an online survey. Instructors who were also program coordinators were excluded from the survey. Instructors were sent two reminder emails to improve the response rate. Forty-nine instructors responded to the survey (18\% response rate). Thirty-nine of respondents (80\%) were female and 10 were male (20\%).

Respondents and nonrespondents did not differ in gender. 


\section{Data Collection}

This mixed methods study used a focus group to elicit information from HARC program coordinators about the most important barriers and strategies for male participation in HARC programs and to develop a survey about male participation that was subsequently administered to HARC instructors to triangulate findings. The focus group was moderated by a member of the HARC local evaluation team and lasted approximately two hours.

To identify barriers to male participation, the moderator first asked coordinators to provide reasons why it is difficult to recruit older men to participate in HARC programs based on their experiences recruiting participants and implementing the EBPs. The moderator then asked the coordinators to identify strategies that might be effective in increasing male interest and participation in HARC programs. The moderator followed up the initial questions with probes to collect additional information. The moderator documented the ideas reported on an interactive whiteboard grid so that all participants could see the responses as they were given and clarify or expand upon the responses if desired. A note taker from the HARC local evaluation team typed comments from the discussion in an electronic document during the session.

After completing the analysis of the focus group comments, a questionnaire was developed in order to examine instructor perspectives on male participation and to triangulate findings. Major themes from the focus group discussion, interesting but infrequent coordinator comments from the focus group, and participation barriers described in the literature were developed into survey items to examine whether HARC instructors agreed that the factors mentioned by coordinators and existing research were 
barriers to participation for HARC program participants and whether the suggested strategies were likely to be successful with HARC program participants based on the instructors' experiences interacting with participants. HARC instructors received an email inviting them to participate in an online survey. The email included an explanation of the purpose of the study, instructions for accessing the survey questionnaire, a statement explaining that participation was voluntary, and a description of the confidentiality of responses. If participants did not complete the survey within two weeks of receiving the first email, they received two reminder emails spaced one week apart.

The questionnaire was administered using Qualtrics online software and included items that assessed barriers to participation and strategies to increase participation. Items regarding barriers required respondents to rate their level of agreement with possible explanations for non-participation by older males and statements about their perceptions of male program participants. Items regarding strategies required respondents to indicate the likelihood that each of several potential strategies would be successful in increasing male participation in HARC programs. Open-ended questions asked respondents to describe any barriers to male participation in HARC programs and to list any strategies to increase male participation in HARC programs.

\section{Data Analysis}

The focus group data were analyzed by two members of the HARC local evaluation team who collaboratively organized statements from the SMART Board grids and the discussion document into common topics and summarized the data. Descriptive statistics were calculated for the fixed-choice survey questions. Ratings of strongly 
disagree and disagree and ratings of agree and strongly agree were collapsed. Similarly, ratings of very unlikely and unlikely and ratings of likely and very likely were collapsed.

Thematic analysis was used to examine the responses to the open-ended survey questions. Thematic analysis involves familiarizing oneself with the dataset, generating codes, combining the codes into themes, and reviewing and refining the themes (Braune \& Clark, 2006). The responses to the open-ended survey questions were downloaded from Qualtrics. A member of the evaluation team assigned open codes to words, phrases, or sentences. A second member of the evaluation team validated the codes and then worked collaboratively with the first coder to group the codes into themes.

\section{Focus Group}

\section{Results}

When asked to provide reasons why it is difficult to recruit men in HARC programs, coordinators expressed that older men may not be comfortable in activities where most participants are women and that attention to health in general is not consistent with male gender roles. Coordinators also reported that health promotion programs are not a part of the senior male culture, there are fewer men at senior sites where coordinators recruit participants, social programs are not appealing to men, and there are too many women instructors. Coordinators also believed that men view EnhanceFitness (EF) as an aerobics class and would prefer other physical activities.

When asked to provide a list of strategies to increase male interest and participation in HARC programs, coordinators suggested getting male community leaders to support the programs, producing advertisements showing men, encouraging women to bring men to the workshops, and providing meaningful incentives. Coordinators also 
suggested encouraging instructors to do less dancing in EF and hiring more male instructors.

\section{Survey}

\section{Agreement with barriers to male participation and men's beliefs.}

When asked in the online survey whether older men viewing exercise programs as aerobics classes for females was a barrier to participation, nearly $78 \%$ of instructors agreed (Table 3.1). Similarly, nearly 74\% of instructors agreed that machismo or cultural beliefs prevent older men from participating and that older males think personal problems should not be discussed. More than $80 \%$ of instructors disagreed with statements that older males are uncomfortable with female instructors and that older males think they will not be respected if they participate in health promotion programs.

Table 3.1 Agreement with Statements Explaining Why Older Males Do Not Participate in HARC Programs $(n=49)$

\begin{tabular}{lcc}
\multicolumn{1}{c}{ Statement } & Agree & Disagree \\
\hline Older males view exercise programs as aerobics classes for females. & $77.6 \%$ & $22.4 \%$ \\
\hline $\begin{array}{l}\text { Machismo or cultural beliefs prevent older men from participating in } \\
\text { health promotion programs. }\end{array}$ & $73.5 \%$ & $26.5 \%$ \\
\hline $\begin{array}{l}\text { Older males think personal problems should not be discussed. } \\
\text { There are too many women in health promotion classes. }\end{array}$ & $73.5 \%$ & $26.5 \%$ \\
\hline $\begin{array}{l}\text { Older males feel that there is a negative stigma associated with } \\
\text { participating in health promotion programs for older adults. }\end{array}$ & $42.9 \%$ & $51.0 \%$ \\
\hline $\begin{array}{l}\text { Older males believe that they will be perceived as old if they } \\
\text { participate in a health promotion program. }\end{array}$ & $30.6 \%$ \\
\hline $\begin{array}{l}\text { Older males think that they will not be respected if they participate } \\
\text { in a health promotion program. }\end{array}$ & $22.5 \%$ \\
\hline \begin{tabular}{l} 
Older males are not comfortable with female instructors. \\
\hline
\end{tabular} & $18.4 \%$ & $87.5 \%$ \\
\hline
\end{tabular}

When asked in the online survey to rate their level of agreement with statements regarding men’s beliefs and participation, almost $96 \%$ of respondents agreed that men are more likely to participate if they see other men in the group and 87\% agreed that men are 
more likely to participate if they come with their spouse or partner (Table 3.2). Over 74\% of respondents disagreed that men prefer male instructors.

Table 3.2 Agreement with Statements Regarding Men's Beliefs and Participation ( $n=47)$

\begin{tabular}{llc}
\hline \multicolumn{1}{c}{ Statement } & Agree & Disagree \\
\hline Men are more likely to participate if they see other men in the group. & $95.7 \%$ & $4.3 \%$ \\
\hline Men are more likely to participate with their spouse/partner. & $87.2 \%$ & $12.8 \%$ \\
\hline Men view group exercise as a female activity. & $76.6 \%$ & $23.4 \%$ \\
\hline Men are reluctant to attend organized health promotion activities. & $66.0 \%$ & $34.0 \%$ \\
\hline $\begin{array}{l}\text { Men believe they have little control over what happens to them in the aging } \\
\text { process. }\end{array}$ & $57.4 \%$ & $42.6 \%$ \\
\hline Male participants are not actively engaged in workshops. & $57.4 \%$ & $42.6 \%$ \\
\hline Men think that seeking health advice makes them seem weak or dependent. & $55.3 \%$ & $44.7 \%$ \\
\hline Men will stop coming to classes if they are the only male in the class. & $55.3 \%$ & $44.7 \%$ \\
\hline Men feel awkward or embarrassed in an exercise or health education class. & $51.1 \%$ & $48.9 \%$ \\
\hline $\begin{array}{l}\text { Male participants think the material covered in the workshops is "silly" or } \\
\text { too "touchy-feely". }\end{array}$ & $44.7 \%$ & $55.3 \%$ \\
\hline Male participants are likely to lose interest during a workshop session. & $44.7 \%$ & $55.3 \%$ \\
\hline Men prefer male instructors to female instructors. & $25.5 \%$ & $74.5 \%$ \\
\hline
\end{tabular}

\section{Descriptions of barriers to male participation.}

Four themes emerged from open-ended items that asked instructors to describe barriers to male participation. Instructors expressed that more women attend health promotion classes, so men feel outnumbered by women if they do attend. Male gender roles became another apparent theme. One respondent said, "Traditionally, females attend to the family's health issues," and another said, "Older males like to feel independent, self-sufficient, and knowledgeable. I think they believe attending one of the classes will indicate the opposite." Respondents also expressed that men are often not comfortable seeking help or engaging in conversations about health issues.

Another common theme was that men prefer to do other activities rather than attending workshops. Instructors explained that men prefer physical activities and competition. One respondent said, "Sitting in a classroom is not something that older 
males look forward to," and another said, "Older men are more about doing and fixing than talking." Regarding the EnhanceFitness (EF) program in particular, a common theme was that males would prefer other types of fitness activities. Respondents explained that men feel EF is not vigorous enough and emphasizes dancing too much.

A final theme that emerged was negative perceptions of health promotion programs. One respondent said, "The biggest barrier seems to be the attitude of older men towards the healthcare profession. They are less inclined to visit doctors and are not as proactive about their health as women." One instructor shared that a man described the health promotion classes as "long-winded with a lot of common sense stuff."

\section{Likelihood that strategies will succeed in increasing male participation.}

When presented with a list of strategies and asked to rate the likelihood that each strategy would increase male participation, all of the strategies were rated as likely to succeed by the majority of instructors. Over $90 \%$ of instructors rated advertisements showing men engaging in health promotion and including pictures of single older males in promotional materials as likely to succeed (Table 3.3).

Table 3.3 Likelihood of Strategies Successfully Increasing Male Participation in HARC Programs (n=46)

\begin{tabular}{lcc}
\multicolumn{1}{c}{ Strategy } & Likely & Unlikely \\
\hline $\begin{array}{l}\text { Produce advertisements that show men engaging in health promotion } \\
\text { programs. }\end{array}$ & $95.7 \%$ & $4.3 \%$ \\
\hline $\begin{array}{l}\text { Have pictures of single older males in program brochures, flyers, and posters } \\
\text { (not just couples). }\end{array}$ & $91.3 \%$ & $8.7 \%$ \\
\hline $\begin{array}{l}\text { Get male community leaders to publicly support the program (example: } \\
\text { church leaders, politicians, community leaders as advocates). }\end{array}$ & $89.1 \%$ & $10.9 \%$ \\
\hline Air public service announcements aimed at men. & $89.1 \%$ & $10.9 \%$ \\
\hline Get well known public figures to endorse male participation. & $87.0 \%$ & $13.0 \%$ \\
\hline Encourage women who register for classes to bring men. & $82.6 \%$ & $17.4 \%$ \\
\hline $\begin{array}{l}\text { Provide meaningful incentives (example: gift card to a store where men } \\
\text { typically shop). }\end{array}$ & $78.3 \%$ & $21.7 \%$ \\
\hline Go to barbershops. & $63.0 \%$ & $37.0 \%$ \\
\hline Hire more male instructors. & $60.9 \%$ & $39.1 \%$ \\
\hline
\end{tabular}




\section{Strategies suggested to increase male participation.}

Three main themes emerged from the open-ended question regarding strategies to improve male participation in health promotion programs. The most common theme among strategies suggested by respondents involved advertising and support for the HARC programs. Instructors suggested using local sports franchises and retired athletes to endorse the programs. They also suggested having male instructors and doctors promote the programs. Social media, television, and newspapers were suggested as important mediums for advertising older men participating in health promotion programs. Targeting advertisements where men congregate and actually offering programs where men congregate were also suggested to increase male participation.

The second theme discovered among suggested strategies was normalizing male participation in health promotion programs. The strategies to normalize male participation are closely linked with strategies to improve advertising and support for the programs. Including men in class advertisements and having recognized men in the community endorse male participation were suggested as strategies to "make attendance more acceptable or normal for older men." Instructors also mentioned that offering menonly programs may help.

Another common theme that emerged deals with the content and perceptions of the EF program. Instructors suggested that the male participation in EF would be improved by using exercises that resemble circuit training, incorporating sports moves that both men and women could enjoy, and reducing the amount of dancing. 


\section{Discussion}

People who engage in healthy lifestyle behaviors have a reduced risk for chronic disease morbidity and mortality (Ford, Bergman, Boeing, Li, \& Capewell, 2012). Evidence-based health promotion programs have the potential to help participants adopt health behaviors to improve their wellbeing, but participation by males is suboptimal. Maximizing male participation in health promotion is an important goal for public health, because men are more likely than women to engage in most health risk behaviors, die at higher rates than women from the leading causes of death, and have shorter life spans than women (Courtenay, 2000; CDC 2011b).

The current study enrolled HARC program coordinators and instructors who provided their perspectives on the barriers to recruiting older males in EBPs and suggested strategies to increase male participation. Coordinators and instructors are responsible for recruiting and engaging participants in EBPs, so their combined perspectives are valuable in understanding and improving male participation. Findings from the focus group and survey revealed that male gender roles, men's views of health promotion programs, preferences for other activities, and low numbers of males in the classes are barriers to engaging males in health promotion programs. Findings from the survey supported most of the ideas reported in the focus group. Survey respondents did not, however, support the idea that women instructors are a barrier to male participation.

Findings from this study are in line with previous research which has reported that gender is associated with health beliefs and behavior (Bei, Goins, Laditka, Ignatenko, \& Goedereis, 2009; Courtenay, McCrary, \& Merighi, 2002). From the perspective of the constructionist theory of gender, men and women think and act as they do because of 
socially constructed concepts about masculinity and femininity in their culture (Courtenay, 2001; West \& Zimmerman, 1987). The male gender role includes being independent, strong, and self-reliant, and does not tend to include seeking care (Courtenay, 2000). Applying this theory, men may avoid attending health promotion programs if participation in the program does not align with their concepts of masculinity.

Coordinators and instructors reported that men hold negative views of health promotion programs and the health care profession. This finding may reflect men's view of help seeking in general. Researchers have reported that men with traditional beliefs about male gender roles have more negative attitudes about seeking help and are less willing to seek help (Addis \& Mahalik, 2003). Machismo, defined as strong masculine pride, has also been reported to affect help-seeking among Latino men and South Florida has a large Latino population (Peak, Gast, \& Ahlstrom, 2010). Latino men who participated in a study of gender beliefs and prostate cancer screening indicated that machismo impedes preventive healthcare and screening (Rivera-Ramos \& Buki, 2011). The present study builds upon previous research by indicating that machismo acts as a barrier to male participation in EBPs as well.

A qualitative study of older British men's health needs indicates that although masculine culture has a strong influence on the way men think about health, men still wanted more health services and information, were open to discussing their health care needs, and were dissatisfied with masculine stereotypes in advertising and health information for men (Coles et al., 2010). These findings emphasize the importance of acknowledging the influence of masculinity reported in the current study while remaining 
sensitive to the multitude of other factors, such as culture, socioeconomic status, ethnicity, and sexual orientation, that may influence men's needs and preferences related to health promotion programs.

Coordinators and instructors indicated that older men prefer alternatives to the current discussion-based activities provided in HARC programs. Previous research on masculinity and health beliefs supports that men do not discuss health issues unless they are serious and solvable and that men are averse to disclosing vulnerability (Verdonk, Seesing, \& de Rijk, 2010). Gast and Peak (2011) reported that men are willing to discuss health concerns but that male-friendly health education programs are needed because men may not feel comfortable with the way services are currently delivered. Men’s Sheds represent a novel approach to enhancing the health of men in Australia by providing a male-friendly space and should be investigated for use with older men in the United States (Ballinger, Talbot, \& Verrinder, 2009). The Men’s Shed is a large shed that allows men to come together to socialize and partake in meaningful activities such as woodwork or metalwork which help to provide a sense of connection and purpose that support health (Ballinger et al., 2009). The Australian Men’s Sheds do not ensure the provision of specific health information or skills needed by older adult men, but lessons learned from work with Men's Sheds about the activities and environments used to reach men could be applied to health promotion programs and recruiting strategies.

Coordinators and instructors expressed that females outnumbering males was a barrier to participation. Carroll et al. found that homogenous group composition was important for creating a safe dynamic and supported the engagement of men in community-based health and physical activity promotion programs (Carroll, Kirwan, \& 
Lambe, 2014). Saunders et al. also found that men were more likely to participate in male-only church-based programs and appreciated the opportunity to develop relationships with male peers and to discuss topics affecting them (Saunder et al., 2015). It is possible that male participation could be improved by offering workshops exclusively for men, but respondents in the current study also indicated that attending with spouses or partners could improve male participation. Staff delivering chronic disease and management programs in rural areas in Canada were interviewed in a qualitative study and also reported that spouses were important for encouraging male participation (Gavarkovs, Burke, Reilly, \& Petrella, 2015).

Other strategies relate to the participation barriers posed by gender roles.

Instructors suggested that public support of the programs by male community leaders and advertisements that highlight male participation would help to normalize and increase male participation in the programs. Friedman et al. confirmed that using mass media, partnering with businesses and churches, enlisting community leaders and role models as spokespeople, and culturally appropriate messages were seen by middle-aged and older African American men important strategies for promoting physical activity programs (Friedman, Hooker, Wilcox, Burroughs, \& Rheaume, 2012).

The strategies described in the current study also emphasize addressing content and perceptions of EnhanceFitness to make it more appealing to men. Respondents did not explicitly suggest adapting the other evidence-based programs offered by the HARC, but the barriers they described point to program adaptation as an important strategy for meeting the needs of men. 


\section{Limitations}

The main limitation of this study was that the older male participants and nonparticipants were not included in the study. Instructors and coordinator perspectives were examined to understand the barriers to recruiting and engaging older adult men in the region served by the HARC. Future research should examine male gender roles, perceptions of health promotion programs, and preferences among older males who participate and older males who decline the opportunity to participate in EBPs.

Another limitation of the study was the low response rate for instructors. Many HARC instructors taught on a volunteer basis and likely did not respond due to the transient nature of their positions as HARC instructors. Also, the majority of the study participants were female which introduces the potential for gender bias. However, analysis did not reveal gender differences in the percentage of instructors reporting agreement with the barriers or the percentage of instructors rating the likelihood of success of strategies. Finally, this study asked instructors and coordinators about EBPs in general but it will be important to investigate whether there are similarities across programs or if the factors influencing male participation differ by program.

\section{Conclusion}

This study provided novel information about barriers to older male participation in EBPs and strategies to improve participation by older males. The barriers to male participation identified by program coordinators and instructors suggest that men feel outnumbered in health promotion programs, perceive participation as incompatible with the male gender role, and prefer other activities. Overall, the findings highlight a number of ways in which the EBPs are not suited to the needs of older men. Findings indicate that 
program planners could increase male participation in EBPs by tailoring recruiting strategies to men's gender-based perceptions regarding participation in health promotion, adapting health promotion programs to the beliefs and preferences of men, and improving advertising efforts. To advance men’s health promotion, research should examine programs and recruiting strategies to ensure that they are meeting older men’s needs.

\section{References}

Ackermann, R.T., Williams, B., Nguyen, H.Q. Berke, E.M., Maciejewski, M.L. \& LoGerfo, J.P. (2008). Healthcare cost differences with participation in a community-based group physical activity benefit for Medicare Managed Care health plan members. Journal of the American Geriatrics Society, 56(8), 14591465. doi: 10.1111/j.1532-5415.2008.01804.x

Addis, M.E., \& Mahalik, J.R. (2003). Men, masculinity, and the contexts of help seeking. American Journal of Psychology, 58, 5-14. doi: 10.1037/ 0003-066X.58.1.5

Administration for Community Living. (2014). Administration on Aging: Disease prevention and health promotion services (OAA Title IIID). Retrieved from http://www.aoa.acl.gov/ AoA_Programs/HPW/Title_IIID/index.aspx

Ballinger, M.L, Talbot, L.A., \& Verrinder, G.K. (2009). More than a place to woodwork: a case study of a community-based Men's Shed. Journal of Men's Health, 6(1), 20-27. doi: 10.1016/j.jomh.2008.09.006

Batra, A., Melchior, M., Seff, L., Newman, F., \& Palmer, R.C. (2012). Evaluation of a community-based falls prevention program in South Florida, 2008 - 2009. Preventing Chronic Disease, 9, E1. doi: 10.5888/pcd9.110057

Bei, W., Goins, R.T., Laditka, J.N., Ignatenko, V., \& Goedereis, E. (2009). Gender differences in views about cognitive health and healthy lifestyle behaviors among rural older adults. The Gerontologist, 49(51), 572-578. doi: 10.1093/geront/gnp077

Belza, B., Shumway-Cook A., Phelan, E. A., Williams, B., Snyder, S. J., \& LoGerfo, J. P. (2006). The effect of a community-based exercise program on function and health in older adults: The EnhanceFitness program. Journal of Applied Gerontology, 25, 291-306. doi:10.1177/gbh0733464806290934 
Biedenweg, K., Meischke, H., Bohl, A., Hammerback, K., Williams, B., Poe, P., \& Phelan, E.A. (2014). Understanding older adults' motivators and barriers to participating in organized programs supporting exercise behaviors. Journal of Primary Prevention, 35, 1-11. doi: 10.1007/s10935-013-0331-2

Brady, T.J., Murphy, L., O’Colmain, B.J., Beauchesne, D., Daniels, B., Greenberg, M., ...Chervin, D. (2013). A meta-analysis of health status, health behaviors, and health care utilization outcomes of the Chronic Disease Self-Management Program. Preventing Chronic Disease, 10, E07. doi:10.5888/pcd10.120112

Braun, V., \& Clarke, V. (2006). Using thematic analysis in psychology. Qualitative Research in Psychology, 3(2), 77-101. doi: 10.1191/ 1478088706qp063oa

Bunn, F., Dickinson, A., Barnett-Page, E., Mcinnes, E., \& Horton, K. (2008). A systematic Review of older people's perceptions of facilitators and barriers to participation in falls-prevention interventions. Aging \& Society, 28, 449-472. doi: 10.1017/S0144686X07006861

Carroll, P., Kirwan, L., \& Lambe, B. (2014). Engaging 'hard to reach’ men in community-based health promotions. International Journal of Health Promotion and Education, 52(3), 120-130. doi: 10.1080/14635240. 2013.876185

Centers for Disease Control and Prevention. (2011a). Healthy aging: Helping people to live long and productive lives and enjoy a good quality of life. Retrieved from https://www.aarp.org/content/dam/aarp/livablecommunities/learn/health/ Healthy-Aging-Helping-People-to-Live-Long-and-Productive-Lives-and-Enjoy-aGood-Quality-of-Life-2011-AARP.pdf

Centers for Disease Control and Prevention. (2011b). Deaths: Final data for 2011. Retrieved from http://www.cdc.gov/nchs/data/nvsr/nvsr63/nvsr63_03.pdf.

Centers for Disease Control and Prevention. (2013). The State of Aging and Health in America 2013. Atlanta, GA: CDC, US Department of Health and Human Services.

Coles, R., Watkins, F., Swami, V., Jones, S., Woolf, S., Stanistreet, D. (2010). What men really want: A qualitative investigation of men's health needs from the Halton and St. Helens Primary Care Trust men's health promotion project. British Journal of Health Psychology, 15, 921-939. doi: 10.1348/135910710X494583

Courtenay, W.H. (2000). Behavior factors associated with disease, injury, and death among men. Evidence and implications for prevention. The Journal of Men's Studies, 9, 81-142.doi: 10.3149/jms.0901.81 
Courtenay, W.H. (2001). Constructions of masculinity and their influence on men's wellbeing: a theory of gender and health. Social Science \& Medicine, 50, 1385-1401. doi:10.1016/S0277-9536(99)00390-1

Courtenay, W.H., McCrary, D.R., \& Merighi, J.R. (2002). Gender and ethnic differences in health beliefs and behaviors. Journal of Health Psychology, 7(3), 219-213. doi: $10.1177 / 1359105302007003216$

Ford, E.S., Bergman, M.M., Boeing, H., Li, C., \& Capewell, S. (2012). Healthy lifestyle behaviors and all-cause mortality among adults in the United States. Preventive Medicine, 55, 23-27. doi: 10.1016/j.ypmed.2012.04.016

Friedman, D.B., Hooker, S.P., Wilcox, S., Burroughs, E.L., \& Rheaume, C.E. (2012). African American men's perspectives on promoting physical activity: "We're not that difficult to figure out!” Journal of Community Health, 17(10), 1151-1170. doi: 10.1080/10810730.2012.665424

Gast, J. \& Peak, T. (2011). “It used to be that if it weren’t broken and bleeding profusely, I would never go to the doctor": Men, masculinity, and health. American Journal of Men's Health, 5(4), 318-331. doi: 10.1177/ 1557988310377926

Gavarkovs, A.G., Burke, S.M., Reilly, K.C., \& Petrella, R.J. (2015). Barriers to recruiting men into chronic disease prevention and management programs in rural areas: Perspectives of program delivery staff. American Journal of Men's Health. Advance online publication. doi:10.1177/155798831 5596226

Han, H.R., Kang, J., Kim, K.B., Ry, J.P., \& Kim, M.T. (2007). Barriers to and strategies for recruiting Korean Americans for community-partnered health promotion research. Journal of Immigrant \& Minority Health, 9, 17-146. doi: 10.1007/s10903-006-9022-x

Hung, W.W., Ross, J.S., Boockvar, K.S., \& Siu, A. (2011). Recent trends in chronic disease, impairment, and disability among older adults in the United States. BMC Geriatrics, 11, 47. doi: 10.1186/1471-2318-11-47

Lorig, K.R., Sobel, D.S., Stewart, A.L., Brown, B.W. Jr., Bandura, A., Ritter, P., ...Holman, H.R. (1999). Evidence suggesting that a chronic disease selfmanagement program can improve health status while reducing hospitalization: a randomized trial. Medical Care, 37(1), 5-14. Retrieved from http://www.ncbi.nlm.nih.gov/pubmed/10413387

Melchior, M.A., Seff, L.R., Albatineh, A.N., McCoy, H.V., Page, T.F., \& Palmer, R.C. (2013). Intermediate outcomes of Chronic Disease Self-Management Program offered by members of the Healthy Aging Regional Collaborative of South Florida. Research on Aging, 36(4), 431-449. doi: 10.1177/0164027513500054 
Miller, A.M., \& Iris, M. (2002). Health promotion attitudes and strategies in older adults. Health Education \& Behavior, 29(2), 249-267. doi: $10.1177 / 109019810202900209$

National Council on Aging (2014). Title III-D highest tier evidence-based health promotion/disease prevention programs. Retrieved from http://www.ncoa. org/ improve- health/center-for-healthy-aging/content-library/Title-IIIDHighest-Tier-Evidence-FINAL.pdf

Ory, M.G., Smith, M.L., Parker, E.M., Jiang, L., Chen, S., Wilson, A.D., Stevens, J.A., Ehrenrich, H., \& Lee, R. (2015). Fall prevention in community settings: results from implementing Tai Chi: Moving for Better Balance in three states. Frontiers in Public Health, 2, 216-221. doi: 10.3389/ fpubh.2014.00258

Lee, S., Ory, M. G., Zollinger, A., Smith, M., \& Jiang, L. (2014). Translation of Fit \& Strong! for middle-aged and older adults: Examining implementation and effectiveness of a lay-led model in central Texas. Public Health Education and Promotion, 2, 187. doi: 10.3389/ fpubh.2014.00111

Peak, T., Gast, J., \& Ahlstrom, D. (2010). A needs assessment of Latino men’s health concerns. American Journal of Men's Health, 4, 22-32. doi:10.1177/1557988308327051

Rivera-Ramos, Z.A., \& Buki, L.P. (2011). I will no longer be a man! Manliness and prostate cancer screenings among Latino men. Psychology of Men and Masculinity, 12(1), 13-25. doi: 10.1037/a0020624

Robinson, M. \& Robertson, S. (2014). Health information needs of men. Health Education Journal, 73(2), 150-158. doi: 10.1177/0017896912471039

Saunders, D.R., Holt, C.L., Le, D., Slade, J.L., Muwwakkil, B, Savoy, A., Williams, R., Whitehead, T.L., Wang, M.Q., Naslund, M.J. (2015). Recruitment and participation of African American men in church-based health promotion workshops. Journal of Community Health, 40(6), 1300-1310. doi: 10.1007/s10900-015-0054-9

Smith, M.L., Ory, M.G., Ahn, S., Kulinski, K.P., Jiang, L. ,Horel, S., \& Lorig, K. (2015). National dissemination of chronic disease self-management education programs: an incremental examination of delivery characteristics. Frontiers in Public Health, 2, 81-87. doi:10.3389/fpubh.2014.00227

Tomioka M., Sugihara N., Braun K. L. (2012). Replicating the EnhanceFitness physical activity program in Hawai'i’s multicultural population, 2007- 2010. Preventing Chronic Disease, 9, 110155. doi: 10.5888/ pcd9.110155 
U.S. Census Bureau. (2010). Profile of general population and housing characteristics: 2010. Retrieved from http://factfinder2.census.gov.

Verdonk, P., Seesing, H., \& de Rijk, A., 2010. Doing masculinity, not doing health? A qualitative study among Dutch male employees about health beliefs and workplace physical activity. BMC Public Health, 10, 712.

doi: 10.1186/1471-2458-10-712

West, C., \& Zimmerman, D.H. (1987). Doing gender. Gender \& Society, 1(2), 125-151. doi: 10.1177/0891243287001002002

Wright, T.J., \& Hyner, G.C. (2009). Principal barriers to health promotion program participation by older adults. American Journal of Health Studies, 24(1), 215-222. Retrieved from http://search.proquest.com/docview/304508660/114E2030EC7 A4628PQ/1

Wright, T.J., \& Hyner, G.C. (2011). Older adult participation in health promotion programs: Perspectives of facility administrators. Educational Gerontology, 37, 1030-1039.doi: 10.1080/03601277.2010.492734

Yamamoto, D. H. (2013). Health care costs - from birth to death. In Health Care Cost Institute's Independent Report Series, Report 2013-1. Retrieved from http://www.healthcostinstitute.org/files/Age-Curve-Study_0.pdf 


\section{CHAPTER IV}

\section{Manuscript Title: Adhering to EnhanceFitness: Do Demographic Factors and}

\section{Health Matter for Short-Term and Long-Term Adherence?}

\section{Introduction}

Florida has the greatest proportion of older adults in the United States with individuals age 65 and older representing 18.7\% of the state population (U.S. Census Bureau, 2015). Chronic conditions such as diabetes, heart disease, arthritis, and lung disease are prevalent among older adults and reduce quality of life. Chronic disease care among older adults is expensive and accounts for $66 \%$ of the entire healthcare budget in the United States (CDC, 2013). Strategies to improve the health of older adults are required to reduce the disease burden and associated costs. Evidence indicates that physical activity can prevent at least some of the chronic conditions and loss of function that have been associated with aging (Chandler \& Hadley, 1996; Orr et al., 2006).

For the first time ever, national guidelines for physical activity were published in 2008 (USDHHS). To obtain important health benefits, the U.S. Department of Health and Human Services recommends that adults ages 65 and older obtain at least 150 minutes of moderate-intensity physical activity, 75 minutes of vigorous-intensity physical activity, or an equivalent combination of moderate and vigorous physical activity each week (USDHHS, 2008). Nearly $86 \%$ of older adults in Florida did not meet the national guidelines for physical activity (Florida Department of Health 2011). Further, 33\% of Floridians over age 65 reported that they did not participate in any leisure time physical activity (Florida Department of Health, 2011). 
Prompted by the health needs of the large older adult population in Florida, the Health Foundation of South Florida (HSFS) established the Healthy Aging Regional Collaborative (HARC) to make evidence-based health promotion programs accessible to older adults in community settings throughout Broward, Miami-Dade, and Monroe counties. HFSF funded evidence-based programs to address four main threats to healthy aging including lack of physical activity, depression, falls, and inability to manage chronic health conditions. EnhanceFitness (EF) was chosen by HARC to address lack of physical activity among older adults.

EF (formerly named the Lifetime Fitness Program) was developed by Senior Services in Seattle to improve the functional fitness and well-being of older adults. The program is a structured 1-hour group exercise class taught three times a week by a certified EnhanceFitness instructor. The class consists of a warm up, aerobics, a cool down, strength training with ankle and wrist weights, and stretching. EF was designed to challenge active older adults while being safe for older adults who are unfit or frail.

EF was found to be effective at improving measurements of functional fitness in a randomized controlled trial (Wallace et al., 1998). Participants have also demonstrated improvements in emotional and social health (Belza et al., 2006). Positive program outcomes have been replicated with diverse populations in various settings (MooreHarrison et al., 2009; Tomioka, Sugihara, \& Braun, 2010; Palmer et al., 2016). The Administration on Aging placed EnhanceFitness in highest tier of evidence-based programs in 2006 for Physical Activity, and the program has been added to the list of approved programs for Chronic Disease Self-Management Support and Falls Prevention (Snyder, Thompson, \& Denison, 2014; National Council on Aging, 2017). Evidence- 
based programs are programs that have been researched in controlled settings and that have demonstrated consistent improvements in health-related measures (NCOA, 2017) Participants of evidence-based programs translated to community settings must receive at least the minimum dose upon which the evidence for the effectiveness of the program is based to have the best chance of experiencing the desired program outcomes (Cross \& West, 2011; Frank, Coviak, Healy, Belza, \& Casado, 2008; Ackerman et al., 2003). In one study of EF offered three times a week at congregate meal sites, participants who attended fewer than 32 sessions within the first 4 months did not show a significant difference in performance measures from baseline to 4-month follow up, whereas participants who attended 32 or more sessions showed significant improvements in measurements of functional fitness (Belza. et. al, 2010). Women who attended at least 32 sessions during the first 4 months of EF classes offered by the HARC showed improvements that were nearly twice as great as women who attended fewer than 32 sessions (Batra, Coxe, Page, Melchior \& Palmer, 2016). In another study on the effect of EnhanceFitness participation on healthcare costs, Ackermann and colleagues (2003) found that attending an average of once per week for the first year of participation was necessary in order to observe a significant reduction in healthcare utilization and costs.

A wide range of factors are known to influence adherence to exercise programs including demographics, health, exercise history, social support, culture, instructors, program factors, but limited research exists on the factors that influence adherence to EnhanceFitness (Jancey et al, 2007; Picorelli et al., 2014; Bethancourt, 2014). Chiang, Seman, Belza and Tsai (2008) interviewed ethnic older adults attending EF and found that environmental factors, program design, social support, and individual factors 
influenced adherence. Gillette, Petrescu-Prahova, Herting and Belza (2015) conducted a cross-sectional survey and identified motivators and barriers for ongoing participation in EF among current participants and former participants. They found that white ethnicity, program, and health barriers were associated with a higher likelihood of dropping out and that participants who stay in the program have more sources of motivation and fewer barriers (Gillette et al, 2015). Batra et al. (2016) examined predictors of adherence among older women who attended EF during the first four years of the HARC and found that residence in Miami-Dade County, age $\geq 80$, and not reporting depression or risk for chronic conditions were associated with a higher likelihood of attending at least 32 sessions within the first 4 months. Palmer et al. (2016) examined the implementation of EF in South Florida and found that the most significant process issues were frequency of attendance and attrition. Only 26\% of HARC EF participants who started from 2009 through 2012 attended at least 32 sessions within the 16 weeks after joining, and $41 \%$ of participants stopped attending altogether within the first 16 weeks (Palmer et al., 2016).

Given that the health benefits and healthcare savings associated with EnhanceFitness are dependent upon participants receiving the minimum effective dose and sustaining adherence, research is needed to understand the factors that influence short-term and long-term adherence to the program. This study expands the body of literature by examining predictors of short-term and long-term adherence to the EnhanceFitness exercise program among diverse HARC participants. Person-level factors that have been found to be associated with physical activity initiation and adherence in previous research include age, gender, race/ethnicity, and health status, so these were the predictors examined in relationship to EF adherence in the current study (Bouchard et al., 
2012; King \& King, 2010; Sjogren \& Stjernber, 2010; Anderson et al., 2006; Van Stralen et al., 2009).

\section{Methods}

\section{Setting}

An evidence-based group exercise program called EnhanceFitness was offered on an ongoing basis to older adults in South Florida by the Health Aging Regional Collaborative of South Florida beginning in 2008. The program is still being offered by multiple agencies in south Florida, but this study examines participants of classes offered from October 2008 through December 2013. During this five-year period, 14 agencies offered 177 classes in Broward, Miami-Dade, and Monroe counties. Classes were delivered by certified EF instructors at 114 sites including community centers, senior residences, clinics, parks, meal sites, senior centers, and churches.

\section{Participants}

The HARC aimed to reach adults age 60 and over, so in the current study, an older adult is defined as an individual who is 60 years of age of older. Agencies offering EF recruited participants from their existing client bases and targeted recruiting efforts in places with high numbers of older adult residents. EF participants self-selected into the program. Participants for this study include racially/ethnically diverse individuals ages 60 and older who attended at least one EF class offered by the HARC from 2008 to 2013. A total of 5,619 individuals in the database met these criteria.

\section{Data Collection}

The investigation builds upon an evaluation project established for HARC. HARC received funding for a period of five years from the Health Foundation of South Florida 
to implement and evaluate evidence-based programs, including EF, in Broward, MiamiDade, and Monroe counties. Site information was submitted to the team evaluating the HARC on a workshop registration form. On the first day of attendance, participants completed a consent form, participant information form, and health history form. Instructors from the HARC EF member agencies were responsible for distributing the forms and collecting data. Instructors were also responsible for completing monthly class attendance rosters that contained participant names and the dates of attendance for each participant. Only data from the participant information form, one question from the fitness check form, and attendance dates were used in this study. The variables are described in the following section.

During the first two years of the HARC, agencies were responsible for entering data for their participants into an online database and sent their forms the HARC local evaluation team (LET) on a monthly basis for random data verification. The LET checked the data in the online database against the original forms for $30 \%$ of the workshops offered by each agency. If an error rate greater than $10 \%$ was found for a workshop, the forms were returned to the agency for re-entry. Beginning in the third year of the HARC, the LET took over data entry and cleaned the data from the first two project years. The agencies sent the forms and attendance rosters to the HARC local evaluation team on a monthly basis for entry into the online database.

\section{Measures}

Demographic Variables: Demographic characteristics of participants were selfreported on the participant information form that included questions of gender, age, race, and ethnicity. Age was recoded into four age groups including 60-69, 70-79, 80-89, and 
90+. Race and ethnicity were combined and recoded into five categories including Hispanic/Latino, Haitian/Other non-Hispanic Caribbean, black, white, and other.

Health Status: On the fitness check form, participants were asked to report their health status using the BRFSS general health measure. The response scale ranged from 1=poor to $5=$ =xcellent (CDC, 2008). Retest reliability for self-reported health has been reported at 0.75 or higher in general (Andresen et al., 2003). The reliability is slightly lower for older adults who have more variable health ranging from 0.58 to 0.76 .

Adherence: Data regarding the dependent variable of adherence was determined from attendance rosters on which instructors recorded participant attendance for each date the class was offered. In this study, short-term adherence is defined based on attendance to a minimum of 32 EnhanceFitness classes during the first 16 weeks of program participation. Participants who attended fewer than 32 sessions within the first 16 weeks of participation were categorized as non-adherent while participants who attended 32 or more sessions within the first 16 weeks of participations were categorized as adherent. This categorization of short-term adherent and non-adherent participants is based on previous findings that participants who attended fewer than 2 of 3 classes a week did not show a significant difference in performance measures from baseline to 4month follow up (Belza et al., 2010). Participants were categorized as long-term adherent if they attended an average of at least one class per week during the first year of attendance and were categorized as non-adherent if their average attendance per week during the first year was less than one. This categorization of long-term adherent and non-adherent participants is based on previous findings that EF participants who attended fewer than 52 classes during the first year did not experience the same reductions in 
healthcare costs and hospitalizations as participants who attended at least 52 classes during the first year (Ackerman et al., 2008).

\section{Data Analysis}

Data from October 1, 2008 through December 31, 2013 was extracted from the HARC's PeerPlace online database. Data were checked for accuracy and then imported into Statistical Package for the Social Sciences (SPSS) version 24 (IBM Corp., 2016) for cleaning and analysis. Participants younger than 60 years of age were removed from the dataset. Data was cleaned of outliers and evaluated for normality. Descriptive statistics were calculated for participant characteristics and to compare participant characteristics between adherent and non-adherent participants. Attendance data were analyzed to calculate the percent of participants meeting criteria for short-term and long-term adherence.

Logistic regression was performed to examine the association of demographic factors and health status with adherence. A model for short-term adherence and a model for long-term adherence were developed using enter method logistic regression. Age, race/ethnicity, gender, and health status were all found to be significant predictors of short-term adherence in the bivariate analysis and were included in the model. Only age and race/ethnicity were found to be significant predictors of long-term adherence in the bivariate analysis but gender and health status were still included in the long-term adherence model because they were reported as significant predictors in other studies (Van Stralen et al., 2009; Tak, van Uffelen, Paw, van Mechelen, \& Hopman-Rock, 2012). Model fit was assessed using the Hosmer-Lemeshow goodness of fit test (Hosmer \& Lemshow, 2004). 


\section{Results}

\section{Sample Characteristics.}

A total of 5,619 individuals ages 60 and older attended at least one EnhanceFitness class offered by the HARC between October 1, 2008 and December 31, 2013. Over $40 \%$ of all participants were ages $70-79$ and nearly $46 \%$ were non-Hispanic whites (Table 4.1). Almost 85\% of participants were female and 44.3\% reported good health while another $28.2 \%$ reported very good health and $11.2 \%$ reported excellent health (Table 4.1). Among HARC EF participants, only 1,403 (25\%) were adherent to the program in terms of attending at least 32 sessions within the first 16 weeks and only 1,972 (35\%) were adherent long-term based on the definition of attending an average of once per week in the year following enrollment. Demographics and health status of adherent participants were compared to non-adherent participants using Pearson's chisquare tests for both short-term adherence and long-term adherence (Tables 4.1 and 4.2).

\section{Predictors of Short-Term Adherence.}

In the logistic regression analysis, age, race/ethnicity, gender, and health status were significantly associated with short-term adherence (Table 4.3). Participants ages 8089 were more likely to be categorized as adherent than participants ages 60-69 (OR=1.27, 95\% CI: 1.05 -1.53, $p=.01)$. Likelihood of short-term adherence increased further with age with participants ages $90+$ being over one and half times more likely to meet the criteria for short-term adherence than participant ages 60-69 (OR=1.67, 95\% CI: 1.262.21, $p=.001$ ). Black participants were less likely than white participants to be adherent $(\mathrm{OR}=0.82$, 95\% CI: .67 $-1.00, p=.05)$ while Hispanic participants were more likely than white participants to be adherent (OR=1.25, 95\% CI: 1.06-1.47, $p=.008)$. Participants 
identifying an "other" race/ethnicity were 1.8 times more likely than whites to be adherent in the short term (OR=1.8, 95\% CI: 1.27-2.54, $p=.001)$.

Men were nearly one and a half times more likely to meet the criteria for shortterm adherence than women (OR=1.47, 95\% CI: 1.2301.76, $p=.001)$. Participants reporting good health were more than twice as likely than participants reporting poor health to meet criteria for short-term adherence (OR=2.23, 95\% CI:1.19-4.19, $p=.01)$ and participants reporting very good health were 2.6 times as likely to be categorized as adherent (OR=2.60, 95\% CI: 1.38-4.92, $p=.003$ ). Compared to participants with poor health status, likelihood of short-term adherence was higher for participants reporting excellent health (OR=1.83, 95\% CI: .95-3.53, $p=.07)$. The Hosmer and Lemeshow test was not significant $(\chi 2=5.99, d f=8, p=0.65)$ indicating that the model had a good fit, but the Nagelkerke pseudo $\mathrm{R}^{2}$ which estimates the proportion of variance explained by the model was only 0.028 .

\section{Predictors of Long-Term Adherence.}

In the logistic regression analysis, age, race/ethnicity, gender, and health status were significant predictors of long-term adherence (Table 4.4). Participants ages 70-79 were more likely to meet the attendance criteria for long-term adherence than participants ages 60-69 (OR=1.26, 95\% CI 1.08-1.47, $p=.003)$. The likelihood of long-term adherence was even higher with increased age. Participants ages 80-89 were nearly one and a half times more likely than 60-69 year olds to be adherent (OR=1.45, 95\% CI:1.221.73, $p=.001$ ) and participants ages $90+$ were nearly twice as likely to be adherent (OR=1.98, 95\% CI: $1.52-2.57, p=.001$ ). Compared to white participants, Hispanic participants were slightly more likely to be adherent long-term (OR=1.30, 95\% CI: 1.11- 
1.52, $p=.001$ ) and Haitians were twice as likely to be adherent (OR=2.03, 95\% CI: 1.532.70, $p=.001)$. Black participants were also more likely than white participants to be adherent long-term (OR=1.77, 95\% CI: 1.49-2.10, p-.000) along with participants reporting “other" race/ethnicity (OR=1.53, 95\% CI: 1.09-2.15, $p=.01)$.

Men were slightly more likely than women to adhere long-term (OR=1.19, 95\% CI: 1.19, 1.01-1.41, $p=.04)$. Compared to participants reporting poor health, participants reporting good health were 1.59 times as likely to be adherent long term (OR=1.59, 95\% CI: .97 - 2.59, $p=.07$ ) and participants reporting very good health were 1.76 times as likely to be adherent long-term (OR=1.76, 95\% CI: 1.06-2.89, $p=.03)$. Participants reporting excellent health were 1.78 times more likely to be adherent long term than participants reporting poor health (OR=1.78, 95\% CI: 1.06-2.99, $p=.03)$. The HosmerLemeshow goodness of fit test did not indicate poor model fit at the 0.05 level of significance $(\chi 2=13.73, d f=8, p=0.089)$. Based on the Nagelkerke R Square, the model only explained around $2.6 \%$ of the variance in long-term adherence.

\section{Discussion}

EnhanceFitness has been widely implemented and program benefits are well documented, but low adherence rates have been reported (Belza et al., 2006; Batra et al, 2016; Palmer et al., 2016). Evidence indicates that adherence is essential for obtaining health benefits and healthcare savings and has been cited as the most important factor for program outcomes (Woodward \& Berry, 2005; Marks \& Allegrante, 2005; Belza et al, 2010; Batra et al., 2016; Ackerman et al., 2008). This study aimed to fill a gap in the exercise adherence literature by examining predictors of short-term and long-term adherence to the EnhanceFitness program among older adult participants in South 
Florida. Results indicate that demographics and health status are related to adherence but that some of these factors differentially affect short-term and long-term adherence to EF.

The Healthy Aging Regional Collaborative of South Florida offered EF classes in community-based settings three times a week for five years. Only $25 \%$ of HARC participants attended at least 32 sessions within the first 16 weeks to meet the criteria for short-term adherence, and only $35 \%$ of participants attended an average of at least once a week during the first year of participation in order to meet the criteria for long-term adherence. Wallace et al. (1998) reported a 90\% attendance rate at classes offered in the initial trial of EF, but the design was a randomized controlled trial and participants received telephone calls from a nurse at 2, 4, and 16 weeks which could have contributed to a higher attendance rate.

A review of prospective studies addressing adherence to exercise programs among older adults reported that participants attended a range of 58\% to $77 \%$ of sessions offered. Several of the studies included in the review were randomized trials lasting less than six-months and involved different types of exercise such as home exercise, walking and yoga (Picorrelli et al., 2014). The current study examined adherence to a group exercise program offered for five years outside of controlled research conditions, which may help to explain the discrepancy between the high adherence rates reported in the previous studies and the relatively low adherence rates in the current study.

Farrance et al. (2016) reviewed adherence of participants attending communitybased exercise programs lasting at least six months and reported that an average of $69.1 \%$ of participants were adherent based on the number of sessions attended or completion of the program. Rather than examining adherence as the percent of sessions attended or as 
the percent of participants who did not drop out during the period of interest as was done in many other studies, this study examined whether participants attended the number of sessions linked to program benefits in previous studies of EF (Belza et al., 2010; Ackerman et al., 2003). This measure was selected to capture the percent of participants receiving the minimum necessary dose of the EnhanceFitness program, but is difficult to compare to adherence rates reported in other studies.

In the Washington study that found lower health costs for EF participants attending the community-based program at least once per week for a year, 50\% of the participants met the criteria for adherence (Ackerman et al., 2003). A study estimating the cost-benefits of EF offered in community settings in Kaua'i reported a higher adherence rate with $67 \%$ of participants attending at least once per week. The low short-term and long-term adherence rates in this study are concerning because participants must participate on a regular basis in order to maximize program benefits and achieve healthcare cost savings associated with the program (Wallace et al, 1998; Belza et al., 2010; Ackerman et al., 2003; Page, Batra, Ghouse, \& Palmer, 2014).

Knowledge of the factors associated with adherence can inform program design and strategies to improve adherence rates, so logistic regression was conducted to identify predictors of short-term and long-term adherence to EF. Results of the logistic regression showed that older participants were more likely than younger participants to adhere to the program short-term and long-term. This finding was surprising, because compared to younger adults, older adults report lower intentions to initiate or sustain participation in physical activity (Bouchard et al., 2012; King \& King, 2010). Batra et al. (2016) reported that female HARC EF participants ages 80 and older had stronger 
positive beliefs about their fitness compared to women ages 60-79, and a positive relationship between fitness beliefs and exercise participation has been reported in other research. It is possible that fitness beliefs or other factors associated with older age that influence commitment to exercise led to a higher likelihood of adherence among older participants in the current study.

Rates of physical inactivity are higher among racial and ethnic minorities than whites (Anderson et al., 2006), but the finding that white participants were less likely to be adherent than some races is consistent with previous research on adherence to exercise programs among older adults (Gilette et al, 2015). Black participants were less likely than white participants to meet the criteria for short-term adherence but more likely than whites to meet the criteria for long-term adherence. This mixed finding is in line with a review of older adults' adherence to exercise in randomized controlled trials which found that different variables were associated with adherence at different time points and to different aspects of adherence such as frequency, intensity, and duration (Martin \& Sinden, 2001). In the current study, long-term adherence required attending an average once per week for a year, whereas short-term adherence required attending twice per week for 16 weeks, so it is possible that black participants were committed to sustaining their participation over time but faced barriers to attending more than once per week.

Gender is another demographic variable that has an inconsistent relationship with exercise participation in existing research (Martin \& Sinden, 2001). Physical inactivity is highly prevalent among women, and women may face more barriers to exercise participation based on gender roles (Sjogren \& Stjernber, 2010; Anderson et al., 2006). Gender was not, however, found to predict attrition in another physical activity 
intervention for older adults (Jancey et al., 2007). This study provided evidence that men are more likely than women to be adherent to exercise both short-term and long-term. Motivators and barriers associated with intention to exercise have been found to differ by gender (Newson \& Kemps, 2007). The majority of participants in the study were women, so understanding their unique motivators and barriers will be an essential step toward improving adherence.

In the bivariate analysis, health status was a significant predictor of short-term adherence but not long-term adherence. Health status varies across the course of participation and thus long-term adherence may not have been predicted as easily by the baseline measurement of health status. In other research, health status has consistently been found to be a determinant of physical activity initiation and maintenance among older adults (Van Stralen et al., 2009). A systematic review of prospective studies examining adherence to exercise programs revealed that having fewer health conditions and better self-rated health were associated with higher adherence (Picorelli et al., 2014). Some research however has shown that poor health motivates attendance among people who see exercise as a way to manage their health (Belza et al., 2004). Although it is beyond the scope of this research, it is important to note that the direction of influence of health status may vary based on other factors.

\section{Limitations}

The findings from this study apply to the EnhanceFitness program among participants in South Florida and may not generalize to other exercise programs and populations. It is possible that participants were participating in other types of exercise which may have influenced their attendance at EF classes. Future research should 
consider whether participants are relying solely on the evidence-based exercise program to meet their exercise needs or if they are also participating in other types of exercise. There are numerous factors that varied across sites, so it would have been desirable to control for site effects, but EF was offered at 114 sites and the dataset did not include a site variable in the participant records. The availability of predictor variables in the database was also limited, so a substantial amount of variance in adherence remains unexplained.

\section{Conclusion}

This study provides evidence of the association between age, gender, race/ethnicity, and health status with short-term and long-term adherence to EnhanceFitness in community settings. These findings can help to inform program implementation strategies and efforts to improve adherence. Short-term and long-term adherence rates were low, and the models only explained a small percent of the variance in adherence, so additional research is needed to improve understanding of factors related to adherence to EF. When replicating evidence-based programs on a wide-scale in community settings, it is important to consider the unique needs of the priority population. Research should incorporate the perspectives of EF participants to understand their experiences with the program and identify barriers and motivators that are relevant to their adherence. Given the central role of adherence in the success of evidence-based programs, strategies to improve adherence are needed. Improving adherence rates will help to maximize the return on investment for evidence-based exercise program for older adults which in turn will help to ensure sustainability of the programs in community settings. 
Table 4.1 Sample Characteristics and Comparison of Participants Who Met the Criteria for Short-Term Adherence of Attending $\geq 32$ Sessions in 16 Weeks with Those Who Attended $\leq 32$ Sessions in 16 Weeks

\begin{tabular}{|c|c|c|c|c|}
\hline Variable & $\begin{array}{l}\text { All Participants } \\
\mathrm{N}=5,619\end{array}$ & $\begin{array}{l}\text { Short-Term } \\
\text { Adherent } \\
\text { n=1,403 } \\
\text { n (\%) }\end{array}$ & $\begin{array}{l}\text { Short-Term } \\
\text { Non- } \\
\text { Adherent } \\
\text { n=4,216 } \\
\text { n (\%) }\end{array}$ & $p$-Value ${ }^{a}$ \\
\hline \multicolumn{5}{|l|}{ Age } \\
\hline $60-69$ & 1561 (27.8\%) & 344 (24.5\%) & 1217 (28.9\%) & \multirow{4}{*}{.003} \\
\hline $70-79$ & 2340 (41.6\%) & 596 (42.5\%) & $1744(41.4 \%)$ & \\
\hline 80-89 & 1340 (23.8\%) & 348 (24.8\%) & $992(23.5 \%)$ & \\
\hline$\geq 90$ & $378(6.7 \%)$ & $115(8.2 \%)$ & $263(6.2 \%)$ & \\
\hline \multicolumn{5}{|l|}{ Race/Ethnicity } \\
\hline White & 2415 (45.9\%) & 625 (46.6\%) & $1790(45.7 \%)$ & \multirow{5}{*}{.000} \\
\hline Hispanic & 1392 (26.5\%) & 382 (28.5\%) & $1010(25.8 \%)$ & \\
\hline Haitian & 275 (5.2\%) & 72 (5.4\%) & $203(5.2 \%)$ & \\
\hline Black & 1007 (19.1\%) & 202 (15.1\%) & 805 (20.5\%) & \\
\hline Other & $171(3.3 \%)$ & $61(4.5 \%)$ & $110(2.8 \%)$ & \\
\hline \multicolumn{5}{|l|}{ Gender } \\
\hline Female & 4549 (84.5\%) & 1089 (80.8\%) & 3460 (85.7\%) & \multirow[t]{2}{*}{.000} \\
\hline Male & $836(15.5 \%)$ & $259(19.2 \%)$ & 577 (14.3\%) & \\
\hline \multicolumn{5}{|l|}{ Health Status } \\
\hline Poor & 86 (1.8\%) & 14 (1.1\%) & 72 (2.1\%) & \multirow{5}{*}{.001} \\
\hline Fair & 702 (14.5\%) & 166 (12.5\%) & 536 (15.3\%) & \\
\hline Good & 2139 (44.3\%) & 606 (45.7\%) & 1533 (43.8\%) & \\
\hline Very Good & 1360 (28.2\%) & 410 (30.9\%) & $950(27.2 \%)$ & \\
\hline Excellent & $538(11.2 \%)$ & $130(9.8 \%)$ & 408 (11.7\%) & \\
\hline
\end{tabular}

a. $p$-values were obtained from Pearson's chi-square tests 
Table 4.2 Comparison of Participants Who Met the Criteria for Long-Term Adherence by Attending an Average of at Least Once Per Week for One Year with Those Who Attended Less Than an Average of Once Per Week for One Year

\begin{tabular}{|c|c|c|c|}
\hline Variable & $\begin{array}{l}\text { Long-Term } \\
\text { Adherent } \\
\mathrm{n}=1,972 \\
\mathrm{n}(\%) \\
\end{array}$ & $\begin{array}{l}\text { Long-Term Non- } \\
\text { Adherent } \\
\text { n=3,647 } \\
\text { n (\%) }\end{array}$ & $p$ - Value ${ }^{a}$ \\
\hline \multicolumn{4}{|l|}{ Age } \\
\hline $60-69$ & 484 (24.5\%) & 1077 (29.5\%) & \\
\hline $70-79$ & 839 (42.5\%) & 1501 (41.2\%) & .000 \\
\hline $80-89$ & 489 (24.8\%) & $851(23.3 \%)$ & \\
\hline$\geq 90$ & $160(8.1 \%)$ & $218(6.0 \%)$ & \\
\hline \multicolumn{4}{|l|}{ Race/Ethnicity } \\
\hline White & 762 (40.9\%) & 1653 (48.7\%) & \\
\hline Hispanic & 487 (26.1\%) & 905 (26.6\%) & .000 \\
\hline Haitian & $121(6.5 \%)$ & $154(4.5 \%)$ & \\
\hline Black & 425 (22.8\%) & $582(17.1 \%)$ & \\
\hline Other & 68 (3.7\%) & 103 (3.0\%) & \\
\hline \multicolumn{4}{|l|}{ Gender } \\
\hline Female & 1587 (83.8\%) & 2962 (84.8\%) & .307 \\
\hline Male & $307(16.2 \%)$ & $529(15.2 \%)$ & \\
\hline \multicolumn{4}{|l|}{ Health Status } \\
\hline Poor & 27 (1.5\%) & 59 (2.0\%) & \\
\hline Fair & 261 (14.3\%) & 441 (14.7\%) & .719 \\
\hline Good & $824(45.1 \%)$ & 1315 (43.9\%) & \\
\hline Very Good & $512(28.0 \%)$ & 848 (28.3\%) & \\
\hline Excellent & $204(11.2 \%)$ & 334 (11.1\%) & \\
\hline
\end{tabular}


Table 4.3. Logistic Regression Model of Factors Predicting Short-Term Adherence $(\mathrm{N}=4,409)$

\begin{tabular}{lcccc}
\hline Predictor & $\begin{array}{c}\text { Odds Ratio } \\
\text { (OR) }\end{array}$ & $\boldsymbol{p}$ & \multicolumn{2}{c}{$\mathbf{9 5 \%}$ CI for OR } \\
& & & Lower & Upper \\
\hline Age & REF & & & \\
$60-69$ & 1.17 & .061 & .993 & 1.388 \\
$70-79$ & 1.27 & .014 & 1.048 & 1.529 \\
$80-89$ & 1.67 & .000 & 1.263 & 2.205 \\
$\geq 90$ & & & & \\
Race/Ethnicity & REF & & & \\
White & 1.25 & .008 & 1.060 & 1.470 \\
Hispanic & 1.23 & .183 & .906 & 1.679 \\
Haitian & 0.82 & .045 & .669 & .996 \\
Black & 1.80 & .001 & 1.269 & 2.538 \\
Other & & & & \\
Gender & REF & & & \\
Female & 1.47 & .000 & 1.233 & 1.760 \\
Male & & & & \\
Health Status & REF & & & \\
$\quad$ Poor & 1.70 & .107 & .892 & 3.256 \\
Fair & 2.23 & .013 & 1.188 & 4.188 \\
$\quad$ Good & 2.60 & .003 & 1.376 & 4.917 \\
$\quad$ Very Good & 1.83 & .073 & .945 & 3.529 \\
$\quad$ Excellent & & & & \\
& & &
\end{tabular}


Table 4.4 Logistic Regression Model of Factors Predicting Long-Term Adherence $(\mathrm{N}=4,409)$

\begin{tabular}{|c|c|c|c|c|}
\hline \multirow[t]{2}{*}{ Predictor } & \multirow{2}{*}{$\begin{array}{c}\text { Odds Ratio } \\
\text { (OR) }\end{array}$} & \multirow[t]{2}{*}{$p$} & \multicolumn{2}{|c|}{ 95\% CI for OR } \\
\hline & & & Lower & Upper \\
\hline \multicolumn{5}{|l|}{ Age } \\
\hline $60-69$ & REF & & & \\
\hline $70-79$ & 1.26 & .003 & 1.083 & 1.472 \\
\hline $80-89$ & 1.45 & .000 & 1.221 & 1.727 \\
\hline$\geq 90$ & 1.98 & .000 & 1.522 & 2.574 \\
\hline \multicolumn{5}{|l|}{ Race/Ethnicity } \\
\hline White & $\mathrm{REF}$ & & & \\
\hline Hispanic & 1.30 & .001 & 1.114 & 1.517 \\
\hline Haitian & 2.03 & .000 & 1.533 & 2.700 \\
\hline Black & 1.77 & .000 & 1.489 & 2.101 \\
\hline Other & 1.53 & .014 & 1.090 & 2.152 \\
\hline \multicolumn{5}{|l|}{ Gender } \\
\hline Female & $\mathrm{REF}$ & & & \\
\hline Male & 1.19 & .044 & 1.005 & 1.413 \\
\hline \multicolumn{5}{|l|}{ Health Status } \\
\hline Poor & REF & & & \\
\hline Fair & 1.34 & .256 & .807 & 2.232 \\
\hline Good & 1.59 & .067 & .969 & 2.594 \\
\hline Very Good & 1.76 & .028 & 1.064 & 2.894 \\
\hline Excellent & 1.78 & .030 & 1.058 & 2.999 \\
\hline
\end{tabular}




\section{References}

Ackermann, R. T., Cheadle, A., Sandhu, N., Madsen, L., Wagner, E. H., \& LoGerfo, J. P. (2003). Community exercise program use and changes in healthcare costs for older adults. American Journal of Preventive Medicine, 25(3), 232-237.

Ackermann, R.T., Williams, B., Nguyen, H.Q. Berke, E.M., Maciejewski, M.L. \& LoGerfo, J.P. (2008). Healthcare cost differences with participation in a community-based group physical activity benefit for Medicare Managed Care health plan members. Journal of the American Geriatrics Society, 56(8), 14591465. doi: 10.1111/j.1532-5415.2008.01804.x

Anderson, E.S., Wojcik, J.R., Winett, R.A., \& Williams, D.M. (2006). Health Psychology, 25(4), 510-520.

Andresen, E.M., Catlin, T.K., Wyrwich, K.W., Jackson-Thompson, J. (2003). Retest reliability of surveillance questions on health related quality of life. Journal of Epidemiology and Community Health, 57(5), 339-343.

Batra, A., Coxe, S., Page, T.F., Melchior, M., Palmer, R.C. (2016). Evaluating the factors associated with the completion of a community-based group exercise program among older women. Journal of Aging and Physical Activity, 24(4), 649-658.

Belza, B., Shumway-Cook A., Phelan, E. A., Williams, B., Snyder, S. J., \& LoGerfo, J. P. (2006). The effect of a community-based exercise program on function and health in older adults: The EnhanceFitness program. Journal of Applied Gerontology, 25, 291-306. doi:10.1177/gbh0733464806290934

Belza, B., Synyder, S., Thompson, M., \& LoGerfo, J. (2010). From research to practice: EnhanceFitness, an innovated community-based senior exercise program. Topics in Geriatric Rehabilitation, 26(4), 299-309.

Bethancourt, H.J., Rosenburg, D.E., Beatty T., \&Arterburn, D.E. (2014). Barriers to and facilitators of physical activity program use among older adults. Clinical Medicine \& Research, 12(1-2), 10-20.

Bouchard, D., Langlois, M., Domingue, M., Brown, C., LeBrun, V., \& Baillargeon, J. (2012). Age differences in expectations and readiness regarding lifestyle modifications in individuals at high risk of diabetes. Archives of Physical Medicine and Rehabilitation, 93(6), 1059-64. doi:10.1016/j.apmr.2011.12.028

Centers for Disease Control and Prevention (2008). 2008 Behavioral Risk Factor Surveillance System Questionnaire. Retrieved from https://www.cdc.gov/brfss/annual_data/pdf-ques/2008brfss.pdf 
Centers for Disease Control and Prevention. (2013). The state of aging and health in America 2013. Atlanta, GA. Retrieved from http://www.cdc.gov/features/ agingandhealth/state_of_aging_and_health_in_america_2013.pdf

Chandler, J.M., \& Hadley, E.C. (1996). Exercise to improve physiologic and functional performance in old age. Clinical Geriatric Medicine, 12,761-784.

Chiang, K., Seman, L., Belza, B., \& Hsin-Chun Tsai, J. (2008). "It is our exercise family Of ethnic older adults in a group-based exercise program. Preventing Chronic Disease, 5(1). http://www.cdc.gov/pcd/issues/2008/jan/06_0170.htm.

Cross, W. F. \& West, J. C. (2011). Examining implementer fidelity: Conceptualizing and measuring adherence and competence. Journal of Children's Services, 6, 18-33.

Farrance, C., Tsofliou, F., \& Clark, C. (2016). Adherence to community based group exercise interventions for older people: A mixed-methods systematic review. Preventive Medicine, 87, 155-166.

Florida Department of Health (2011). Florida Behavioral Risk Factors: Results from the 2000-2009 Behavioral Risk Factor Surveillance System. Retrieved from http://www.floridahealth.gov/statistics-and-data/survey-data/behavioral-riskfactor-surveillance-system/reports/_documents/flbrf.pdf

Frank, J. C., Coviak, C. P., Healy, T. C., Belza, B., \& Casado, B. L. (2008). Addressing Fidelity in Evidence-Based Health Promotion Programs for Older Adults. Journal of Applied Gerontology 27(1), 4-33.

Gillette, D.B., Petruscu-Prahova, M., Herting, J.R., \& Belza, B. (2015). Journal of Geriatric Physical Therapy, 38(4), 194-201. doi:10.1519/JPT.0000000000000041

Hosmer, D., \& Lemeshow, S. (2004). Applied Logistic Regression (2nd ed.). Hoboken, NJ: John Wiley \& Sons.

IBM Corp. (2016). IBM SPSS Statistics for Windows. Armonk, NY: IBM Corp.

Jancey, J., Lee, A., Howat, P., Clarke, A., Wang, K., \& Shilton, T. (2007). Reducing attrition in physical activity programs for older adults. Journal of Aging and Physical Activity, 15, 152-165.

King, A.C., \& King, D.K. (2010). Physical Activity for an Aging Population. Public Health Reviews, 32, 401-426.

Marks, R., \& Allegrante, J.P. (2005). Chronic osteoarthritis and adherence to exercise: A review of the literature. Journal of Aging and Physical Activity,13(4), 434-460. doi:10.1123/japa.13.4.434 
Martin, K.A., \& Sinden, A.R. (2001). Who will stay and who will go? A review of older adults' adherence to randomized controlled trials of exercise. Journal of Aging and Physical Activity, 9, 91-114.

Moore-Harrison, T.L., Johnson, M.A., Quinn, M.E. Cress, M.E. (2009). An evidencebased exercise program implemented in congregate meal sites. Journal of Physical Activity and Health, 6, 247-251.

National Council on Aging (2017). Title III-D highest tier evidence-based health promotion/disease prevention programs. Retrieved from https://www.ncoa. org/wp-content/uploads/Title-IIID-Highest-Tier-Evidence_Feb.-2017-1.pdf

National Council on Aging (2018). 2017 Impact Report. Retrieved from https://www.ncoa.org/wp-content/uploads/2017-NCOA-Impact-Report-web.pdf

Newson, R.S., \& Kemps, E.B. (2007). Factors that promote and prevent exercise engagement in older adults. Journal of Aging and Health, 19(3), 470-481.

Page, T.F., Batra, A., Ghouse, M.M., Palmer, R.C. (2014). Implementation Cost Analysis of a Community-Based Exercise Program for Seniors in South Florida. Health Promotion Practice, 15(4), 585-591. doi: 10.1177/1524839913518221

Palmer, R.C., Batra, A., Anderson, C., Page, T., Vieira, E., \& Seff, L. (2016). Implementation of an Evidence-Based Exercise Program for Older Adults in South Florida. Journal of Aging Research, 2016, Article ID 9630241. http://dx.doi.org/10.1155/2016/9630241

Picorelli, A.M.A., Pereira, L.S.M. Pereira, D.S., Felicio, D., \& Sherrington, C. (2014). Adherence to exercise programs for older people is influenced by program characteristics and personal factors: a systematic review. Journal of Physiotherapy, 60, 151-156.

Sjogren, K., \& Stjernberg, L. (2010). A gender perspective on factors that influence outdoor recreational physical activity among the elderly. BMC Geriatrics, 10, 34. doi: 10.1186/1471-2318-10-34

Snyder, J.S., Thompson, M., \& Denison, P. (2014). EnhanceFitness: a 20-year dissemination history. Frontiers in Public Health, 2, 1-2. doi: 10.3389/fpubh.2014.00270

Tak, E.C., van Uffelen, J.G., Paw, M.J., van Mechelen, W., \& Hopman-Rock, M. (2012). Adherence to exercise programs and determinants of maintenance in older adults with mild cognitive impairment. Journal of Aging and Physical Activity, 20(1), 32-46. 
Tomioka M., Sugihara N., Braun K. L. (2012). Replicating the EnhanceFitness physical activity program in Hawai'i's multicultural population, 2007- 2010. Preventing Chronic Disease, 9, 110155. doi: 10.5888/ pcd9.110155

U.S. Census Bureau (2015). Annual Estimates of the Resident Population for Selected Age Groups by Sex for the United States, States, Counties, and Puerto Rico Commonwealth and Municipios: April 1, 2010 to July 1, 2014. Retrieved from https://factfinder.census.gov/faces/table services/jsf/pages/productview.xhtml? src $=$ bkmk

U.S. Department of Health and Human Services (2008). 2008 Physical Activity Guidelines for Americans. Retrieved from https:/health.gov/paguidelines/pdf/ paguide.pdf

Van Stralen, M.M., De Vries, H., Mudde, A.N., Bolman, C., Lechner, L. (2009). Determinants of initiation and maintenance of physical activity among older adults: a literature review. Health Psychology Review, 3(2), 147-207.

Wallace, J.I., Buchner, D.M., Grothaus, L. Leveille, S., Tyll, L., LaCroix, A.Z., \& Wagner, E.H. (1998). Implementation and effectiveness of a community-based health promotion program for older adults. Journal of Gerontology: Medical Sciences, 53a(4), M301-M306.

Woodward, C.M., \& Berry, M.J. (2005). Enhancing adherence to prescribed exercise: structured behavioral interventions in clinical exercise programs. Journal of Cardiopulmonary Rehabilitation, 21(4), 201-209. 


\section{CHAPTER V}

\section{Manuscript Title: Participant and instructor perspectives on adherence to}

\section{EnhanceFitness: a descriptive qualitative study to inform program implementation \\ Introduction}

Physical inactivity has become a global pandemic. Worldwide, over 31\% of adults are physically inactive with even higher rates of inactivity among older adults (Hallal et al., 2012). In the United States, $84 \%$ of older adults fail to meet federal guidelines for both aerobic and strength activity (USDHHS, 2008). Scientific evidence supports physical inactivity as a strong risk factor for the world's most prevalent chronic diseases including heart disease, diabetes, and cancer, so promoting physical activity across the lifespan has the potential to impact health worldwide.

As a result of the recognition of the benefits of physical activity in older adulthood, community-based group exercise programs are increasing in popularity. Evidence indicates that these programs not only help older adults to increase physical activity levels, but also help to improve their functional fitness, well-being, and quality of life (Belza et al., 2006; Hughes et al., 2009; Seguin, Heidkamp-Young, Kuder, \& Nelson, 2010). An ongoing evidence-based group exercise program called EnhanceFitness (EF) has been shown to help older adults become more active and improve their fitness, physical functioning, social functioning, and mental health (Wallace et al., 1998; Belza et al., 2006). The EF program is delivered by a certified instructor three times per week as an hourly session incorporating cardio, strength, flexibility, and balance exercises.

Glasgow, Vogt, and Boles (1999) proposed the RE-AIM model to evaluate the overall population health impact of public health interventions based on five interacting 
dimensions: reaching the intended population, effectiveness, adoption by target settings or institutions, implementation, and maintenance. The implementation dimension of the model assesses the extent to which the program is delivered as intended and includes personal level measures such as participant adherence. Evaluations of EF have provided evidence that participant adherence in terms of attendance is required to obtain maximum program benefits. Belza and colleagues (2010) found that participants who attended fewer than 32 sessions in the first four months after enrollment did not improve significantly on performance measures. Batra and colleagues (2016) also found that improvements were greater for women who attended at least 32 sessions during the first four months. Ackermann and colleagues (2003) reported that significant reductions in healthcare utilization and costs were only observed among EF participants who attended for an average of at least once per week for at least one year.

EF was translated to community-based settings in South Florida by agencies participating in the Healthy Aging Regional Collaborative (HARC). An evaluation of the EF classes implemented in South Florida from 2009 through 2012 indicated that only $26 \%$ of participants received the minimum recommended dose of 32 sessions within the first four months, but the average attendance duration was over one year and 89\% percent of participants reported satisfaction with the program (Palmer et al., 2016). Analysis of five years of HARC EF program data revealed that only $25 \%$ of the participants attended at least 32 sessions within the first 16 weeks to meet the criteria for short-term adherence, and only 35\% attended an average of one per week for one year to achieve long-term adherence. Logistic regression provided evidence for gender, race/ethnicity, age, and 
health status as predictors of short-term adherence and long-term adherence, but a large amount of the variance in adherence remained unexplained.

Factors that have been reported to influence adherence to other community-based group exercise programs include individual characteristics, health status, social support, and beliefs (Killingback, Tsofliou, \& Clark, 2017; Gilette, Petrescu-Prahova, Herting, \& Belza, 2015; Chiang et al., 2008; Farrance, Tsofliou, \& Clark, 2016). Qualitative research has the potential to improve understanding of adherence, but a recent systematic review of quantitative and qualitative studies on adherence to community based exercise program participants found limited evidence on long-term adherence and limited research incorporating the views of participants to identify the reasons that they adhere (Farrance, Tsofliou, \& Clark, 2016).

Only three previous qualitative studies are known to have examined the views of participants who achieved long-term adherence in real life settings. Two of these studies were conducted with ethnically homogenous white populations in Canada and the United Kingdom (Dunlop \& Beauchamp, 2013; Killingback, Tsofliou, \& Clark, 2017). The third study conducted focus groups with Chinese, African American, white, and Japanese older adults to understand the factors promoting adherence to the EF program in Seattle but did not focus specifically on long-term adherence (Chiang et al., 2008). Environmental factors, program design, social support, and individual factors were revealed as the four main themes influencing adherence to EF (Chiang et al., 2008).

Research has also highlighted the influence of the program instructor on participant adherence to group physical activity programs (Farrance, Tsoflious, \& Clark; 2016; Estabrooks et al., 2004; Ecclestone \& Jones, 2004). Quantitative research on 
influences on older adults' adherence to exercise classes identified program instructors' gender, experience, motivational training, and personality as important influences on adherence (Hawley-Hague, Horne, Campbell, Demack, Skelton, \& Todd, 2013). In addition to being an influence on participant adherence, instructors have personal experience with participants and program delivery, so they are an important source of information regarding participant behavior, program and strategies for sustaining adherence.

Researchers who examined instructor perspectives on uptake and adherence to multicomponent exercise classes for older adults in England identified a range of factors that influence participants’ attendance (Hawley-Hague, Horne, Skelton, \& Todd, 2016). Based on the factors identified, the authors recommended that instructors increase social influence by engaging peers and health professionals to promote classes and strengthen long-term motivation. Other recommendations for instructors included offering sample sessions to support perceived behavioral control, focusing on goal setting, showing compassion, and keeping in contact with participants outside of class (Hawley-Hague, Horne, Skelton, \& Todd, 2016). In the study by Hawley-Hague and colleagues, all of the instructors were white and had primarily white class members, so additional research is needed to explore the perspectives of instructors leading community-based group exercise programs in different settings with diverse older adults (Hawley-Hague, Horne, Skelton, \& Todd, 2016).

Advancing the understanding of the factors that diverse older adults and program instructors perceive as barriers and facilitators to long-term adherence to communitybased exercise programs is a necessary step towards improving evidence-based exercise 
programs so that they are effective at engaging participants and sustaining participation and physical activity. The current study explored the experiences and perspectives of a purposive sample of adherent EF participants and instructors in Florida in an effort to identify factors contributing to successful adherence, factors they observed that prevented some participants from adhering, and strategies to improve adherence.

\section{Research Design}

\section{Methods}

As the third segment of a larger mixed methods study, this descriptive qualitative study was designed to describe the factors influencing adherence to EF from the perspectives of older adults attending EF and instructors delivering the EnhanceFitness program. The qualitative descriptive approach was selected because the study was prompted by a need for experiential knowledge of the factors influencing adherence in order to inform efforts to improve the program and its impact. Qualitative research allows unanticipated information to emerge and provides rich and emic data from the viewpoints of participants and instructors (Creswell, 1994).

\section{Framework}

The Theory of Planned Behavior (TPB) was developed to explain intention to engage in behaviors over which people can apply self-control and has frequently been applied to study exercise behavior, so TPB was selected as the framework which guided the study design and analysis (Ajzen \& Fishbein, 2005; Vallance et al., 2011). TPB explains that behavioral intentions are guided by norms, perceived behavioral control, and attitudes which are all preceded by beliefs (Ajzen \& Fishbein, 2005). In order to improve understanding of the factors that contribute to behavioral, normative, and control 
beliefs, the TPB framework was extended to include personal factors, social factors, and program factors because the literature indicated that these factors were likely to influence beliefs related to EF attendance (Hawley-Hague et al., 2013; Killingback et al., 2017).

Approximately 50\% of people who intend to engage in health behaviors actually translate the intention into action (Sheeran, 2002). The cues to action concept from the Health Belief Model was incorporated into the framework because cues to action can bridge the gap between intention and behavior or prompt the formation of an intention (Rosenstock, 1990; Milne, Orbell, \& Sheeran, 2002). Outcomes were also included as a factor in the framework because the benefits experienced from attending EF were expected to be important for encouraging repeated attendance.

\section{Setting}

The Health Foundation of South Florida (HFSF) formed the Healthy Aging Regional Collaborative (HARC) in 2008 to make evidence-based health promotion programs accessible to older adults. From 2008 through 2013, HARC provided funding to 14 agencies offering EF. Multiple agencies in south Florida continue offering the program under the HFSF's EF license with delivery funding from other sources. The classes are offered at community-based sites including senior centers, community centers, residential facilities, clinics, churches, and parks. EF instructors are required to hold a nationally recognized instructor certification and complete a two-day training conducted by an EF Master Trainer. Instructors are required to teach the class as it is described in the EF instructor manual and were randomly selected for fidelity monitoring visits during the HARC evaluation period to ensure that the program was being delivered as prescribed. 


\section{Sampling Strategy and Recruitment}

Older adults who had attended EF an average of at least two times per week for at least one year were recruited to participate in one-on-one, semi-structured interviews. The researcher visited the three active EF sites to present the research opportunity at the beginning of regularly scheduled EF classes. EF participants provided their contact information on a sign-up list or took a flyer with the researcher's contact information if they were interested in participating in the study. Participants who called to indicate interest within two weeks were added to the list of participants who signed up in class. From the list of $29 \mathrm{EF}$ participants who indicated an interest in completing an interview, eligibility was confirmed using attendance and participant records maintained by the organization offering the classes. Stratified purposeful sampling was used to select females and males representing a range of ethnicities and ages. English fluency and being age 60 or older were set as inclusion criteria. Eligible participants were contacted by phone and invited to schedule their choice of a telephone or in-person interview. The researcher contacted active EF instructors from two HARC agencies and invited them to schedule a phone or in-person interview. Only instructors who had been instructing EF for at least two years were contacted in order to ensure sufficient experience with the program and participants.

The researcher continued contacting participants and instructors for interviews until an adequate sample size was reached. Appraisal of information power guided the sample size by considering the five dimensions included in the conceptual model proposed by Malterud et al. (2016): study aim, specificity, use of established theory, quality of dialogue, and analysis strategy. The more information power a sample has, the 
lower the sample size needed for the study (Malterud et al., 2016). The aims of the current study are narrow, the sample was purposefully selected to include individuals with characteristics and experiences specific to the study aims, and an established theory was used to guide the exploration of factors influencing adherence, so a smaller sample was needed to achieve sufficient information power.

The researcher is a novice interviewer but has extensive knowledge of the EF program through her work as a research assistant evaluating the translation of EF in South Florida and observing classes for fidelity. The interviews were brief but the dialogue was strengthened by focused questions and responses that were highly relevant to the study aims. Thematic cross-case analysis required a larger sample in order to gather an adequate supply of descriptions of factors influencing adherence and relevant patterns. For the fictional study that Malterud and colleagues used to develop their information power model, it was estimated that 10 participants with diverse experiences would likely provide sufficient information power to develop knowledge related to the study aims. In the current study, the researcher appraised the information power as sufficient to conduct meaningful analyses after interviewing 12 participants and 10 instructors.

Similar sample sizes have been used in recent research. Signal et al. (2016) conducted semi-structured interviews with 14 participants of a high intensity exercise program to examine what influences acceptability and engagement with the program. Guest, Bunce, and Johnson (2006) demonstrated that saturation can be achieved within the first twelve interviews. While the large population of diverse EF participants in South Florida would require a larger sample to achieve data saturation, the goal of this study 
was to provide new insights that contribute to the understanding of adherence and strategies to improve adherence. Information power was sufficient to achieve these aims.

\section{Data Collection}

\section{Procedures}

Based on the interviewees choice, the researcher conducted interviews by phone or in a private room at the EF class site. Verbal consent was obtained for phone interviews and written consent was obtained for in-person interviews. Interviews lasted an average of 24 minutes. The interviews were recorded using a digital audio recorder and uploaded to a secure folder on a password protected laptop for storage and transcription. Interview participants received a \$10 gift card. The Institutional Review Board at Florida International University approved the study procedures. Interview Guide

The extended TPB framework was applied to develop the EF participant interview guide to ensure that the major factors theorized to influence attendance behavior were addressed. The guide included questions about exercise in general and questions specific to EF. The participant interview guide was pilot-tested for comprehension with three older adults and revised to clarify and reframe questions based on feedback given by the pilot participants. Instructor interviews were also conducted using a semi-structured guide to explore their perspectives on program factors, participants’ motivations for attending, social influences, important instructor characteristics, outcomes, and barriers to adherence. Instructors were also asked about their experience teaching EF and how they encourage participants to attend consistently and what strategies they would recommend to promote adherence. 


\section{Analysis}

Interviews were transcribed into Microsoft Word documents using Express Scribe software. The transcripts were then imported into ATLAS.ti version 7.5.6 for analysis. The analysis approach used was thematic analysis. Thematic analysis is a flexible method that is independent of a particular epistemology and can be used across a wide range of research questions to identify, analyze, organize, and describe the themes within a data set and produce insights (Braun \& Clarke, 2006). Thematic analysis is based on the Noticing, Collecting, and Thinking (NCT) Model, so the analysis was conducted by following the computer-assisted NCT process (Seidel, 1998; Friese, 2012). The approach involves noticing interesting and meaningful elements of the data and assigning codes to them, collecting similar data segments into themes and thinking about how all of the information fits together in order to develop an overall picture of the phenomenon being studied (Friese, 2012). The phases of the process are cyclical.

The intent of the analysis was to describe the participants’ and instructors’ perspectives on factors influencing EF. Working deductively, the researcher assigned structural codes to EF participant transcripts based on the framework and central research questions to index the major categories factors influencing adherence, barriers to adherence, and adherence strategies (Saldana, 2016). Working inductively, descriptive and in vivo codes were applied to meaningful units of text to summarize data representing other factors discussed by participants. After analyzing the first five participant transcripts, few new codes were emerging, so the code list was sorted and structured into a coding system that was applied to the remaining transcripts. Family filters were used to organize the data and build the categories of codes. Within the family 
filters, codes were refined by regrouping or combining them, using conceptual terms, and adding title codes to the categories. Some data that were initially coded under a main theme category were recoded to distinguish the different facets of the theme. For example, social factors were recoded as social benefits, social influences, and instructor influence. The coding system was modified slightly to accommodate new codes and subcategories that emerged during the analysis of the remaining transcripts. The modified coding system was then applied to all transcripts. The relationships between themes were analyzed by querying the data and using the network view function in ATLAS.ti to examine the processes and pathways by which the themes related to adherence. Resulting themes and a conceptual model of the adherence process were confirmed using member checks with one participant from each of the three sites.

For the instructor interviews, the researcher applied codes based on the theory of planned behavior and the adherence process model developed in the analysis of EF participant views (Friese, 2012). Then, the researcher added in vivo codes and descriptive codes. A coding system was developed after coding the first three transcripts and was applied to all of the transcripts. Codes were sorted using family filters in order to identify patterns and form themes.

After analyzing the participant and instructor datasets separately, findings were triangulated using the following-a-thread approach to develop a more complete picture of the factors influencing adherence to EF and to ensure rich findings from a small sample by incorporating different perspectives (Denzin, 2012; Moran-Ellis, Alexander, Cronin, Fielding, \& Thomas, 2006. Recommendations for strategies to improve program implementation and long-term adherence are presented based on the themes identified. 


\section{Findings}

\section{Sample Characteristics}

The sample included 12 adherent EF participants consisting of 50\% female participants and 50\% percent male participants with a mean age of 71 . To represent the most common ethnicities of EF participants in South Florida, Hispanic, black, and nonHispanic white participants each made up one third of the study sample. The sample also included $10 \mathrm{EF}$ instructors. The instructors included four males and six females whose ages ranged from 30 to 73 . The instructors represent a range of experiences because the sample included instructors who delivered EF at various site types including parks, community centers, churches, and senior housing in communities with primarily black, white, and Hispanic participants.

\section{Themes}

The major themes contributing to successful adherence to EF fit into the categories of goals of EF participation, cues to action, personal factors, beliefs, intentions, program factors, social factors, and benefits. Themes are listed in Table 5.1 and are discussed alongside sample quotations in the sections that follow. Adherent participants and EF instructors also reported potential barriers to attendance (Table 5.2) and strategies to improve adherence (Table 5.3). 


\section{Factors Related to Adherence}

Table 5.1 Categories and Themes That Influence Adherence to EnhanceFitness

\begin{tabular}{|c|c|c|}
\hline Categories & EF Participant Themes & EF Instructor Themes \\
\hline $\begin{array}{l}\text { Cues to } \\
\text { Action }\end{array}$ & $\begin{array}{ll}\text { - } & \text { Health issue } \\
\text { - } & \text { Observe deteriorating } \\
& \text { health of others } \\
\text { - } & \text { Craving activity } \\
\text { - } & \text { Doctor recommendations } \\
\text { - } & \text { Instructor recruiting efforts } \\
\text { - } & \text { Flyers }\end{array}$ & $\begin{array}{ll}\text { - } & \text { Health issue } \\
\text { - } & \text { Observe deteriorating } \\
\text { health of others } \\
\text { - } \text { Craving activity } \\
\text { - } \text { Doctor recommendations } \\
\text { - } \text { Flyers } \\
\text { - } \text { Word of mouth }\end{array}$ \\
\hline Goals & $\begin{array}{l}\text { Physical health: Fitness, } \\
\text { weight loss, mobility, and } \\
\text { pain relief } \\
\text { - Enjoyment } \\
\text { - Opportunity to get out and } \\
\text { socialize }\end{array}$ & $\begin{array}{l}\text { Improve or maintain } \\
\text { physical health }\end{array}$ \\
\hline $\begin{array}{l}\text { Personal } \\
\text { Factors }\end{array}$ & $\begin{array}{ll}\text { - } & \text { Exercise history } \\
\text { - } & \text { Exercise identity }\end{array}$ & - Exercise history \\
\hline Beliefs & 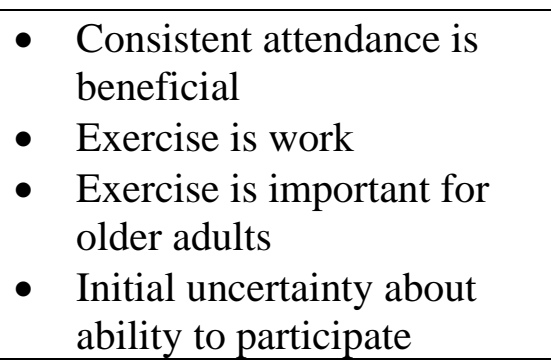 & $\begin{array}{l}\text { Participants recognize } \\
\text { importance of exercise for } \\
\text { older adults } \\
\text { - Uncertainty about ability to } \\
\text { do all of the exercises }\end{array}$ \\
\hline Intentions & $\begin{array}{l}\text { - Arrange schedule to attend } \\
\text { all classes } \\
\text { - Start with commitment to } \\
\text { attending or develop it over } \\
\text { time }\end{array}$ & $\begin{array}{l}\text { - Instructors encourage } \\
\text { participants to attend } \\
\text { consistently } \\
\text { - Commitment to attending } \\
\text { due to motivations }\end{array}$ \\
\hline $\begin{array}{l}\text { Program } \\
\text { Factors }\end{array}$ & $\begin{array}{ll}\text { - } & \text { Value structure and content } \\
\text { - } & \text { Awareness of benefits of } \\
\text { evidence-based program } \\
\text { - } & \text { Convenient locations } \\
\text { - } & \text { Class schedule } \\
\end{array}$ & 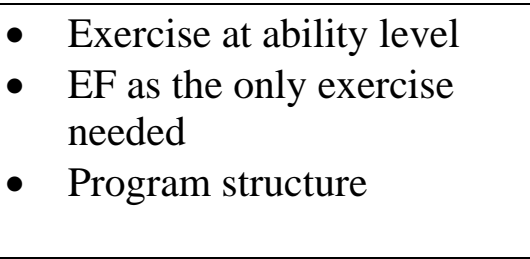 \\
\hline $\begin{array}{l}\text { Social } \\
\text { Factors }\end{array}$ & $\begin{array}{l}\text { - } \quad \text { Camaraderie and friendship } \\
\text { - } \text { Group challenges } \\
\text { participants and makes } \\
\text { exercise fun } \\
\text { - } \quad \text { Feel like part of the group } \\
\text { - }\end{array}$ & $\begin{array}{ll}\text { - } & \text { Social activity } \\
\text { - } & \text { Keeping in touch } \\
\text { - } & \text { Instructor characteristics } \\
& \text { and effort }\end{array}$ \\
\hline
\end{tabular}




\begin{tabular}{|c|c|c|}
\hline & $\begin{array}{ll}\text { - } & \text { Instructor important } \\
\text { influence } \\
\text { - } \\
\text { Staying in contact about } \\
\text { absences and checking in } \\
\text { with classmates } \\
\text { - Social support } \\
\text { - Support and } \\
\text { recommendations from } \\
\text { doctors }\end{array}$ & \\
\hline Benefits & $\begin{array}{ll}\text { - } & \text { Social benefits } \\
\text { - } & \text { Health outcomes } \\
\text { - } & \text { Enjoyment }\end{array}$ & $\begin{array}{ll}\text { - } & \text { Health improvements } \\
\text { - } & \text { Feeling good } \\
\text { - } & \text { Pride }\end{array}$ \\
\hline
\end{tabular}

Goals of EF Participation

Participants described several reasons for joining the EF program and maintaining their participation. The reasons reported all reflect goals of EF participation listed in Table 5.1. Goals centered around physical health including fitness, weight loss, mobility, and pain relief. Other reasons for participating in EF included exercising for enjoyment and the opportunity to "get out of the house" and socialize. While the social aspect of the program is valued, the primary goal of attendance is exercise and its associated benefits. One participant said, "We acknowledge each other and talk a little bit, but basically, I think everyone is really there for one purpose and that's to exercise.”

Based on their experiences recruiting participants and interacting with participants during class, instructors described their perceptions of factors that motivate participants to attend EF. Themes among reasons for attending perceived by instructors included improving or maintaining physical health and desire for activity. One instructor said that participants "just want to be able to be pain free and mobile.” EF provides an opportunity to get out and do something, which instructors explained is especially important for participants who live alone. 


\section{Cues to Action}

Participants reported specific cues to action that led them to begin attending EF. Most of the participants reported that experiencing a health issue personally or observing the deteriorating health of others highlighted the need for exercise and led them to start attending EF. One participant said, "I was losing the use of my legs, my balance was gone. Then I found Enhance and to me it was a Godsend.” Another participant expressed the desire to avoid health issues, "I weighed over 200 pounds and it was always difficult to keep my A1C down, cholesterol down, and also the blood pressure...The motivation behind it was because of health issues and I did not want to end up with a heart attack. I did not want to end up with a stroke.”

Awareness of the benefits of physical activity and observation of the consequences of physical inactivity were also powerful cues to action for participants. One participant explained, "I was looking for something because I had seen both my mother and father and brother die because they just didn't move enough you know, and my poor mother was just crippled with arthritis but she didn’t move. I just knew that old people should have some sort of physical activity.” Instructors also explained that participants are prompted to attend EF because "they see the condition of their friends who have not been involved and who have sat around.”

As shown in Table 5.1, other participant themes among cues to action included doctor recommendations, EF instructor recruitment efforts, or seeing a flyer, but participants mentioned initial reluctance to participating following these types of cues. One participant said "I would get flyers from my insurance company and I put it off for awhile before I started.” Referring to the EF class, another participant said, "my doctor 
kept sending me there but I wouldn't go. She was trying to send me there for about two years before I decided to go.” Ultimately, the recommendations and informational cues needed to be coupled with other motivators before leading to EF enrollment. One participant who had been receiving flyers decided to attend after retiring and another who had been referred to EF by a doctor finally decided to attend after realizing that her pain would not subside without action.

Instructors reported distributing flyers to promote EF and explained that interest in the class spreads via word of mouth and participants who invite friends. One instructor who was a former participant said, "people hear about a program like this from somebody who is already in it and hear gee it's kind of fun, we have some laughs, occasionally we'll have a luncheon, you make friends.” Instructors also viewed doctor recommendations for exercise as common cues to action that led participants to attend EF.

The other major cue to action perceived by instructors was a craving for activity. One instructor explained, “Well for the most part, they're seniors, they're retired. They find that they don't have anything to do and for me, when I was in that position, my body suddenly screamed at me, you need to do something. I think that people come to a point where they say, I need to get some exercise.” EF participants also described a desire for activity that prompted them to join EF including one who said, "I retired...so I had to find something to do other than just sitting around the house.”

\section{Personal Factors}

Themes among personal factors that contributed to EF adherence included exercise identity and exercise history. In regards to exercise identity, EF participants do 
not necessarily see themselves as athletic or start the program with a strong exercise identity, but they described an enjoyment of movement. Exercise history varied among participants. Some participants described a history of participation in exercise such as walking, dancing, and attending the gym when they were younger. Others described a particular point in time when they decided to adopt exercise. One participant said, “Sometimes I was lazy and didn’t join a gym, but when I got in my 40s, I realized it was necessary and ever since then, I’ve exercised in some way.” Another participant explained "I think as folks get older and realize that with exercise they might live longer and have a better life, then they start to do some exercising.” Instructors also reported that some participants "haven’t necessarily moved in awhile” or did not exercise much before joining EF. Instructors perceived that some participants have a history of exercising, but for others, EF may be the first introduction to exercise.

A commonly reported past experience among participants was failure to exercise on a regular basis or to achieve results exercising alone. One participant said, "The doctor had told me you need to start exercising. I had tried on my own but it just didn’t work.” Participants reported continuing in the EF program because exercising in the class has helped them to achieve results that they were unable to achieve through attempts at independent exercise. Preference for the EF class over other types of exercise was also a common pattern in responses.

Beliefs (Behavioral, Normative, and Control)

Participants expressed several beliefs about exercise behavior, exercise norms, and behavioral control related to their adherence to EF. Themes among participant beliefs are listed in Table 5.1. Participants widely acknowledged that consistent attendance is 
beneficial. When asked why she attended consistently, one participant said, "this is the most important thing I do physically now.” Participants also expressed the behavioral belief that exercise is work. Many mentioned that attending EF can be difficult or painful but that it is worth it. One participant said, "You're breathing heavy, you're sweating. You might be a little sore one morning and it's a little pain...,but you know that it is a good ending. A good result and that's important.” They described the need to challenge oneself but also emphasized that having fun while exercising is positive. One participant commented about the class, “It's fun. We don’t take it seriously but yet the results are amazing.”

When asked about the exercise behaviors of older adults and requirements for exercise, participants had mixed views about whether most adults are exercising enough, but all reported a belief that exercise is important for older adults. One participant said, "I just know that old people should have some sort of physical activity.” Instructors also reported that participant recognition of the benefits of exercise is an important influence on continued attendance.

Some participants reported confidence in their ability to attend EF at the outset due to their strong motivation to get healthy and the ability to go at your own pace in the class. Other participants lacked confidence in their ability to participate in EF initially, but their perceived behavioral control improved over the course of participation. One participant described struggling with the chair stand exercise during the first few classes, but with the support of the instructor, he feels it is now just part of the exercise. Another participant said, “I wasn’t sure if I could attend..., so I watched one session and I decided yes I could do those things.” Instructors expressed that some participants believe they are 
unable do all of the exercises standing up, so the instructors make a point to explain that exercises can be done sitting down and they offer EF-approved modifications so that everyone can participate at their own ability level.

\section{Intentions}

Behavioral intentions are linked to likelihood of engaging in a behavior, so participants were asked about the attendance recommendations that they received and how often they planned to attend. Not all participants were explicitly told about the importance of attending the class at least two times per week in order to obtain benefits, but many were encouraged by the instructor to come to every class or to attend consistently. Some participants did not have a specific intention for how often or how long they would attend when they first joined. Others aimed to attend all three classes during the week and many reported rearranging their schedules and planning appointments around the class. One participant said, "I just accommodate my life to this class," and another explained, "Well what I did was when I saw that this class was probably the best thing for me and would give me all the benefits, I actually took my calendar and scratched out Mondays, Wednesdays, and Fridays until about 12:30 or 1 o'clock no other activities.” Some participants began the program with a sense of commitment to attending while others developed commitment to the program over time. Instructors perceived that participants' reasons for attending EF influence commitment and lead participants to schedule other activities around the class. When asked whether he encourages participants to attend a certain number of times per week, one instructor responded, "EF encourages and expects people to be there $75 \%$ of the time. Each class has three sessions, so everyone that is there is eligible to attend three times a 
week and that's what we would like to see. That's what the program is about. You do that regular exercise program, it's supposed to build your muscles, improve your balance and agility, and make you healthier.” All of the instructors reported encouraging participants to attend consistently which has the potential shape participant attendance intentions.

\section{Program Factors}

When asked about their views on the EF program, participants reported valuing the structure of the class. They commented on how well planned the program is and appreciated the routine of cardio, weights, and stretching. Participants reported satisfaction with the content of the classes commenting that the exercises "cover every part of your body" and "it's just what we need at our age.” Participants also reported liking the music played during class. Many participants also mentioned the evidence for the program and the program developers in Seattle, which revealed their awareness that the program was evidence-based and their recognition of the benefits of a carefully designed and tested program. Participants felt that the class was conveniently located. Some would prefer for the class to be held at a different time but explained that they have adjusted their schedules accordingly.

When instructors were asked about aspects of the EF program that influence adherence, three main themes emerged including exercising at one's ability level, EF as the only exercise needed, and the program structure (Table 5.1). Instructors described EF as providing a non-threatening environment where older adults can feel comfortable exercising at their own ability levels. One instructor stated, "If we see that someone is weak, there's a chair right next to them and they can still engage and do other things. There's always that inclusion. That word is so big. Inclusion, where a person feels that 
there’s just something for everybody.” Another instructor explained, “Here we have a group of people in about the same age range and we have health issues and we still can come here, get exercise, have fun, and go home.” While the no pressure environment is a positive aspect of the program, instructors also mentioned the challenges that come along with teaching older people with different abilities.

Instructors also described EF as a complete option for physical activity. One instructor said participants attend EF because "it encompasses a whole hour of functional fitness and everything that you would want in a class. They don't have to do anything other or more.” Other instructors agreed that attending EF provides sufficient physical activity.

The final instructor theme in relation to EF program factors was the program structure. The structure of the program was perceived as both a positive and negative feature. Instructors extolled the value of the evidence-base supporting the program and the effectiveness of the exercises. Instructors also emphasized participant enjoyment of the cardiovascular component of the program which allows the instructor to incorporate lively music and dancing. One instructor remarked, "anything that has to do with movement and dancing they just love.” However, the structure of the program, particularly the mandatory upper and lower body strength exercises were described as a “monotonous routine,” and instructors described challenges “trying to keep it fresh.” Although instructors described some of the program components as monotonous, they did not believe that monotony and boredom were strong reasons for non-adherence. 


\section{Social Factors}

The social aspect of EF was emphasized by all participants as a key to enjoyment and success in the program. Participants cited social benefits from attending the class including connection, camaraderie, and friendships. One participant explained that EF "gives the seniors something to look forward to and gets them out when they would be in the house alone.” Participants appreciate that the group challenges them and makes exercise fun. Participants explained that after attending repeatedly, they began to feel like part of the group and that they missed the group and were missed by the group when absent. Being part of the group contributed to their sense of accountability and provided motivation to continue attending.

Instructors also provided rich descriptions of the social aspects of EF. One instructor mentioned, "I can see the results for people and how they enjoy coming for the class and just enjoying the camaraderie of each other. Other instructors commented "an equal part of the activity is a social activity" and "in my class, the social component is a very strong to keep people involved.” Instructors shared that participants congregate before class, laugh together during the class, talk during breaks, and also attend gatherings coordinated by the instructor outside of class. Instructors described the EF class as becoming like an "extended family" and commented about participants, "They love one another. The hugging and carrying on that we see when they come together is amazing.”

In addition to social influence from EF classmates, participants described the instructor as a critically important influence on attendance. One participant described "a kind of psychological support and maybe a little bit of social pressure” that the instructor 
uses and found it to be helpful in encouraging attendance. Participants described the importance of the instructor's personality, knowledge, and understanding of the limitations of older adults. One participant said, "Probably the most influential is the instructor because when I've experienced subs it's very off-putting that they don't understand the limits of an older person's muscularity.”

Instructors were asked about the skills and characteristics needed to be successful as an EF instructor. Key characteristics included experience, personality, passion, understanding, and humor. The instructors did not necessarily have prior experience teaching fitness classes or working with older adults before becoming an EF instructor, but at that time of the study interview, all of the instructors had at least four years of experience teaching EF. Four of the instructors started EF as participants and became instructors.

Personality was also frequently cited as an influential instructor characteristic. Instructors said "there are many things that you can train someone but if that person isn't comfortable and you don't see that light and that personality come out from them, it could be very technical, cut dry and bland.” Other instructors described how instructing EF transformed their personalities, "I was always very introverted and to see me now in front of a class, you'd never think that. I have gone through this transformation over the years and part of that has been because of this class. I never thought I'd be doing anything like this before. I actually like myself better and I put myself out there.” Another instructor disclosed, “I’m a little shy, but with this group, we became like a family, so I was able to communicate with them and make it fun and make them want to tell a neighbor.” 
Whether instructors are outgoing or shy, they agreed that having a passion for working with older adults and interest in understanding them are essential instructor characteristics. They asserted, "You just have to be passionate about what you do. It shows," and "You gotta be friendly, motivated, willing to take time. The active adults like to be able to tell about their improvement and what the doctor is telling them and to keep up the good work, so they need to have a listening ear. You have to treat them as if they were family. That works here for me. Basically you have to love what you're doing.” Instructors described being vested, accessible, and interested in the experiences of participants. Finally, instructors emphasized the importance of using humor and making the class fun. Instructors described EF as having a "fun factor" and explained “it’s not a humdrum exercise program. We're having fun in the process.” One instructor added, "I think it also helps if you're funny and if you can inject humor into situations.” They explained that they make an effort to make the class fun so that people look forward to attending.

Another common social influence described by both participants and instructors was staying in contact (Table 5.1). Participants said they are expected to inform the instructor if they will be absent and that this expectation contributed to their conscientiousness about consistent attendance. Participants said that if someone was absent for more than a few classes, the instructor or classmates would reach out to check in and encourage them to return. The social support of classmates and knowledge that people in the class cared about them encouraged participants to continue attending. One participant said, "I remember when I was ill, I kept getting notes from members and that they missed my attendance and when I returned, I felt humbled by the response.” Another 
person explained, "If one person is sick, then we will get cards, we will find them, and we will check in on each other...we've developed family.” All of the instructors also described the importance of keeping in touch and said that they check in on participants if they are absent and encourage them to return.

The final theme among social influences described by participants was support from their doctors. Participants explained how doctor recommendations prompted participation, and supportive attitudes of doctors towards EF also increased their confidence and motivation for attending. Instructors also mentioned that many participants began attending because their doctors recommended more exercises but did not describe doctors as influencing continued attendance.

Benefits

In addition to the social benefits reinforcing EF attendance, participants described numerous health outcomes that reinforce attendance as listed in Table 5.1. Many of the participants had joined EF for health reasons and reported experiencing the health benefits that they had hoped to achieve. When asked about the benefits of EF, participants mentioned improvements in a number of chronic disease risk factors and indicators including blood pressure, weight, A1C levels, and blood sugar. They also reported increased energy and pain relief. One participant said, "I've had lower back problems and I've tried everything I can. Chiropractors, etcetera, massages, all kinds of ointments. Nothing worked like this class.”

Other physical outcomes include increased mobility, balance and strength and improved overall fitness. Participants commented on the importance of seeing their improvement on fitness checks, which are brief instructor administered fitness tests that 
are prescribed to be conducted every four months. The fitness checks are conducted using the functional fitness test battery developed by Rikli and Jones and provide a measure mobility, arm strength, and leg strength (Rikli \& Jones, 1999). Participants also reported mental health benefits, stress relief, and feeling better in general. Some participants did not see physical benefits of the program right away, but their enjoyment of the exercises and the social environment of the class kept them coming back and they later started to experience positive health outcomes.

In addition to the social and physical outcomes experienced, participants described the enjoyment of attending EF to be reinforcing in itself. One participant said, "I love that class. I can't wait to get to it three times a week." When asked what keeps her coming back to EF class after class, another participant responded "I like the way it makes me feel so that's why I try to get there as often as I can.” In addition to enjoyment of the class content and exercises, participants also emphasized that they look forward to attending because they enjoy the company of the group and the instructor.

Instructors shared a wide range of benefits that they had observed in participants or that participants had reported in class (Table 5.1). Descriptions of outcomes centered on health improvements such as improved balance, weight loss, and reduced frailty. Instructors said that participants reported lower blood pressure and cholesterol, fewer doctor visits, and some were even taken off of medications. Instructors also noted improvements on fitness checks which are prescribed to be conducted every four months to track changes in functional fitness through the performance of three timed physical tests. 
In addition to improvements in physical health, instructors described participants as "feeling good" as a result of attending. One instructor explained, "the biggest thing with coming to the class is you leave better than you came. A lot of people because of what they may be going through because of their age, they feel down, so when they come in the class and they say because of you joking with us... I feel better when I leave than when I come.” When asked about what keeps participants coming back, another instructor stated, “When I walk out of class, I feel good. I'm 'complaining' and moaning to myself on the way to class, but when I walk out of class, I feel better. I feel good. So I think they get that feel good attitude.”

Instructors also described the pride that participants feel in receiving positive comments from their doctors, sharing testimonials with the class, and also in being able to do more things as a result of EF. One instructor provided an example, "Some of them might have worked a car wash over the weekend and outlasted the younger generation or worked 8 hours. You realize they didn’t realize how strong they were and now they have all this endurance and aerobic threshold, so I'm proud and so excited for them.”

\section{Adherence as Process}

After examining the various factors that participants discussed in relation to adherence and the relationships between factors, a model was developed to illustrate a process by which the participants achieved long-term adherence (Figure 1). Participants all have a personal exercise history and identity and beliefs about exercise. A cue to action activates or changes beliefs which in turn influence motivations and intention to attend EF. Participants also have goals that they hope to achieve by attending EF. The importance or significance of these goals has the potential to influence the strength of the 
intention. A combination of social factors and program factors influence the actual experience of attending EF and beliefs about attending. Benefits experienced as a result of attending EF feed back into beliefs and goals related to EF attendance thereby strengthening intention to attend and leading to repeated attendance. After attending consistently over time, participants reported that EF became a part of themselves and their lives.

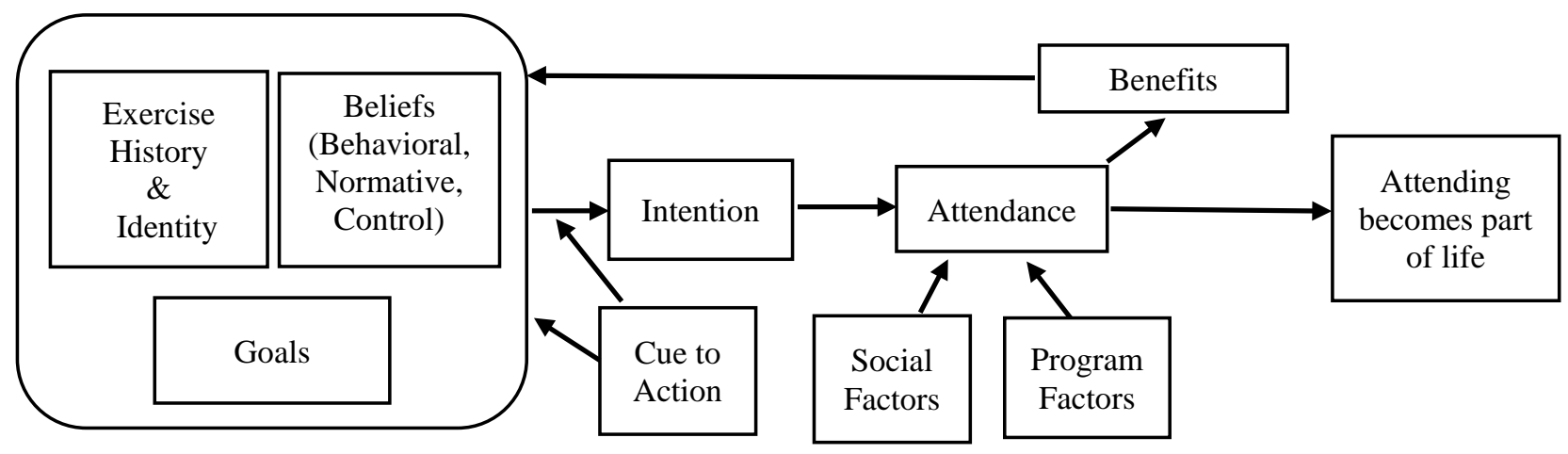

When asked why participants continue attending consistently, they said things like, “it’s just a part of me now" and "it’s a way of life.” Participants take pride in attending consistently, see themselves as part of the group, and explained that they dislike missing class and truly miss the experience and the group when they are absent. Being a member of the EF class and attending consistently becomes part of their identities.

\section{Barriers to Adherence}

Participants and instructors mentioned several factors that could prevent someone from adhering to EF attendance recommendations. These factors could interrupt the adherence process at various points. As shown in Table 5.2, common barriers to adherence perceived by participants included health issues, serious life events, caregiving 
responsibilities, and family issues. Doctor appointments also led some participants to miss class. Some participants live in Florida seasonally or travel frequently which interferes with consistent attendance. Laziness was seen by some participants as a potential barrier but others disagreed.

Table 5.2 Themes Among Barriers to Adherence

\begin{tabular}{|c|c|c|}
\hline & EF Participant Themes & EF Instructor Themes \\
\hline Barriers & $\begin{array}{l}\text { - Health Issues } \\
\text { - } \text { Serious life events } \\
\text { - } \text { Caregiving } \\
\text { - } \text { Family issues } \\
\text { - } \text { Travel or season residence } \\
\text { - } \quad \text { Paziness } \\
\quad \text { exercise } \\
\text { - Class perceived as not being } \\
\text { serious enough }\end{array}$ & $\begin{array}{ll}\text { - } & \text { Health issues } \\
\text { - } & \text { Appointments } \\
\text { - } & \text { Caregiving } \\
\text { - } & \text { Grieving } \\
\text { - } & \text { Travel or seasonal } \\
& \text { residence }\end{array}$ \\
\hline
\end{tabular}

Preference for other types of exercise and lack of fit with the group were offered as potential explanations for dropout. One participant explained that “My neighbor didn’t like the class. He thought we weren’t serious enough.” Participants mentioned “joking around," "silliness," and having fun with the exercises, so people who would prefer to focus intensely and be serious while exercising may not enjoy the social aspect of the EF class. Another participant said, “The results are amazing but I don’t know if probably a 30 year-old or a 40-year old went in there with obviously much more physical capabilities, they would probably say they're bored and it's not enough, but for me, it's enough.” Although the class is designed for older adults, if an advanced participant is not challenged by the class or does not enjoy the social environment, they may be unlikely to receive the physical or social benefits or the sense of belonging that were reported to be important for adherence. 
Instructor accounts of reasons for non-adherence revealed six main barriers:

health issues, appointments, caregiving responsibilities, grieving, and absence due to travel or seasonal residence in Florida (Table 5.2). The health issues described included illnesses that required time away from class and injuries or illnesses that led doctors to order the participants to stop attending. Instructors noted that the people in the age group have a lot of appointments that can interfere with adherence but that many participants make a conscious effort to schedule around the EF class time. Many older adults are responsible for caring for grandchildren or other ill family members which can disrupt their schedules. Due to the age of EF participants, experiencing the death of family members and friends is a common occurrence which can lead to grief that permeates their lives and alters their priorities. Many of the participants are retired, so travel and seasonal residence are also factors that instructors explained can influence attendance among this population. Less commonly cited reasons for nonadherence included laziness, soreness, transportation, and trying other programs.

\section{Strategies to Improve Adherence}

Table 5.3 Themes Among Strategies Suggested to Improve Adherence

\begin{tabular}{|c|c|c|}
\hline & EF Participant Themes & EF Instructor Themes \\
\hline Strategies & $\begin{array}{ll}\text { - } & \text { Add variety } \\
\text { - } & \text { Remove fees } \\
\text { - } & \text { Adjust class schedule }\end{array}$ & 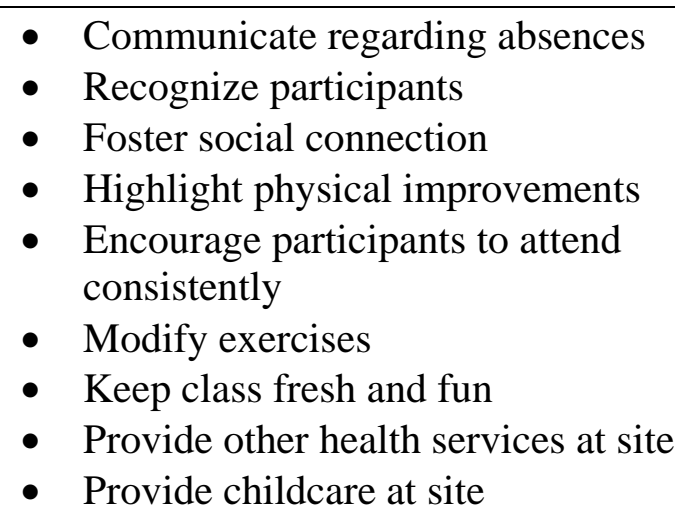 \\
\hline
\end{tabular}


Strategies suggested by participants to improve adherence include adding more variety to the class to keep in interesting, removing fees, and adjusting the class schedule. Ash shown in Table 5.3, instructors described several strategies that they use to encourage attendance. Instructors communicate with participants who are absent for more than a few classes to check on them, let them know that someone cares, and encourage them to return when they are able. Instructors recognize participants by congratulating them on making the effort to come to class and one instructor even awards certificates to participants who achieve perfect attendance each month. Instructors emphasize the health benefits of attending by creating graphs or charts showing individual participants their improvements on fitness checks over time.

To build confidence and prevent participants from feeling like the class is too challenging, instructors described modifying exercises and not having participants use weights until they feel comfortable with the movements. Instructors express to participants the importance of attending consistently and encourage participants to come to class even if they need to do less on a given day or exercise at a slower tempo or without weights. Efforts to keep the class fresh and fun were also described as important for keeping participants interested and challenged. Instructors expressed that EF should not just be about exercise and emphasized fostering a social environment in class and organizing social gatherings outside of class. Finally, instructors suggested offering other health services at the class sites to make attending even more beneficial and offering staff for childcare so that grandparents who are responsible for their grandchildren are able to attend EF. 


\section{Discussion}

The purpose of this qualitative study was to explore the perspectives of older adults who had adhered to the program for at least one year and EF instructors who had been leading classes in a variety of community-based settings with diverse older adults in order to improve understanding of factors influencing participant adherence and to identify strategies to support adherence. An extended theory of planned behavior framework guided the exploration of influential factors. Overall, the factors included in the initial framework were all reported by participants to play a role in adherence but were found to connect through a different process than expected, and other important themes emerged. The findings from interviews with EF instructors provide evidence for a variety of factors associated with adherence to exercise among diverse older adult participants that have been documented in the literature among other populations. Findings revealed goals of EF participation, cues to action, personal factors, program factors, social factors, benefits, and barriers that influence participant adherence to EF. The facilitators and barriers will be discussed in relation to the theory of planned behavior and previous research. Instructors explained several strategies that they have used or would suggest to encourage adherence. Based on the facilitators and barriers to adherence that the participants and instructors described, additional strategies are also recommended throughout the discussion.

The finding that EF participants were prompted to join for health reasons is supported by another study that found the primary reason for enrolling in an exercise program was for perceived health benefits (Canuto et al., 2013). Instructors’ perceived participant motivations for attending EF included improving or maintaining physical 
health and desire for activity. Another study with EF participants also found support for expected physical benefits as a motivation for joining the program (Kohn, Belza, Petrescu-Prahova, \& Miyawaki, 2016). Doctor encouragement of exercise has also been supported as a motivator of exercise in a quantitative study of determinants of ongoing participation in EF (Gillette, Petrescu-Prahova, Herting, \& Belza, 2015).

Although improving or maintaining health was the primary reason for joining EF among participants in this study, many participants reported that their adherence was supported by the social aspects of the class and the connections with other members. Ethnic older adults participating in EF in Seattle also cited the importance of social support as a reason that they looked forward to attending and reported that their commitment to attending was increased by the enjoyment of the class (Chiang et al., 2008). A study of older adult men's experiences with community- based group exercise found that some participants saw the class as a social activity with the opportunity for exercise whereas others saw the class as an exercise activity with the opportunity to socialize and that this divergence was perceived to be problematic (Dunlop \& Beauchamp, 2013). Participants in the current study also reported that some participants did not view the class as serious or challenging enough and dropped out or switched to another class.

The social aspect of community-based group exercise programs has been consistently reported as an important factor influencing adherence (Chiang, Seman, Belza, \& Hsin-Chun Tsai, 2008; Killingback et al., 2017 Dunlop \& Beauchamp, 2013). A review of studies examining adherence to community based group excise programs found that all five qualitative studies on the topic reported belongingness, demographic 
similarity, opportunities for socializing, and support as determinants of adherence (Farrance et al., 2016). In this study, instructors described the camaraderie and the sense of family that develops among people in the program which leads them to look forward to attending.

Other research has found that participants join EF to get out of the house and desire for a social environment (Kohn et al., 2016). The current study reveals that retired older adults may experience a physical and mental urge for activity after a prolonged amount of time spent sitting around at home. This finding ties in with the life course perspective which suggests that transitions such as retirement are an opportunity for positive or negative changes in physical activity and provide an ideal time for interventions (Hirvensalo \& Lintunen, 2011). Given the importance of staying active and engaged following retirement, additional research should be done to improve understanding of the process that leads retired older adults to desire activity and how to convert the need for activity into action.

Participants and instructors described the importance of the social environment of the class, but participants explained that some people do not enjoy the amount of socializing and joking that goes on in class. Taken together, these findings suggest that while instructors and program developers should continue to encourage social connection and fun to support adherence, it is important to make an effort to engage participants who want to be challenged and maintain their focus on the exercises. The other conclusion from these findings is simply that the not all group exercises classes will be a good fit for everyone. In a qualitative study of physical activity program uptake among older adults, dislike of group activities and desire for more variation in exercises were barrier to 
participation in EF or SilverSneakers classes (Bethancourt, Rosenberg, Beatty, \& Arterburn, 2014). Also, the particular tone of the class is influenced by instructors and the participants and may not be enjoyed by everyone. Some older adults may find more success exercising on their own or in unstructured forms of physical activity.

Instructors viewed EF program factors as supportive of adherence because the non-threatening environment and modifiable program content allow participants to exercise at their own ability levels. In terms of the theory of planned behavior, these aspects of the program improve perceived behavioral control. Previous research has also found that participants attending other community-based exercise programs appreciated adaptable exercise content and being able to exercise without judgment (Killingback et al., 2017; Dunlop \& Beauchamp, 2013). The finding that EF instructors view the program as the only exercise needed is in line with views reported by participants including that EF addresses every part of the body is and is well matched to the exercise needs of the age group (Anderson, Seff, Batra, Bhatt, \& Palmer, 2016). The fact that EF is designed specifically for older adults and is evidence-based is widely acknowledged as an advantage of the program, but this study highlights the need to be mindful about adding variety within the program structure and making the class fun to keep participants engaged.

Participants explained how much the instructors contributed to their enjoyment of the class and that the instructors' understanding of older adults was critically important. The influence of high quality instructors is evident in other qualitative studies of adherence to exercise programs for older adults. These studies reported common characteristics of instructors including being enthusiastic, making exercise fun, and 
enjoying working with older adults. (Killingback et al., 2017; Hawley-Hague, 2016; Chiang et al., 2008, Dunlop \& Beauchamp, 2013). The quality and behavior of instructors have the potential to influence participants' attitudes and adherence to group exercise programs (Hawley-Hague et al., 2014; Seguin et al., 2010; Chiang et al., 2008; Estabrooks et al., 2004). Previous studies have explored participants’ perceptions of desirable instructor characteristics, but limited literature exists on instructors’ perspectives of the approaches that contribute to successful classes and participant adherence. Instructors teaching exercise programs in England said that they encouraged commitment to attending by staying in touch with participants and building cohesion (Hawley-Hague et al., 2016). Similarly, EF instructors in this study acknowledged the impact of contacting participants when they are absent in order to support them in returning to class and building social connection by organizing social gatherings.

In addition to social factors supporting adherence, participants also noted that the benefits that they experienced motivated them to continue attending. Participants reported that attending EF led to health improvements, social benefits, and feeling good overall. The goals of participation reported by adherent EF participants and instructors match up with the actual benefits that participants experienced. Many of the participants had experienced health issues themselves or observed the health issues of others, and joined EF with the expectation that participation in the class would improve or maintain their health. According to the theory of planned behavior, behavioral beliefs are an important influence on behavior that reflect anticipated outcomes of the behavior, so the positive outcomes resulting from EF strengthened behavioral beliefs that supported continued attendance (Ajzen, 1991). Goal setting has the power to strengthen intentions, so it is 
worth conducting additional research to explore whether the types of goals that participants have and explicit goal setting influence adherence to evidence-based group exercise programs like EF.

For adherent EF participants, intention to attend EF was initially prompted by a cue to action along with personal factors and beliefs about exercise. A combination of program factors, social influences, and benefits led to repeated attendance. As consistent attendance continued, participants came to feel like part of the group and the class became an important part of their lives. The finding from this study that EF becomes an important part of participants' lives and identities can be understood through the lens of identity theory and by looking at other research that has examined identity in relation to health behavior. Identity theory explains that when people endorse a particular identity, they behave in ways that are consistent with that identity. Strachan and colleagues (2015) conducted a study with undergraduate students to examine exercise identity, selfregulatory efficacy, and exercise behavior. The study found that students who had a stronger exercise-related identity had a higher likelihood of exercising and exercised more consistently (Strachan et al. 2015). Students with a strong exercise identity also had greater confidence to overcome barriers and plan their exercise which helped them to be more active (Strachan et al., 2015). EF participants in the current study did not necessarily enter the program with a strong exercise identity, but over the course of attending the program, their identities as EF class members and consistent attenders developed and strengthened. EF participants view the class as one of the most important things they do and plan their schedules around class. For adherent EF participants, attending EF feels good and they feel upset when they miss class. 
Participants suggested a limited number of strategies for improving adherence, but in the discussion of reasons for not adhering, a theme of temporary lapses in attendance and return to class was revealed. The attendance lapses described were often due to health issues or responsibilities such as caregiving. These causes of the lapses are not factors that can be easily modified, so strategies to encourage return after lapse are suggested as a target for interventions to improve long-term adherence. Participants reported that contact from the instructor and knowing that other people in the class care about them is meaningful and can encourage people to return to EF after a lapse.

In addition to the strategies to promote adherence that were explicitly recommended by instructors, a few other strategies are suggested based on the facilitators and barriers that instructors described. It is clear from the current findings and previous research that instructors can influence older adults' attitudes and adherence, so organizations should recruit instructors who have an interest in understanding older adults, a passion for working with them, and the ability to make exercise lighthearted and fun (Hawley, Skelton, Campbell, \& Todd, 2012).

Instructors highlighted the importance of doctor recommendations for exercise and positive feedback that participants received from doctors regarding the health improvements obtained from EF. These findings suggest that engaging healthcare providers would be a promising way to promote adherence to the program. A few instructors also reported that doctors had instructed some participants to stop attending EF due to injuries or illnesses, so engaging healthcare providers could also help to ensure that the providers understand how EF works and support participants in returning to class if their health condition allows. 
Loss and grief were mentioned as common issues that older adults deal with that can lead to missed classes. Referring participants to mental health providers or programs could help to ensure that participants have the skills to cope with loss and continue engaging in the activities that they enjoy. Bereavement in older adulthood has been associated with negative health outcomes such as decreased physical health, depressive symptoms, higher mortality risk, increased medication use, and higher rates of disability (Elwert \& Christakis, 2006). Physical activity can reduce the risk of all of these negative health outcomes, so educating participants on the risks of bereavement and the benefits of physical activity could lead them to see how exercise can help the grieving process.

Notable new themes identified from instructor perspectives on adherence included the importance of incorporating humor into classes, encouraging participants to attend even if they need to do less than normal or to modify exercises, and grief as a barrier to adherence and possible target for interventions to promote adherence.

\section{Strengths and Limitations}

The qualitative approach helped to access participant and instructor experiences with EF and their perspectives on strategies for promoting adherence. The sample size for this study is small even for qualitative research, but even though it cannot be claimed that saturation was achieved, the focused dialogue, use of established theory, and specific sample selection provided sufficient information power to achieve the aims of the study (Malterud, Siersma, \& Guassora, 2016). Outcomes of the analysis of this set of interviews do not provide a complete description of all factors influencing adherence to EF for all participants, but the themes identified provide meaningful insights to guide strategies to improve the program and long-term adherence. 
Including the perspective of EnhanceFitness instructors working with racially and ethnically diverse older adult participants in Florida strengthened the study findings of factors influencing participant adherence and strategies to support adherence. Another strength of the study was the use of a theoretical framework which provided an organizational structure to think about the data and emerging themes in a focused way. The theoretical framework also supported the consideration of relationships between factors and led to the discovery of a process that underlies adherence to EF.

While participants in the study were diverse, the sample size was too small to stratify analysis of themes by gender, ethnicity, or age. The sample consisted of participants who were adherent and happy with the program, so dropouts and nonadherent participants should be consulted to improve understanding of reasons for nonadherence and to identify additional strategies to improve adherence. Participants and instructors self-selected into the study, so it is possible that those who did not agree to participate may have shared different perspectives.

\section{Conclusion}

This study provides insight into the factors influencing adherence to EnhanceFitness from the perspective of EF participants and instructors. These findings can help health professionals, program developers, and organizations offering exercise programs to develop strategies related to influential factors in order to improve long-term adherence and maximize the impact of community-based exercise programs for older adults. Future research should examine the process of long-term adherence among other populations and test strategies to encourage adherence following a lapse in attendance. 


\section{References}

Ackermann, R. T., Cheadle, A., Sandhu, N., Madsen, L., Wagner, E. H., \& LoGerfo, J. P. (2003). Community exercise program use and changes in healthcare costs for older adults. American Journal of Preventive Medicine, 25(3), 232-237.

Ajzen, I., \& Fishbein, M. (2005). The influence of attitudes on behavior. In D. Albarracín, B. T. Johnson, \& M. P. Zanna (Eds.), The handbook of attitudes (pp. 173-221). Mahwah, NJ: Erlbaum.

Ajzen, I (1991). The theory of planned behavior. Organizational Behavior and Human Decision Processes, 50(2):179-211.

Anderson, C., Seff, L., Batra, A., Bhatt, C., \& Palmer, R.C. (2016). Recruiting and Engaging Older Men in Evidence-Based Health Promotion Programs: Perspectives on Barriers and Strategies. Journal of Aging Research. Available at http://dx.doi.org/10.1155/2016/8981435

Batra, A., Coxe, S., Page, T.F., Melchior, M., Palmer, R.C. (2016). Evaluating the factors associated with the completion of a community-based group exercise program among older women. Journal of Aging and Physical Activity, 24(4), 649-658.

Bethancourt, H.J., Rosenburg, D.E., Beatty T., \&Arterburn, D.E. (2014). Barriers to and facilitators of physical activity program use among older adults. Clinical Medicine \& Research, 12(1-2), 10-20.

Braun, V., \& Clarke, V. (2005). Using thematic analysis in psychology. Qualitative Research in Psychology, 3(2), 77-101. doi: 10.1191/1478088706qp063oa

Belza, B., Shumway-Cook A., Phelan, E. A., Williams, B., Snyder, S. J., \& LoGerfo, J. P. (2006). The effect of a community-based exercise program on function and health in older adults: The EnhanceFitness program. Journal of Applied Gerontology, 25, 291-306. doi:10.1177/gbh0733464806290934

Canuto, K.J., Spagnoletti, B., McDermott, R.A., \& Cargo, M. (2013). Factors influencing attendance in a structured physical activity program for Aboriginal and Torres Strait Islander women in an urban setting: a mixed methods process evaluation. International Journal for Equity in Health, 12, 11. doi: 10.1186/1475-9276-12-11

Chiang, K., Seman, L., Belza, B., \& Hsin-Chun Tsai, J. (2008). "It is our exercise family Of ethnic older adults in a group-based exercise program. Preventing Chronic Disease, 5(1). http://www.cdc.gov/pcd/issues/2008/jan/06_0170.htm.

Creswell, J. W. (1994). Research design: Qualitative and quantitative approaches. Thousand Oaks, CA: Sage. 
Denzin, N.K. (2012). Triangulation 2.0. Journal of Mixed Methods Research, 6(2), 80-88. doi: $10.1177 / 1558689812437186$

Dunlop,W.L., Beauchamp, M.R., 2013. Birds of a feather stay active together: a case study of an all-male older adult exercise program. Journal of Aging and Physical Activity, 21(2), 222-232.

Ecclestone, N.A., \& Jones, C.J., (2004). International Curriculum Guidelines for Preparing Physical Activity Instructors of Older Adults, in Collaboration with the Aging and Life Course, World Health Organization. Journal of Aging and Physical Activity, 12(4), 467-479. https://doi.org/10.1123/japa.12.4.467

Elwert, F. \& Christakis, N.A. (2008). The effect of widowhood on mortality by the causes of death of both spouses. American Journal of Public Health, 98 (11). 2092-2098. doi: 10.2105/AJPH.2007.114348

Estabrooks, P.A., Munroe, K.J., Fox, E.H., Gyurcskik, N.C. (2004). Journal of Aging and Physical Activity, 12(3), 232-245. https://doi.org/10.1123/japa.12.3.232

Farrance, C., Tsofliou, F., \& Clark, C. (2016). Adherence to community based group exercise interventions for older people: A mixed-methods systematic review. Preventive Medicine, 87, 155-166.

Friese, S (2012). Qualitative Data Analysis with ATLAS.ti. London: Sage.

Gillette, D.B., Petruscu-Prahova, M., Herting, J.R., \& Belza, B. (2015). Journal of Geriatric Physical Therapy, 38(4), 194-201. doi:10.1519/JPT.0000000000000041

Glasgow, R.E.,Vogt, T.M., \& Boles, S.M. (1999). Evaluating the public health impact of health promotion interventions: the RE-AIM framework. American Journal of Public Health, 89(9), 1322-1327.

Guest, G., Bunce, A., \& Johnson, L. (2006). How Many Interviews Are Enough? An Experiment with Data Saturation and Variability. Field Methods, 18(1), 59-82. doi: 10.1177/1525822X05279903

Hallal, P.C., Andersen, L.B., Bull, F.C., Guthold, R., Haskell, W., \& Ekelund, U. (2012). Global physical activity levels: surveillance progress, pitfalls, and prospects. Lancet, 380(98398), 247-257. doi: 10.1016/S0140-6736(12)60646-1

Hawley, H., Skelton, D.A., Campbell, M., \& Todd, C. (2012). Are the attitudes of exercise instructors who work with older adults influenced by training and personal characteristics? Journal of Aging and Physical Activity, 20, 47-63. 
Hawley-Hague, H. Horne, M., Campbell, M., Demack, S., Skelton, D.A., \& Todd, C. (2013). Multiple levels of influence on older adults attendance and adherence to community exercise classes. The Gerontologist. doi:10.1093/geront/gnt075

Hawley-Hague, H., Horne, M., Skelton, D.A., \& Todd, C. (2016).Older adults’ uptake and adherence to exercise classes: Instructors' perspectives. Journal of Aging and Physical Activity, 24(1):119-28.

Hirvensalo, M. \& Lintunen, T. (2010). Life-course perspective for physical activity and sports participation. European Review of Aging and Physical Activity. doi: 10.1007/s11556-010-0076-3

Hughes, S.L., Seymour, R.B., Campbell, R.T., Whitelaw, N., Bazzarre, T. (2009). American Journal of Public Health, 99(2), 362-368. doi: 10.2105/AJPH.2007.131466

Killingback, C., Tsofliou, F., \& Clark, C. (2017). Older people’s adherence to community-based group exercise programmes: a multiple-case study. BMC Public Health, 17, 115. doi: 10.1186/s12889-017-4049-6

Kohn, M., Belza, B., Petrescu-Prahavo, M., \& Miyawaki, C.E. (2015). Beyond Strength Participant Perspectives on the Benefits of an Older Adult Exercise Program. Health Education \& Behavior, 43(3), 305-312. doi: 10.1177/1090198115599985

Malterud, K., Siersma, V.D., \& Guassora, A.D. (2016). Sample Size in Qualitative Interview Studies: Guided by Information Power. Qualitative Health Research, 26(13), 1753-1760.

Milne, S., Orbell, S., Sheeran, P. (2002). Combining motivational and volitional interventions to promote exercise participation: protection motivation theory and implementation intentions. British Journal of Health Psychology, 7(Pt2), 163-184.

Moran-Ellis, J., Alexander, V.D., Cronin, A., Dickinson, M., Fielding, J., Sleney, J., \& Thomas, H. (2006). Triangulation and integration: processes, claims and implications. Qualitative Research, 6(1), 45-59. doi: 10.1177/1468794106058870

Palmer, R.C., Batra, A., Anderson, C., Page, T., Vieira, E., \& Seff, L. (2016). Implementation of an Evidence-Based Exercise Program for Older Adults in South Florida. Journal of Aging Research, 2016, Article ID 9630241. http://dx.doi.org/10.1155/2016/9630241

Rosenstock, I. M. (1990). The health belief model: Explaining health behavior through expectancies. In K. Glanz, F. M. Lewis, \& B. K. Rimer (Eds.), The Jossey-Bass health series. Health behavior and health education: Theory, research, and practice (pp. 39-62). San Francisco, CA, US: Jossey-Bass. 
Saldana, J. (2009). The Coding Manual for Qualitative Researchers. London: Sage.

Seguin R., Economos C., Palombo R., Hyatt R., Kudar J., Nelson M. (2010). Strength training and older women: A cross-sectional study examining factors related to exercise adherence. Journal of Aging and Physical Activity, 18, 201-218

Seidel, J (1998) Qualitative Data Analyisis. The Ethnograph v5 Manual, Appendix E. Retrieved from http://www.qualisresearch.com/

Sheeran, P. (2002). Intention-Behavior Relations: A Conceptual and Empirical Review. European Review of Social Psychology, 12(1), 1-36. doi: 10.1080/14792772143000003

Signal, N., McPherson, K. M., Lewis, G., Kayes, N., Saywell, N., Mudge, S., \& Taylor, D. (2016). What influences acceptability and engagement with a high intensity exercise programme for people with stroke? A qualitative descriptive study. NeuroRehabilitation. doi: 10.3233/NRE-161382

Strachan, S.M., Brawley, L.R., Spink, K.S., \& Glazebrook, K. (2010). Older adults’ physically-active identity: Relationships between social-cognitions, physical activity and satisfaction with life. Psychology of Sport and Exercise, 11, 114121. doi:10.1016/j.psychsport.2009.09.002

U.S. Department of Health and Human Services (2008). 2008 Physical Activity Guidelines for Americans. Retrieved from https://health.gov/paguidelines/pdf/ paguide.pdf

Vallance, J.K., Murray, T.C., Johnson, S.T,, Elavsky, S. (2011). Understanding physical activity intentions and behavior in postmenopausal women: an application of the theory of planned behavior. International Journal of Behavioral Medicine, 18(2), 139-149. doi: 10.1007/s12529-010-9100-2

Wallace, J.I., Buchner, D.M., Grothaus, L. Leveille, S., Tyll, L., LaCroix, A.Z., \& Wagner, E.H. (1998). Implementation and effectiveness of a community-based health promotion program for older adults. Journal of Gerontology: Medical Sciences, 53a(4), M301-M306. 


\section{Chapter VI: Conclusion}

As chronic disease prevalence, healthcare costs, and the older adult population increase, strategies to promote healthy aging and reduce healthcare costs grow in

importance. Evidence-based programs (EBPs) are demonstrated to improve health and to reduce disease, disability, and injuries among older adults (USDHHS:ACL, 2018). EBPs also decrease the need for medical care and in turn reduce healthcare costs. The availability and implementation of scientifically backed health promotion and disease prevention programs for older adults has grown significantly since the early 2000s with the support of national, state, and local healthy aging initiatives (Boutaugh \& Lawrence, 2014). The growing popularity of EBPs and limited funds for programs provide motivation for the aging service network and the public health workforce to improve understanding, promotion, and implementation of EBPs for older adults so that the programs have the greatest impact.

The Health Foundation of South Florida created the Healthy Aging Regional Collaborative in 2008 to make EBPs accessible to the more than 800,000 residents of Miami-Dade, Broward, and Monroe counties ages 60 and older. The HARC selected EBPs to address four main threats to healthy aging including physical inactivity, chronic illness, injuries from falls, and depression. The EBPs selected by HARC have been endorsed by the Administration for Community Living, the National Council on Aging, and the Centers for Disease Control and Prevention. EBPs offered by HARC member agencies included EnhanceFitness (EF), Chronic Disease Self-Management Program CDSMP), Diabetes Self-Management Program (DSMP), Matter of Balance (MOB), Healthy IDEAS (HI), and Walk With Ease (WWE). 
The HARC's Year 5 evaluation report covering 2008 through 2013, showed that the HARC served a total of 35,688 participants in 420 unduplicated sites. Forty-two percent of participants were Hispanic/Latino, 35\% were white, $17 \%$ were black, $4 \%$ were Haitian or other Non-Hispanic Caribbean, and the remaining 2\% identified their race/ethnicity as other. Across all of the EBPs implemented by HARC, participants who completed the recommended number of sessions reported increases from pre-test to posttest in health behaviors and skills (Palmer et al., 2016; Melchior et al., 2014; Batra et al., 2012).

From the 5-year HARC evaluation, two main areas for improvement were identified in relation to program reach and implementation that have the potential to influence the public health impact of the EBPs. First, only 19\% of participants reached across all programs were male. This finding indicates that men were underserved by HARC programs when compared to their representation in the 2010 United States Census data. Males made up $44 \%$ of the population age 60 and older across the three counties served by HARC (U.S. Census Bureau, 2015). The underrepresentation of men in evidence-based health promotion programs is a common and significant issue (Ory et al., 2015; Smith et al., 2012). Scientific evidence demonstrates that gender differences exist in health behaviors, but it is not clear why men are less likely than women to participate in EBPs (Courtenay, 2000). The first aim of this dissertation was to address this gap in the literature by exploring program coordinator and instructor perspectives on the barriers to male participation in the EBPs offered by the HARC in south Florida and strategies to improve male participation. 
The second opportunity for program improvement identified during the HARC evaluation relates to implementation. Fidelity monitoring observations indicated that the program content was delivered as the developers intended, but participants must also receive the recommended dose of a program in terms of attendance in order to have the best chance of experiencing the intended outcomes of the programs (Cross \& West, 2011; Frank, Coviak, Healy, Belza, \& Casado, 2008; Ackerman et al., 2003). The percentage of participants meeting the program developers' attendance recommendations were high for the self-management and falls prevention programs, but surprisingly low among participants of the ongoing physical activity program EnhanceFitness. Among CDSMP and DSMP participants, $76 \%$ to $84 \%$ attended at least four of the six workshop sessions, and $82 \%$ of MOB participants attended at least 5 of the 8 workshop sessions. For the ongoing program EnhanceFitness that is offered three times per week, only $25 \%$ attended at least thirty-two sessions within the first sixteen weeks of participation (Palmer et al., 2016).

In one study of EF offered three times a week at congregate meal sites, participants who attended fewer than 32 sessions within the first 4 months did not show a significant difference in performance measures from baseline to 4-month follow up, whereas participants who attended 32 or more sessions showed significant improvements in measurements of functional fitness (Belza. et. al, 2010). Women who attended at least 32 sessions during the first 4 months of EF classes offered by the HARC showed improvements that were nearly twice as great as women who attended fewer than 32 sessions (Batra, Coxe, Page, Melchior, \& Palmer, 2016). In another study on the effect of EnhanceFitness participation on healthcare costs, Ackermann and colleagues (2003) 
found that attending an average of once per week for the first year of participation was necessary in order to observe a significant reduction in healthcare utilization and costs.

While a wide range of factors influencing adherence have been documented in the literature, limited evidence is available on long term-adherence and few studies incorporate the views of program instructors and participants to identify the reasons that participants adhere (Farrance, Tsofliou, \& Clark, 2016). In response to this gap in the literature and the low adherence rate observed among EF participants, a mixed methods study was designed with an emphasis on qualitative design. This segment of the dissertation aimed to examine predictors of short-term and long-term adherence to the EnhanceFitness exercise program among diverse HARC participants and explore the experiences and perspectives of EF participants and who had adhered to the program for at least one year and the perspectives of EF instructors working with racially and ethnically diverse participants to understand the factors and processes supporting adherence and identify strategies to support adherence.

\section{Facilitators and Barriers to Male Participation}

Fourteen program coordinators participated in a focus group to identify barriers and strategies to improve male participation, and 49 instructors participated in a survey to triangulate the findings. Themes among barriers to male participation included women outnumbering men in the implementation sites and programs, conflict between male gender roles and the programs, and preference for other activities. Themes among strategies included public support of programs by male community leaders, program advertisements featuring males, and adapting program content. Survey results supported themes identified in the focus group. Nearly $78 \%$ of survey respondents agreed that the 
perception of exercise programs as feminine was a barrier and over $90 \%$ of survey respondents believed program advertisements featuring men would increase male participation.

Predictors of Short-Term and Long-Term Adherence

Of 5,619 EF participant ages 60 and older who attended at least one EF class from 2008 to 2013, only $25 \%$ of HARC participants attended at least 32 sessions within the first 16 weeks to meet the criteria for short-term adherence, and only $35 \%$ of participants attended an average of at least once a week during the first year of participation in order to meet the criteria for long-term adherence. Logistic regression revealed that age, race/ethnicity, gender, and health status were significantly associated with short-term adherence. Contrary to the hypothesis that younger age, female gender, non-Hispanic white race/ethnicity, and good health at baseline would be positively associated with participant adherence to EnhanceFitness, older age, male gender, and Hispanic ethnicity were associated with a greater likelihood of short-term adherence.

Participants ages 80-89 were more likely to be categorized as adherent than participants ages 60-69 (OR=1.27, 95\% CI: 1.05 -1.53, p=.01). As hypothesized, black participants were less likely than white participants to be adherent short-term $(\mathrm{OR}=0.82$, 95\% CI: .67 - 1.00, p=.05), but Hispanic participants were more likely than white participants to be adherent ( $\mathrm{OR}=1.25,95 \% \mathrm{CI}$ : $1.06-1.47, \mathrm{p}=.008$ ). Men were nearly one and a half times more likely to meet the criteria for short-term adherence than women (OR=1.47, 95\% CI: 1.2301.76, $\mathrm{p}=.001)$. The hypothesis that good health status would be positively associated with short-term adherence was confirmed. Participants reporting good health were more than twice as likely than participants reporting poor health to meet 
criteria for short-term adherence (OR=2.23, 95\% CI:1.19-4.19, $\mathrm{p}=.01)$.

Age, race/ethnicity, gender, and health status were also significant predictors of long-term adherence. As was the case with short-term adherence, the relationship between younger age, white race, and female gender were negatively associated with long-term adherence. Participants ages 70-79 were more likely to meet the attendance criteria for long-term adherence than participants ages 60-69 (OR=1.26, 95\% CI 1.081.47, $\mathrm{p}=.003$ ) and the likelihood of adherence increased even more with age. Compared to white participants, Hattians were two times as likely to be adherent long-term $(\mathrm{OR}=2.03,95 \%$ CI: 1.53-2.70, $\mathrm{p}=.001)$. Hispanic (OR=1.30, 95\% CI: 1.11-1.52, $\mathrm{p}=.001)$, black (OR=1.77, 95\% CI: 1.49-2.10, p-.000), and participants of other races were also more likely to achieve long-term adherence than whites ( $\mathrm{OR}=1.53,95 \% \mathrm{CI}$ : 1.09-2.15, $p=.01)$. Men were slightly more likely than women to adhere long-term ( $\mathrm{OR}=1.19,95 \%$ CI: 1.19, 1.01-1.41, p=.04). As hypothesized, participants reporting good health were more likely to adhere long-term than participants reporting poor health were 1.59 times as likely to be adherent long term (OR=1.59, 95\% CI: .97 - 2.59, $p=.07)$

Participant and Instructor Perspectives on Factors Influencing Adherence to EnhanceFitness

Twelve older adults who had attended EF an average of at least two times per week for at least one year were recruited from three active EF classes to participate in one-on-one, semi-structured interviews. Ten instructors who had been instructing EF for at least two years were also recruited from two former HARC agencies to participate in one-one-one, semi-structured interviews. The Theory of Planned Behavior (TPB) was used as the basis of the framework which guided the study design and analysis. The TPB 
was applied to develop the semi-structured interview guide so that factors expected to be relevant were explored. The theoretical framework was also used to assign structural codes to the interview transcripts and provided a structure to organize the findings in a focused and meaningful way. The framework guided the exploration of relationships between factors described as influencing adherence and led to the discovery of the process by which EF participants come to feel like part of the group and by which the program becomes a part of their lives. EF participants in this study became adherent to EF.

In response to the research question regarding that factors that adherent participants and experienced instructors perceive as important to achieving sustained adherence to EF, thematic analysis of the data revealed several major themes contributing to the participants' successful adherence to EF including goals of attendance, cues to action, exercise history and identity, beliefs, intentions, program factors, social factors, instructor characteristics, and outcomes. Themes among motivational factors reported by instructors included improving or maintaining physical health and desire for activity. When asked about aspects of the EF program that influence adherence, three main themes emerged including exercising at one's ability level, EF as the only exercise needed, and the program structure. Instructors also highlighted social influences on adherence including the social connections among participants and the sense of family that develops. Instructors described key characteristics that are important to be successful as an EF instructor including experience, personality, passion, understanding, and humor. In addition to multiple improvements in physical health, instructors described participants as “feeling good” in general as a result of attending. 
The findings also provide insights into reasons for nonadherence and an answer to the research question posed abut strategies that participants and instructors suggest to improve adherence. Adherent participants reported health issues and competing priorities as the primary barriers to adherence. While these barriers are difficult to modify, participant accounts of reasons for nonadherence revealed a theme of temporary lapses in attendance followed by a return to class, so strategies to encourage participants to return after a lapse are recommended. Instructor accounts of reasons for non-adherence revealed six main barriers: health issues, appointments, caregiving responsibilities, grieving, and absence due to travel or seasonal residence in Florida.

Participants suggested a few strategies to improve adherence that include adding variety, removing fees, and adjusting the class schedule. Strategies that instructors use to encourage attendance include communicating with participants regarding absences, recognize participants for attendance, fostering social connection highlighting physical improvements, explicitly encouraging participants to attend consistently and modify exercises if needed and making efforts to keep the class fresh and fun. In addition to the strategies to promote adherence that were explicitly recommended by instructors a few other strategies are suggested based on the facilitators and barriers that instructors described. These strategies include engaging healthcare providers in promoting attendance and supporting participants in returning to class following lapses due to health issues, educating participants about how exercise can help the grieving process, and recruiting instructors who have an interest in understanding older adults, a passion for working with them, and the ability to make exercise fun. 


\section{Strengths and Limitations}

This study focused on diverse program participants but may not generalize to other programs and populations. The main limitation of the study exploring barriers to male participation was that the study only included EBP coordinators and instructors not the participants themselves or older men who chose not to participate. Due to the limited availability of variables in the database, the logistic regression models only explained a small percent of the variance in adherence. The sample sizes for the studies of participant and instructor perspectives were small, even for qualitative, research, so caution should be taken in interpreting the findings. The researcher did not gain access to participants who were not adherent or who dropped out, so additional research is needed with these types of participants in order to develop a comprehensive picture of the factors influencing adherence.

Despite its limitations, this study makes a contribution to the literature by providing a basis for strategies to improve the participation of older men in EBPS and evidence of the association between age, gender, race/ethnicity, and health status with short-term and long-term adherence to EnhanceFitness in community settings. The study also filled a gap in the literature by providing insight into the factors influencing adherence from participant and instructor perspectives. Another strength of the study was the use of a theoretical framework which enabled the creation of a model of the process of adhering that emerged from the data. The qualitative approach allowed participants and instructors to provide a rich, detailed information on factors influencing adherence to EF. 


\section{Implications}

Findings from this study can help health professionals, program developers, and organizations offering EBPs to develop strategies related to the factors found to be important for male participation in EBPs and older adult adherence to a community-based group exercise program. Instructors can also apply the recommended strategies to encourage attendance in their classes. Findings from the study of factors influencing male participation in EBPs indicate that programs and recruiting strategies need to be tailored to the unique needs and preferences of older men to improve participation.

Findings related to EF adherence highlight the importance of involving doctors and raising awareness about health consequences of physical inactivity, particularly during times of transition such as retirement or entry into old age. Efforts should be made to explicitly encourage consistent attendance, stay in touch, and foster social relationships in class. Selecting instructors with the desired characteristics, ensuring program fidelity, and providing exercise modifications that allow participants to feel confident are also key strategies for supporting long-term adherence. Research should examine the association between participants' personal goals of attendance the strength of their attendance intentions and test the impact of goal setting and tracking on adherence.

Efforts to improve older male participation and older adult adherence that are informed by the perspectives of participants, instructors, and coordinators will help to maximize the impact of EBPs for older adults. The perspectives of men who declined to participate in EBPs and EF participants who did not adhere should be explored in future research. Research is also needed to examine the process of adherence that was found in this study and to test strategies to encourage participants to return to EF after lapses. 


\section{References}

Ackermann, R. T., Cheadle, A., Sandhu, N., Madsen, L., Wagner, E. H., \& LoGerfo, J. P. (2003). Community exercise program use and changes in healthcare costs for older adults. American Journal of Preventive Medicine, 25(3), 232-237.

Batra, A., Coxe, S., Page, T.F., Melchior, M., Palmer, R.C. (2016). Evaluating the factors associated with the completion of a community-based group exercise program among older women. Journal of Aging and Physical Activity, 24(4), 649-658.

Batra, A., Melchior, M., Seff, L., Newman, F., \& Palmer, R.C. (2012). Evaluation of a Community-Based Falls Prevention Program in South Florida, 2008-2009. Preventing Chronic Disease, 9, E13.

Belza, B., Synyder, S., Thompson, M., \& LoGerfo, J. (2010). From research to practice: EnhanceFitness, an innovated community-based senior exercise program. Topics in Geriatric Rehabilitation, 26(4), 299-309.

Boutaugh,, M.L., \& Lawrence (2014). Fostering healthy aging through evidence-based programs. Perspectives from the administration for community living/administration on aging. Frontiers in Public Health, 2, 236. doi: 10.3389/fpubh.2014.00255

Courtenay, W.H. (2000). Behavior factors associated with disease, injury, and death among men. Evidence and implications for prevention. The Journal of Men's Studies, 9, 81-142

Cross, W. F. \& West, J. C. (2011). Examining implementer fidelity: Conceptualizing and measuring adherence and competence. Journal of Children's Services, 6, 18-33.

Farrance, C., Tsofliou, F., \& Clark, C. (2016). Adherence to community based group exercise interventions for older people: A mixed-methods systematic review. Preventive Medicine, 87, 155-166.

Frank, J. C., Coviak, C. P., Healy, T. C., Belza, B., \& Casado, B. L. (2008). Addressing Fidelity in Evidence-Based Health Promotion Programs for Older Adults. Journal of Applied Gerontology, 27(1), 4-33.

Melchior, M.A., Seff, L.R., Albatineh, A.N., McCoy, H.V., Page, T.F., \& Palmer, R.C. (2014). Intermediate outcomes of chronic disease self-management program offered by members of the Healthy Aging Regional Collaborative in south Florida. Research on Aging, 36, (4), 431-449. 
Ory, M.G., Smith, M.L., Parker, E.M., Jiang, L., Chen, S., Wilson, A.D., Stevens, J.A., Ehrenreich, H., \& Lee, R. (2015). Fall prevention in community settings: results from implementing Tai Chi: Moving for Better Balance in three states. Frontiers in Public Health, 2, 216-221.

Palmer, R.C., Batra, A., Anderson, C., Page, T., Vieira, E., \& Seff, L. (2016). Implementation of an Evidence-Based Exercise Program for Older Adults in South Florida. Journal of Aging Research, 2016, Article ID 9630241. http://dx.doi.org/10.1155/2016/9630241

Smith, M., Belza, B., Altpeter, M., Ahn, S., Dickerson, J., Ory, M. (2012). Disseminating an evidence-based disease self-management program for older Americans: implications for diversifying participant reach through delivery site adoption. In: Maddock J, editor. Rijeka. Croatia: InTech (2012). p. 385-404.

U.S. Census Bureau (2015). Annual Estimates of the Resident Population for Selected Age Groups by Sex for the United States, States, Counties, and Puerto Rico Commonwealth and Municipios: April 1, 2010 to July 1, 2014. Retrieved from https:/factfinder.census.gov/faces/table services/jsf/pages/productview.xhtml?] src $=$ bkmk

U.S. Department of Health and Human Services: Administration of Community Living (2018). Office of Disease Prevention and Health Promotion. Upcoming Guidelines. Retrieved from https://health.gov/paguidelines/second-edition 


\section{VITA}

\section{CHELSIE ANDERSON}

2004-2008

2008-2012

2011-Present

2015- Present
Flagler College, St. Augustine, Florida

Bachelor of Arts, Psychology

Florida Atlantic University, Boca Raton, Florida

Master of Arts, Psychology

Research Assistant and Teaching Assistant

Department of Psychology

Florida Atlantic University

Boca Raton, Florida

Florida International University, Miami, Florida

Doctoral Candidate

Research Assistant

Department of Health Promotion and Disease Prevention

Florida International University

Miami, Florida

Florida Health Networks

Operations and Data Manager

North Miami Beach, Florida

\section{PUBLICATIONS AND PRESENTATIONS}

Anderson, C., Seff, L.R., Batra, A. \& Bhatt, C. (2016). Recruiting and engaging older men in evidence-based health promotion programs: perspectives on barriers and strategies. Journal of Aging Research. DOI:

http://dx.doi.org/10.1155/2016/8981435

Anderson, C., Palmer, R.C., \& Batra, A. (2015). Implementing EnhanceFitness: The Importance of Site Characteristics. Roundtable presentation at the American Public Health Association Annual Meeting and Expo, Chicago, IL.

Anderson, C., \& Palmer, R.C. (April 2015). Walk With Ease: Promoting physical activity for urban older adults. Paper presented at the Annual Meeting of the Urban Affairs Association, Miami, FL.

Anderson, C., Seff, L., Batra, A., Bhatt, C., \& Palmer, R.C. (November 2014). Identifying barriers and strategies to increase older male participation in health 
promotion programs. Paper presented at the American Public Health Association Annual Meeting and Expo, New Orleans, LA.

Batra, A., Anderson, C., Bhatt, C., \& Palmer, R.C. (November 2014). EnhanceFitness an evidence-based physical activity program: Factors influencing the participation of older women. Paper presented at the American Public Health Association Annual Meeting and Expo, New Orleans, LA.

Batra, A., Anderson, C., Bhatt, C., \& Palmer, R.C. (November 2014). Translating evidence-based programs into community-based settings: The role of fidelity observations. Roundtable presentation at the American Public Health Association’ Annual Meeting and Expo, New Orleans, LA.

Bhatt, C., Anderson, C., Batra, A., \& Palmer, R.C. (November 2014). Implementation of evidence-based health promotion programs in community-based settings of South Florida: Lessons learned. Roundtable presentation at the American Public Health Association Annual Meeting and Expo, New Orleans, LA.

Bhatt, C., Batra, A., Anderson, C., \& Palmer, R.C. (November 2014). Evaluation of a community-basedDiabetes Self-Management Program in South Florida from 2008-2012. Paper presented at the American Public Health Association Annual Meeting and Expo, New Orleans, LA.

Madhivanan, P., Barreto, G., Revawala, A., Anderson, C., McKinney, S., \& PierreVictor, D. (2013). Where are we with partner treatment in bacterial vaginosis? A critical appraisal of the latest systematic review. Sexually Transmitted Diseases, 40(6):518.

McKinney, S., Palmer, R.C., \& Anderson, C. (November 2013). Influence of gender o colorectal cancer knowledge, attitudes, and intention to screen among African Americans. Poster presented at the American Public Health Association Annual Meeting and Expo, Boston, MA.

Palmer, R., Batra, A., Anderson, C., \& Page, T. (2016). Implementation of an EvidenceBased Exercise Program for Older Adults in South Florida. Journal of Aging Research. http://dx.doi.org/10.1155/2016/9630241 